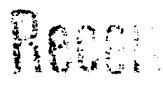

NOV 011991

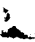

\title{
Ship Tracks and Velocities for WCSEX 1991
}

\author{
Thomas J. Yorkey \\ This paper was prepared for submittal for a workshop \\ Lawrence Livermore National Laboratory \\ Livermore, CA \\ October 28, 1991
}

October 3, 1991

This is a preprint of a paper intended for publication in a journal or proceedings. Since changes may be made before publication, this preprint is made available with the understanding that it will not be cited or reproduced without the permission of the author.

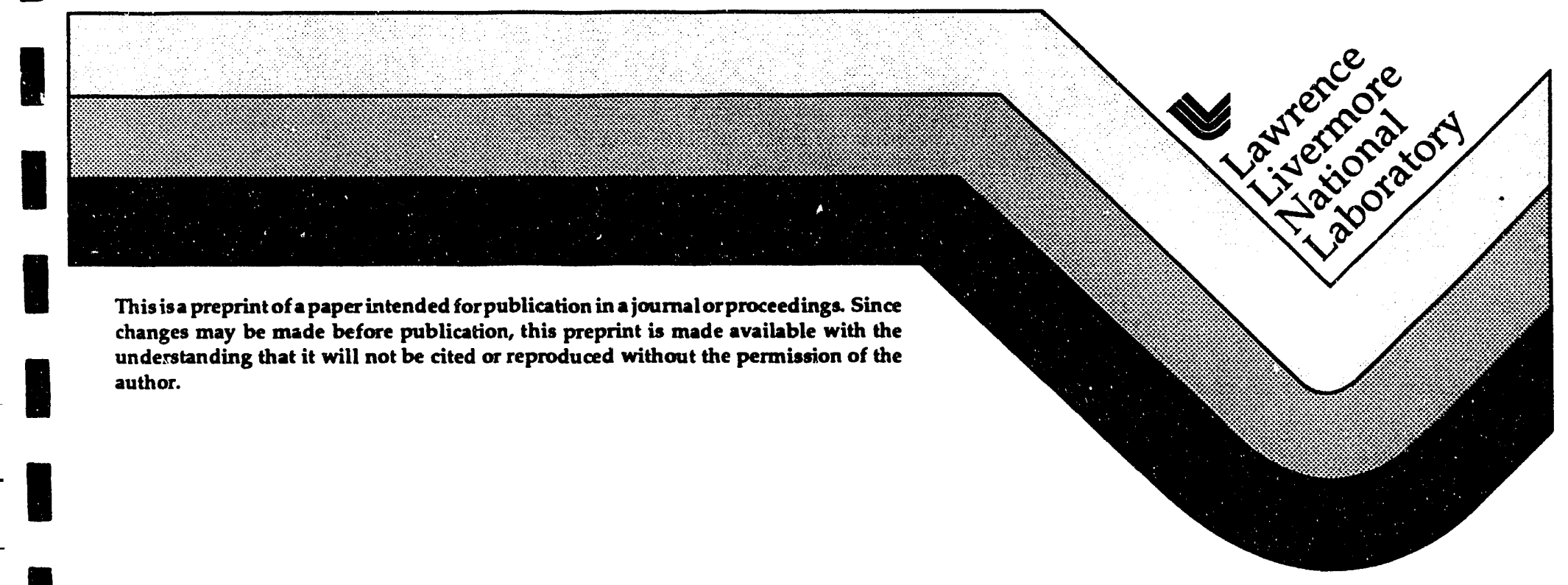


DISCI.AINIER

This document was prepared as an account of work sponsored by an agency of the United Stutes Government. Neither the United States Government nor the (Iniversity of Californiz nor any of their employees, makes any narranty, express or implied, or assumes any lezal liability or responsibility for the accuracy, completeness, or usefulness of any information. apparatus. product. or process disclexed, or represents tbat its use nould not infringe privately owned rights. Reference herein to any specific commercial products. process, or service by trade name, trademark, manufacturer, or otherwise, does not necessarily constitute or imply its endorsement, recommendation. or favoring by the United States Guvernment or the University of California. The views and opinions of authors expressed herein do not necessarily state or reflect those of the United States Government or the University of California. and shall not be used for advertising or product endorsement purposes. 


\title{
Ship tracks and velocities for WCSEX $1991^{1}$
}

\author{
Thomas J. Yorkey \\ L-496 P.O. Box 808 \\ Lawrence Livermore National Laboratory \\ Livermore, CA 94580
}

October 3, 1991

\section{MASTER}

\footnotetext{
${ }^{1}$ Work performed under the auspices of U.S. Department of Energy by the Lawrence Livermore National Laboratory under contract No. W-7405-ENG-48
} 


\section{Description of plots}

Enclosed in this report are plots of the wave generating ship tracks and velocities for the West Coast Scotland EXperiment (WCSEX) 1991. The navigation data was provided by Wimpol Limited. They provided ASCII data for the Roysterer, Arakan, Blue Rover, Calanus, Cairn, Loch Nevis, and Loch Shiel. A typical data set for the Roysterer looks like:

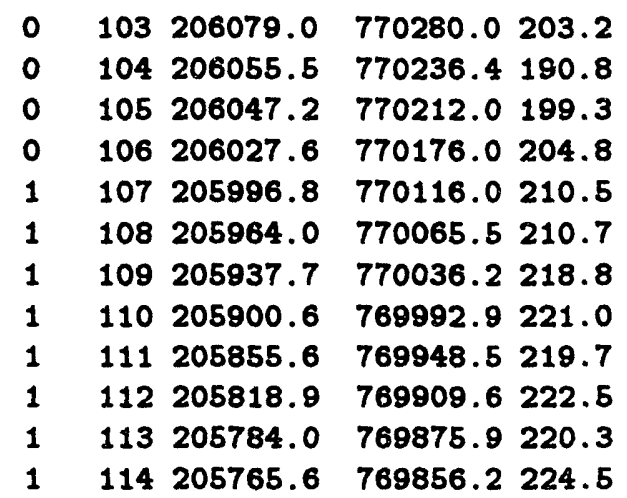
3.0 05-Jul-91 12:58:41
3.1 05-Jul-91 12:59:06
2.3 05-Jul-91 12:59:21
2.6 05-Jul-91 12:59:42
2.7 05-Jul-91 13:00:14
3.4 05-Jul-91 13:00:42
3.3 05-Jul-91 13:00:59
3.2 05-Jul-91 13:01:24
3.1 05-Jul-91 13:01:51
2.8 05-Jul-91 13:02:15
2.6 05-Jul-91 13:02:36
2.7 05-Jul-91 13:02:48

The eight columns are

\begin{tabular}{|l|l|}
\hline Column & Contents \\
\hline 1 & Run number (0 during non run times) \\
2 & Wimpol fix identifier \\
3 & National Grid easting value \\
4 & National Grid northing value \\
5 & Heading \\
6 & Velocity in $\mathrm{m} / \mathrm{s}$ \\
7 & Date \\
8 & GMT time \\
\hline
\end{tabular}

In Section 1 I have plotted the wake making ship's track using the easting and northing grid coordinates fir each run and day. The plots are at a $1: 50000$ scale, ie $2 \mathrm{~mm}=1 \mathrm{~km}$. I have overlayed with circles the posicion of the Cairn and the Calunus so that the instrumentation area is easily found. I have also overlayed time stamps for the data. The first digit of the stamp is the coordinate for that time. The data is supplied sampled at, what appears to me, almost random times, averaging a little over 20 seconds. I put the time stamps on at somewhat nice intervals $(5,10$, or 15 minutes) so there are many points plotted between time Inarks.

In Section 2 I have plotted the wake making ship's velocity as a function of down-track distance. I have also overlayed the same time stamps used in plotting the ship's track position.

There are a few runs where there must have been instrumentation failure, for there is a long stretch of missing data. In this case, I did a linear fit to the existing data. The missing data is:

\begin{tabular}{|l|l|l|}
\hline Date & Run & Missing time \\
\hline $8-J u l-91$ & 3 & $15 \mathrm{~min}$ \\
19-Jul-91 & 2 & $20 \mathrm{~min}$ \\
\hline
\end{tabular}

If you would like the navigational data itself contact:

Shari Turner
(5:0) 422-6975
LLNL
L-495
P.O. Box 808
Livermore, CA 94550


Ship Tracks 


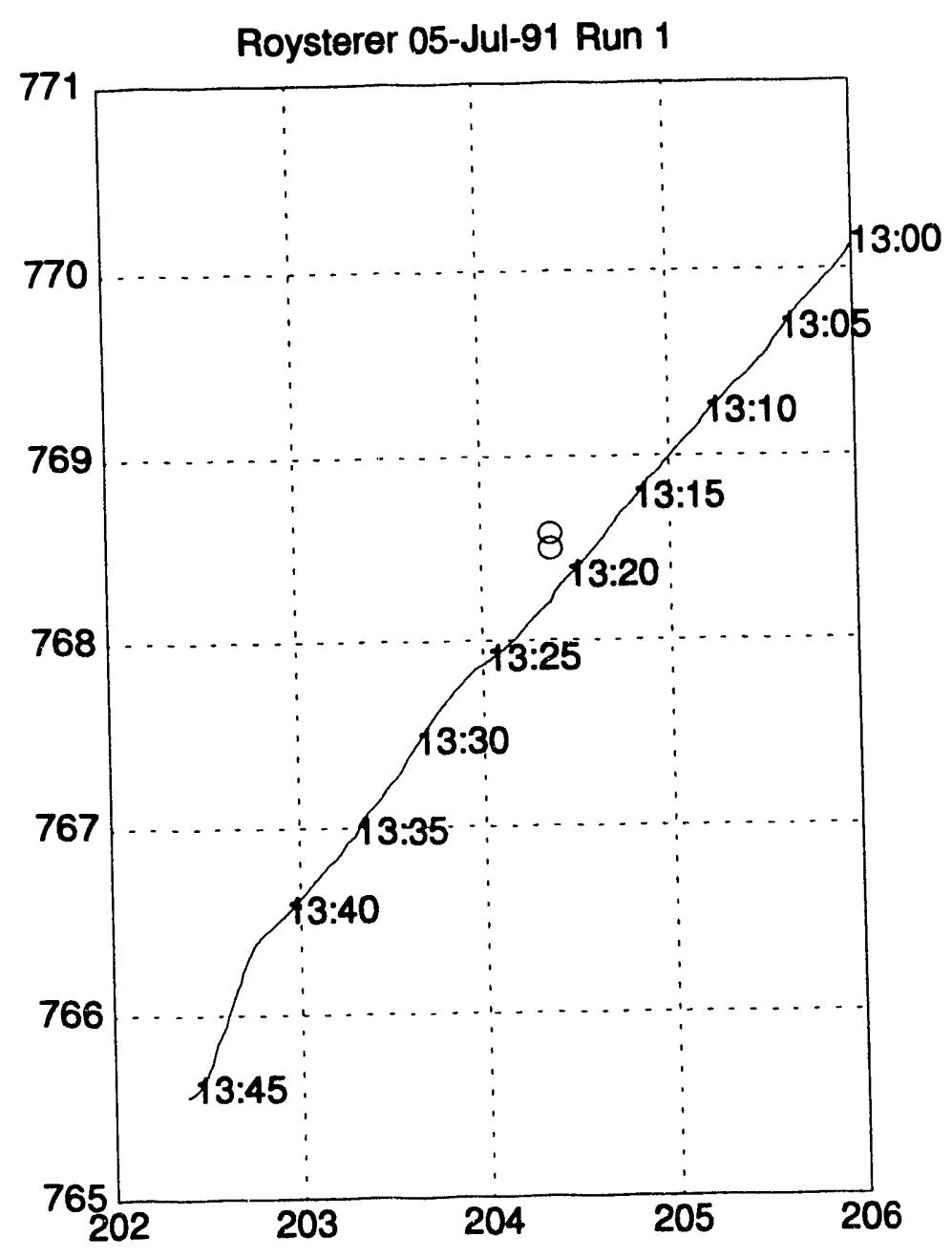




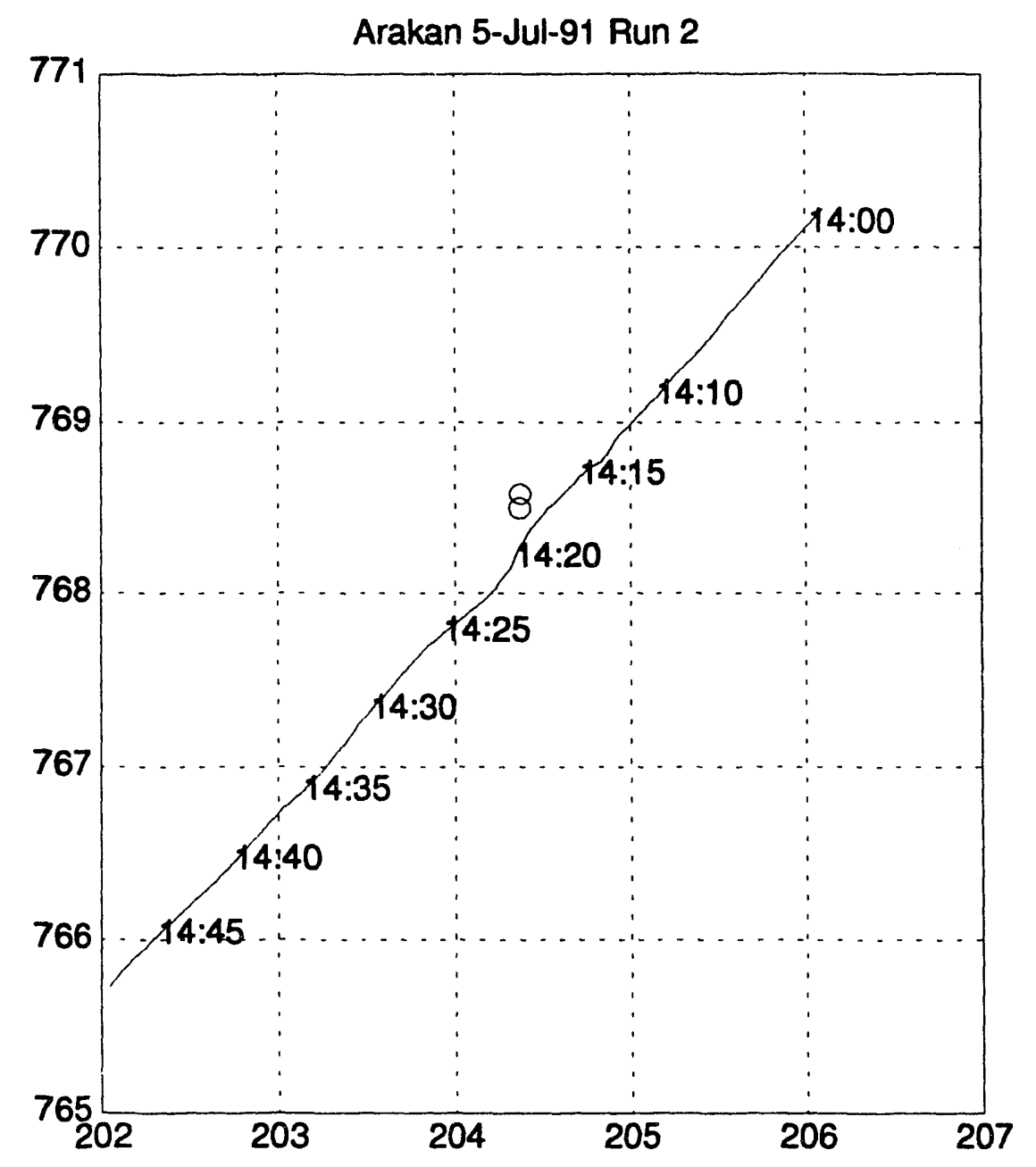




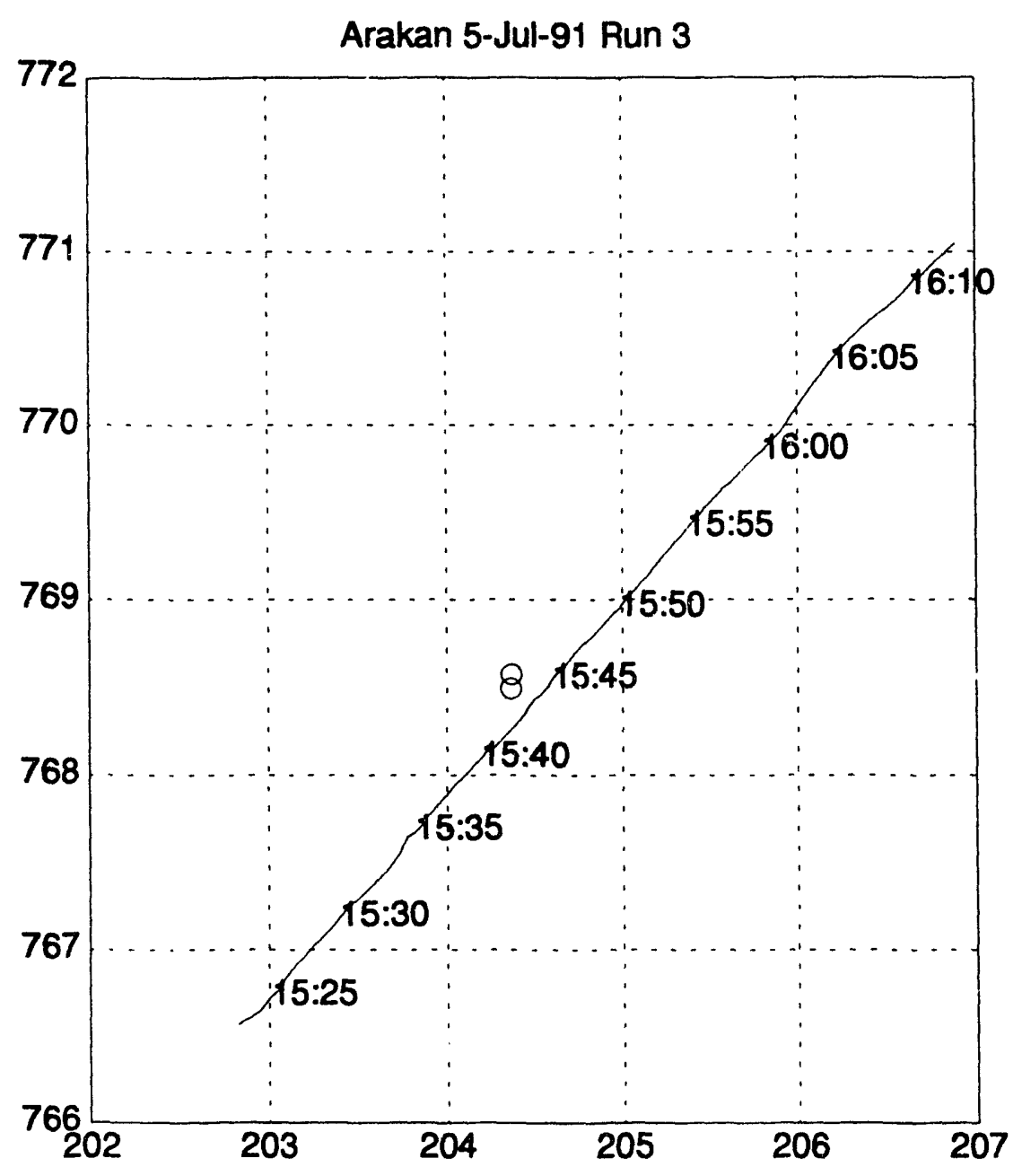


Roysterer 05-Jul-91 Run 4

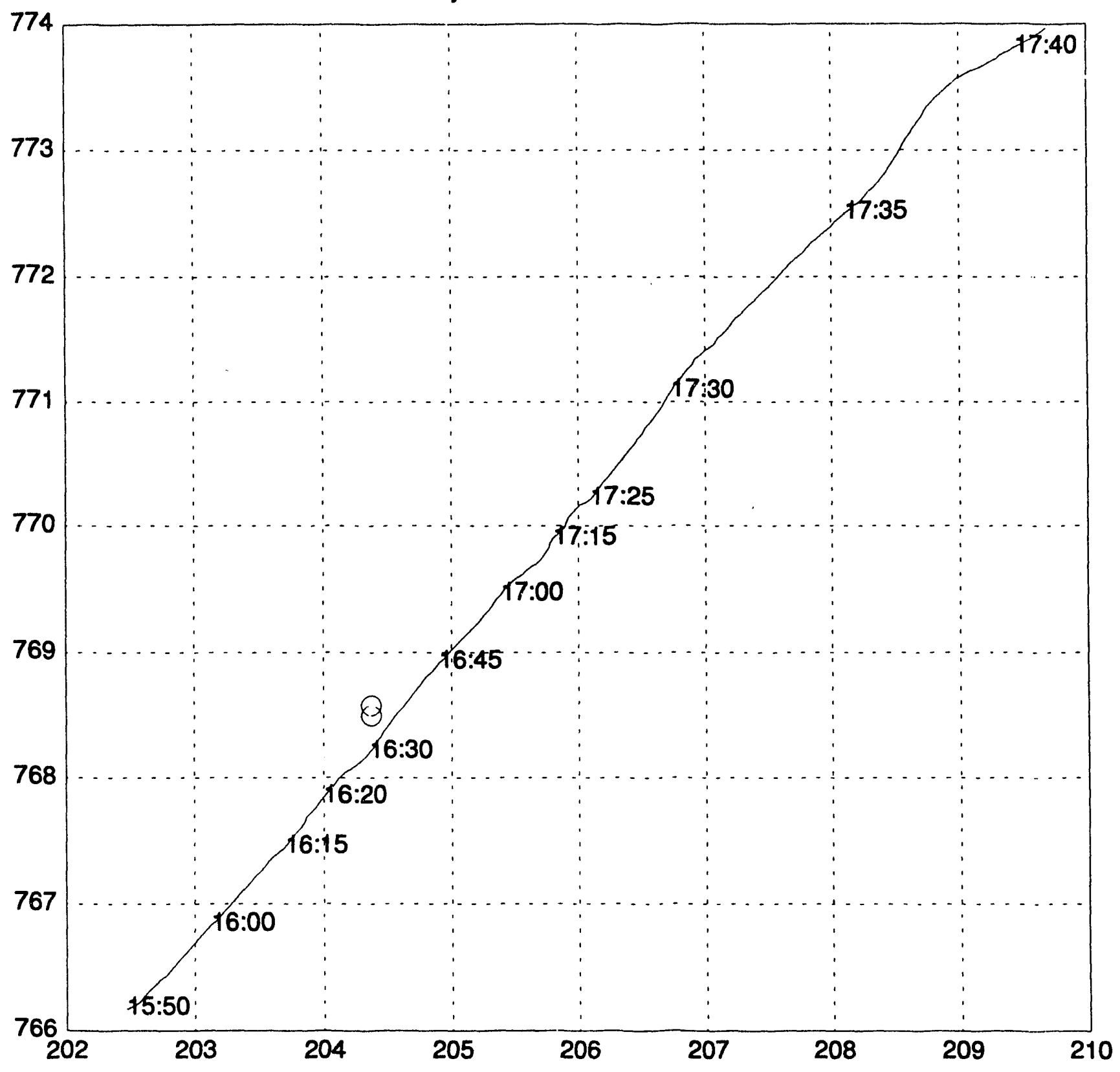


Roysterer 06-Jul-91 Run 1

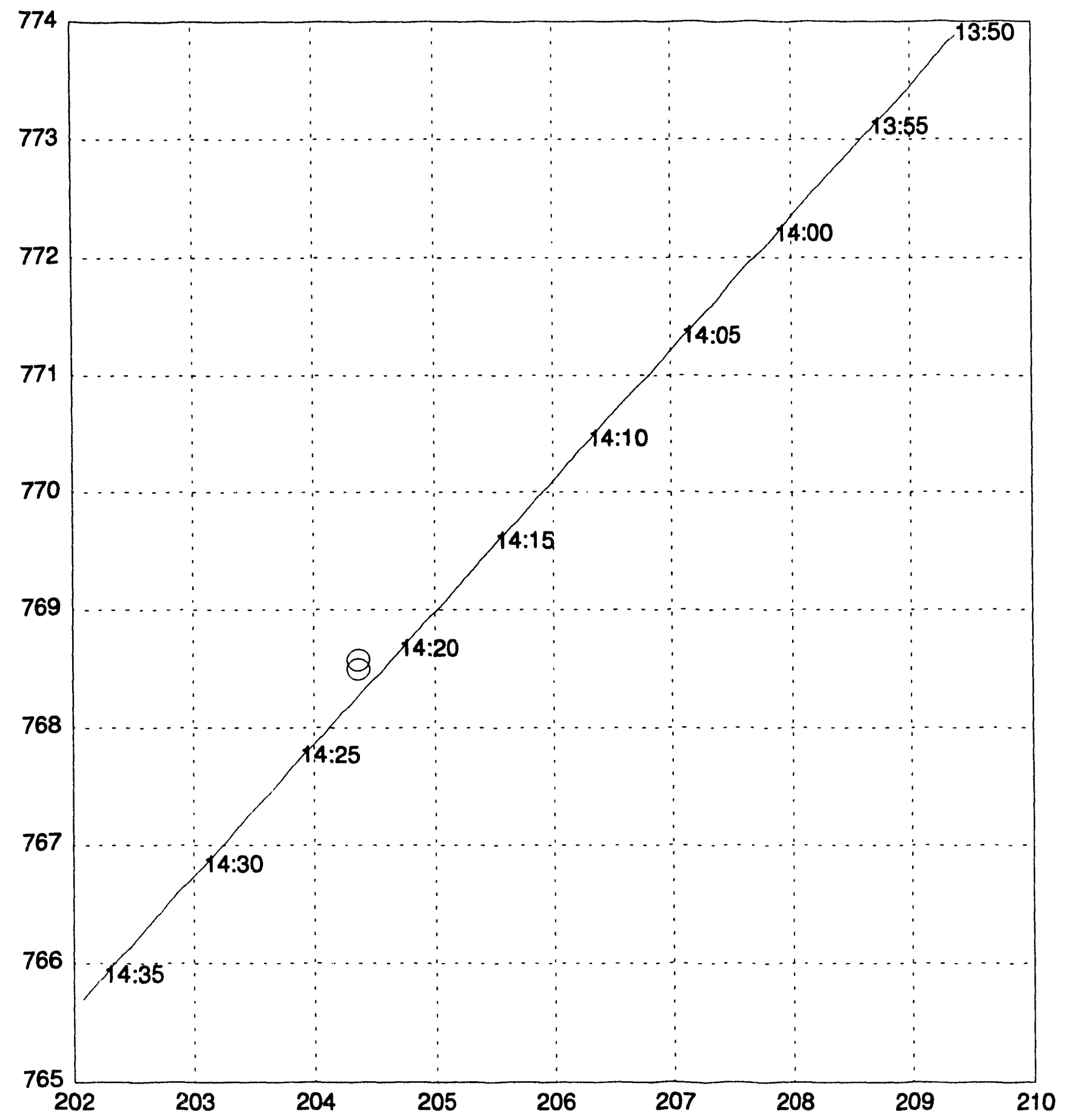


Arakan 6-Jul-91 Run 2

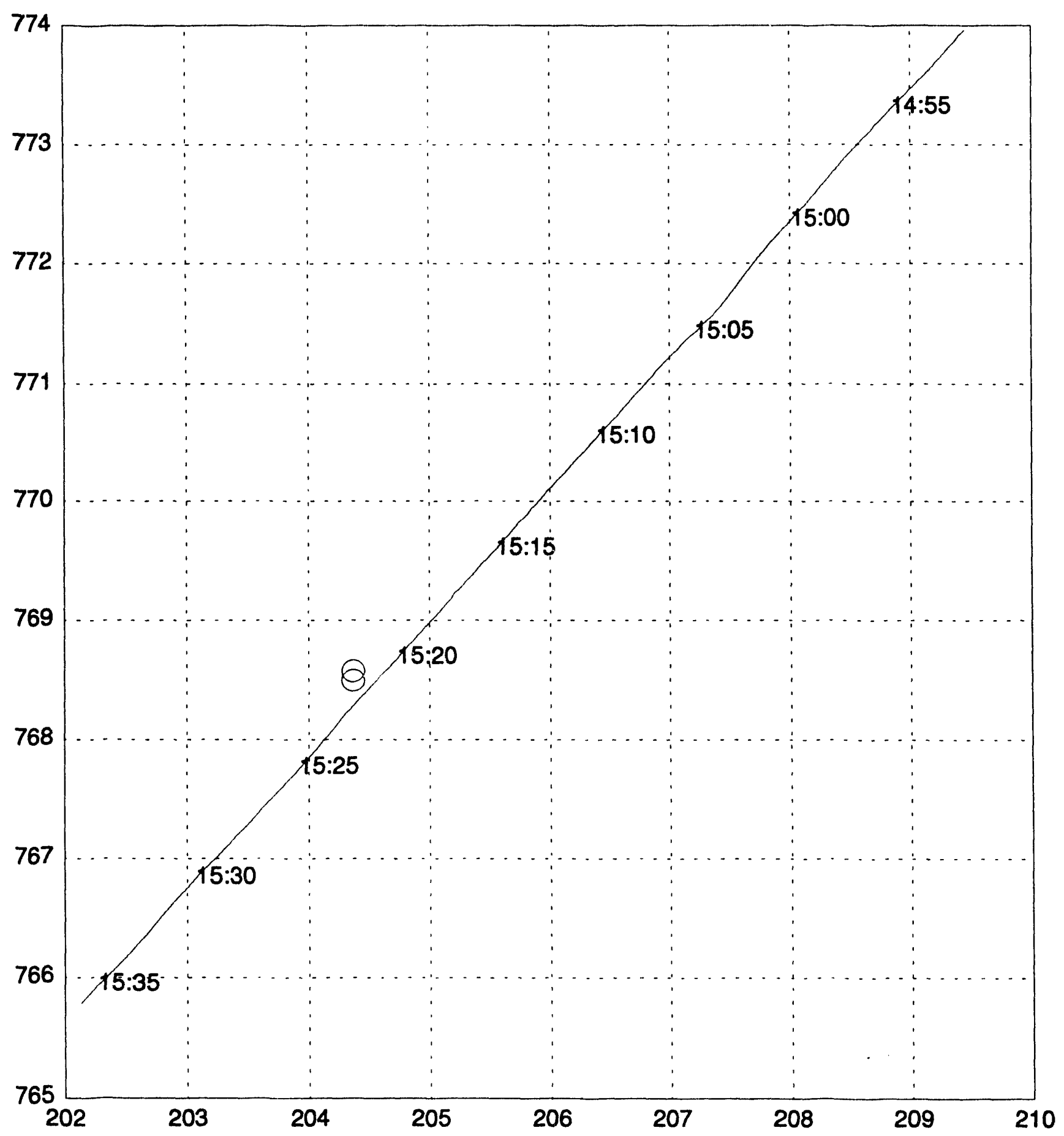


Arakan 6-Jul-91 Run 3

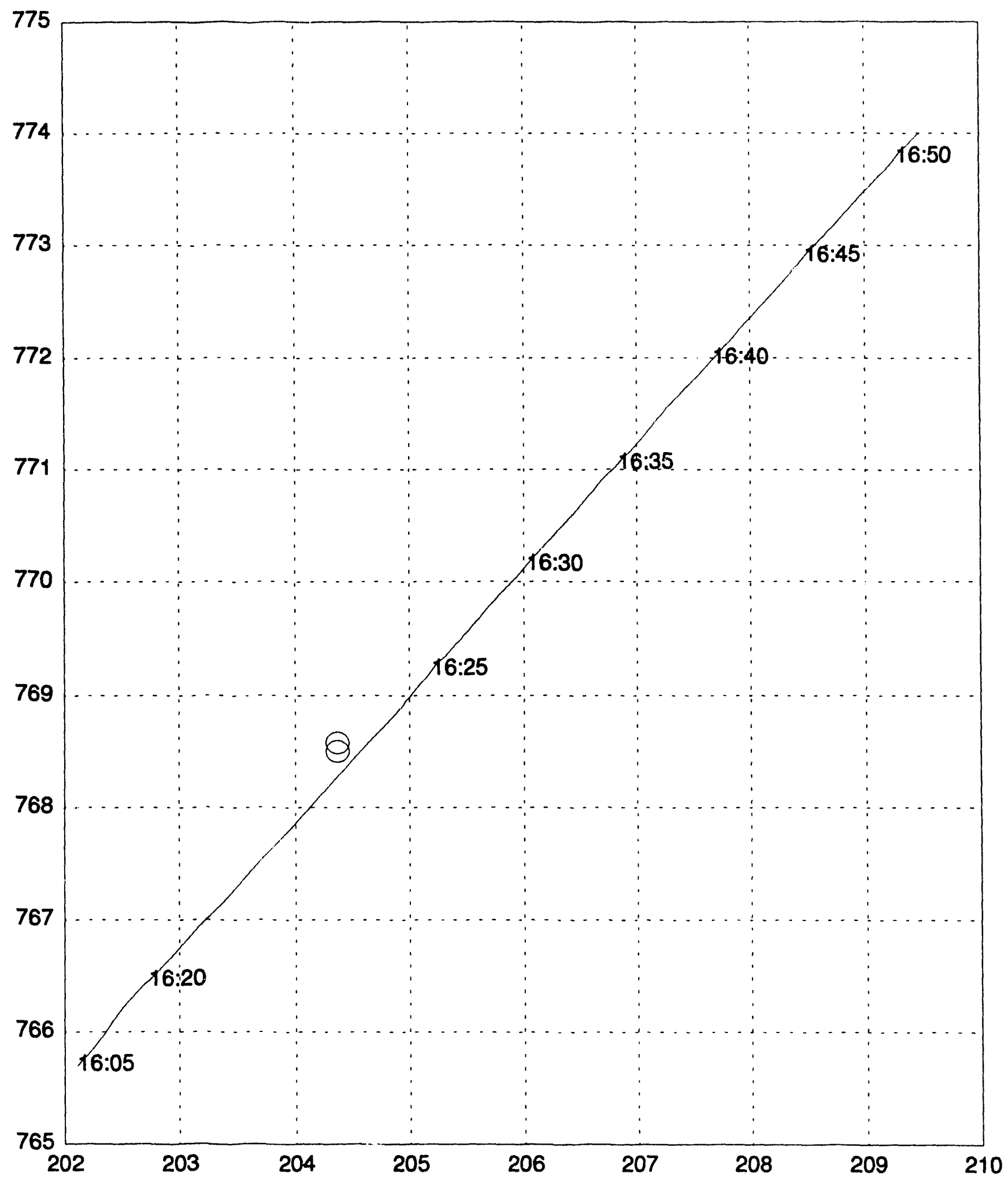


Roysterer 06-Jul-91 Run 4

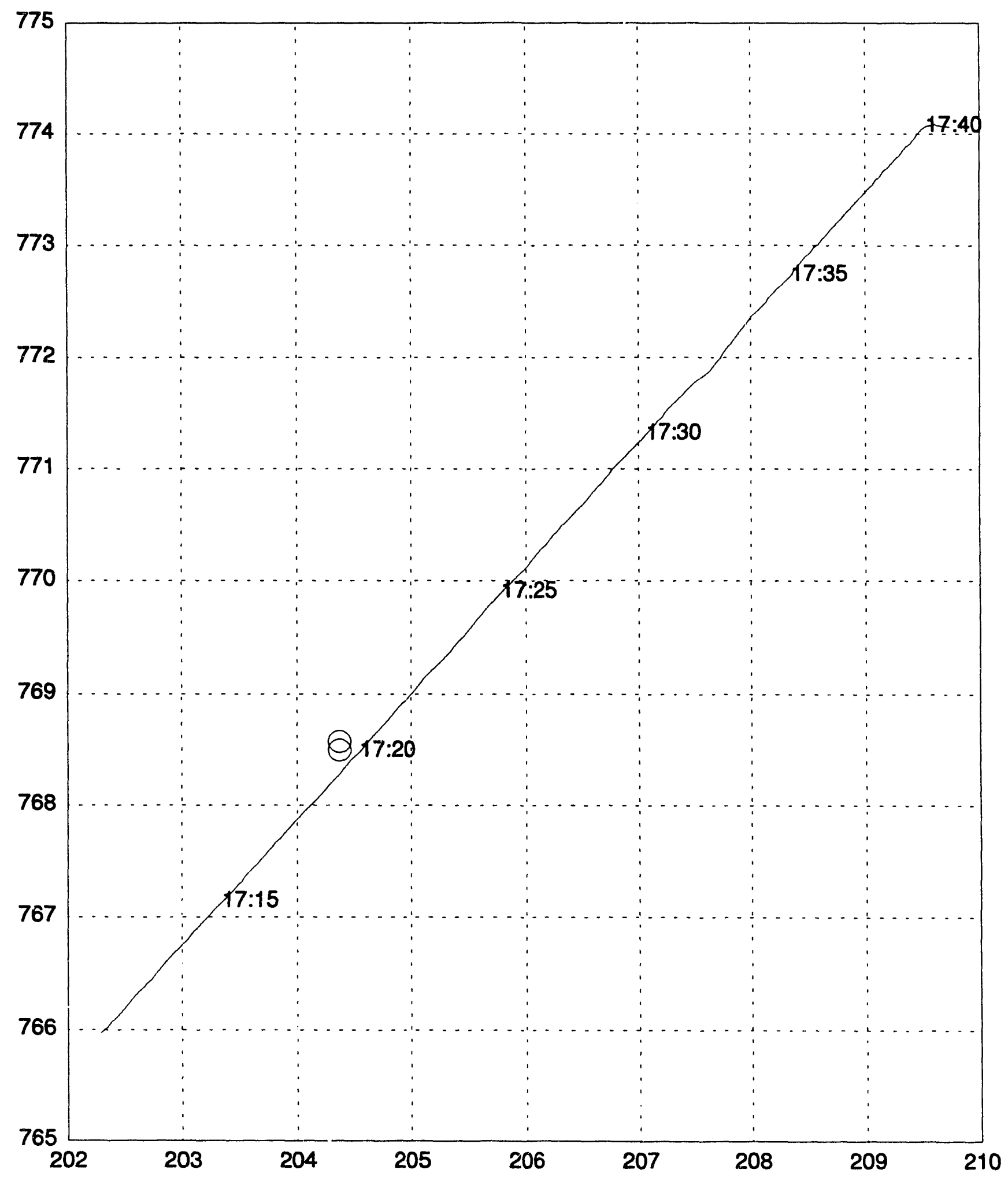




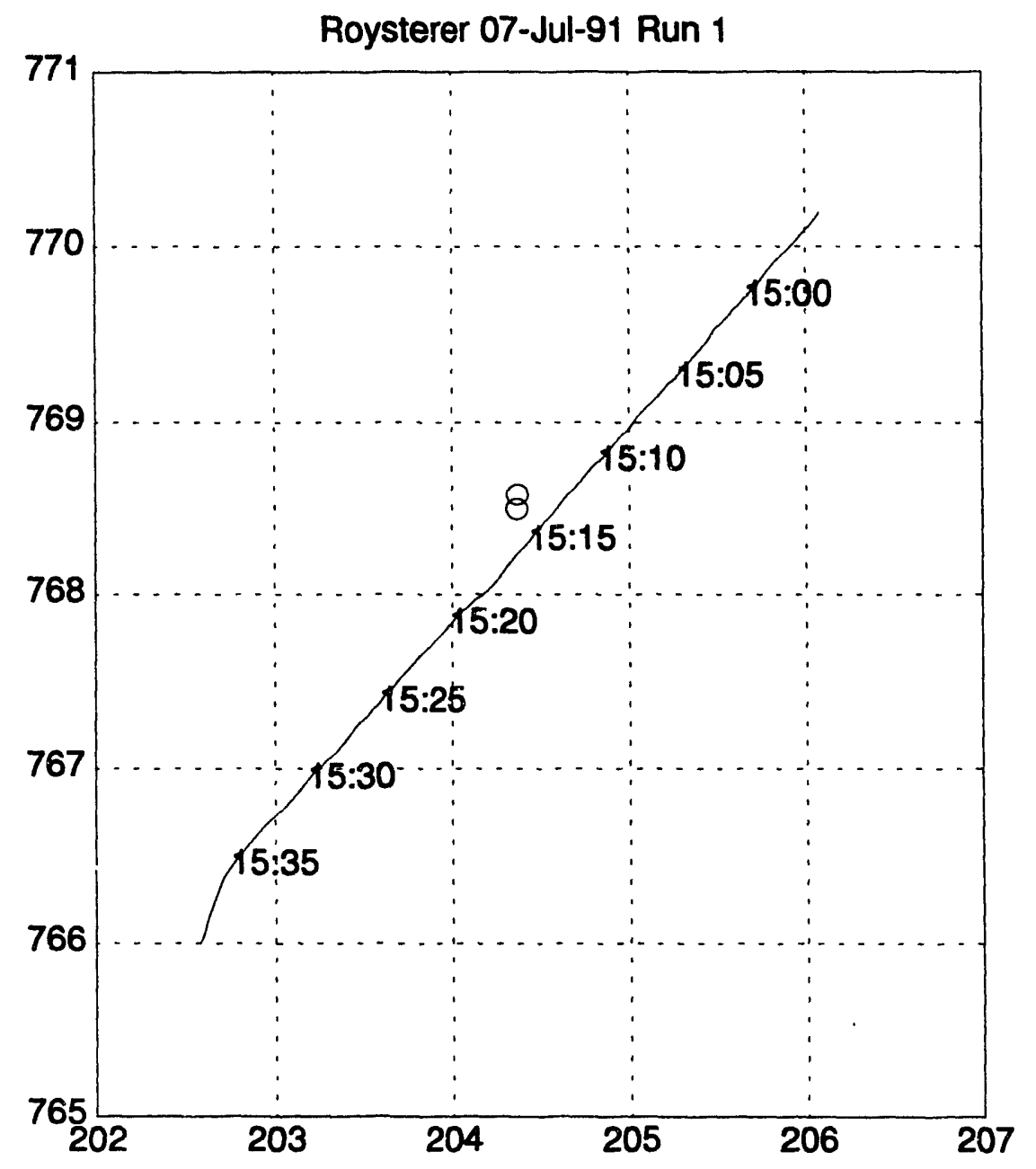




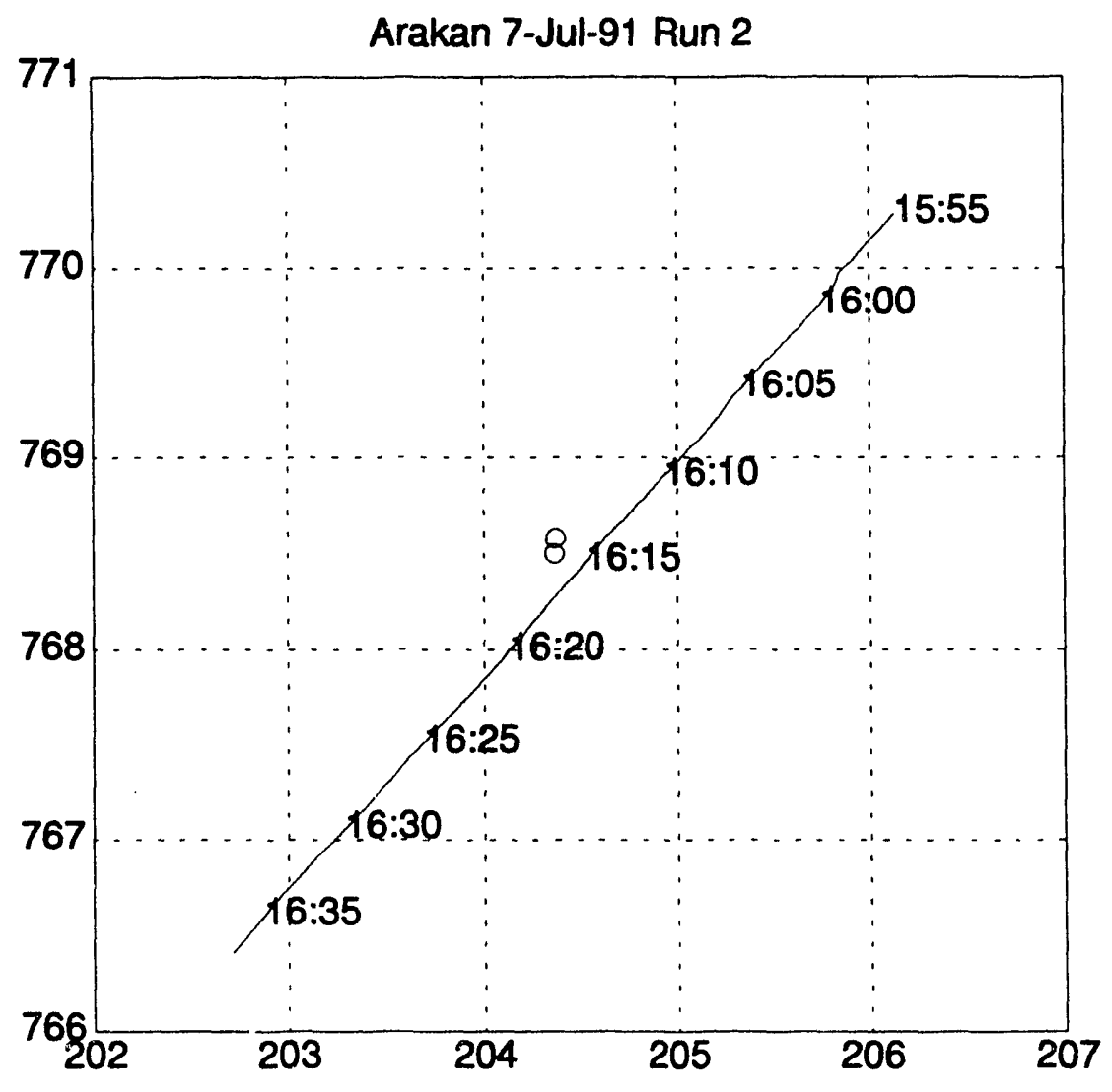




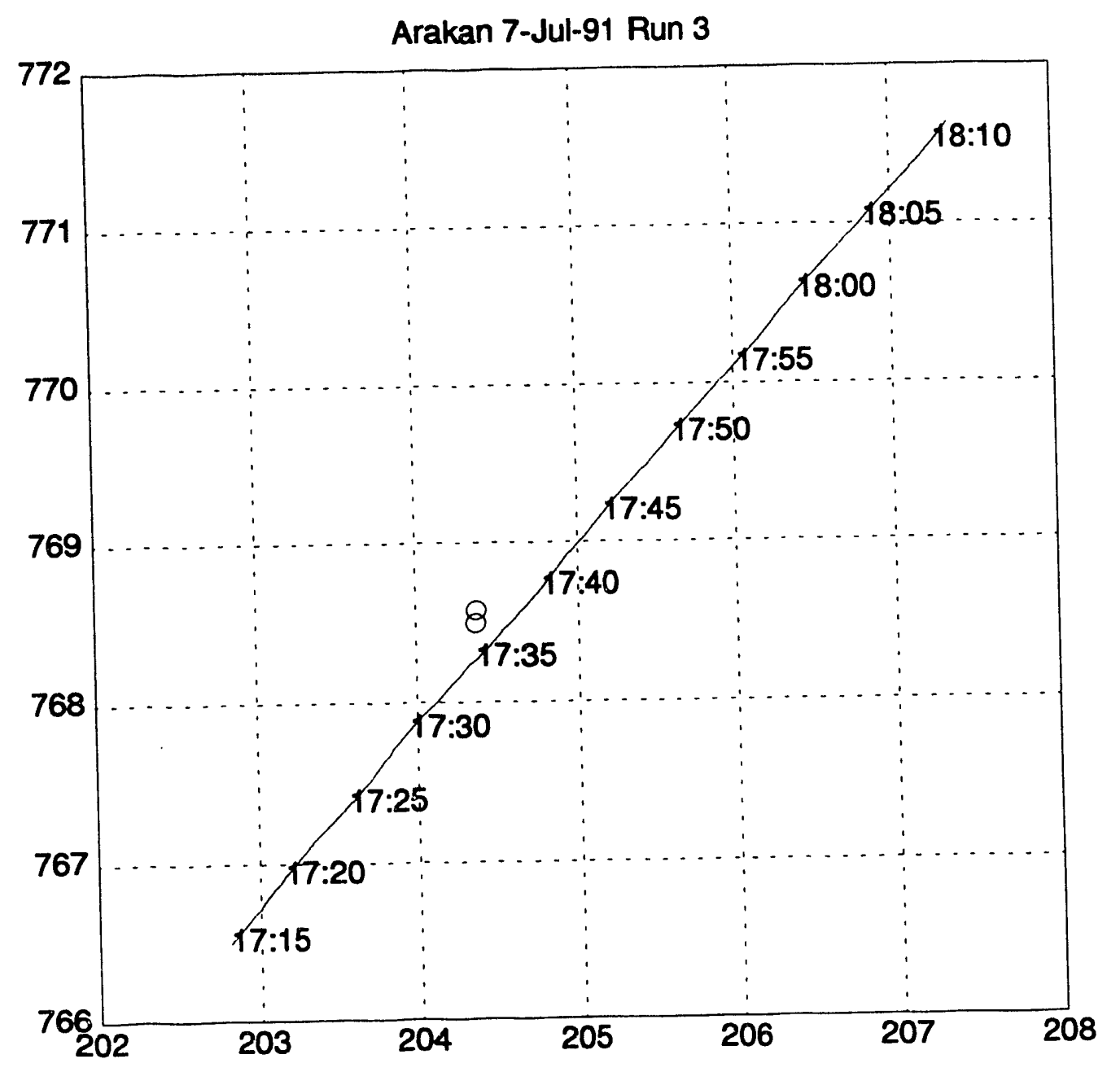


Roysterer 07-Jul-91 Run 4

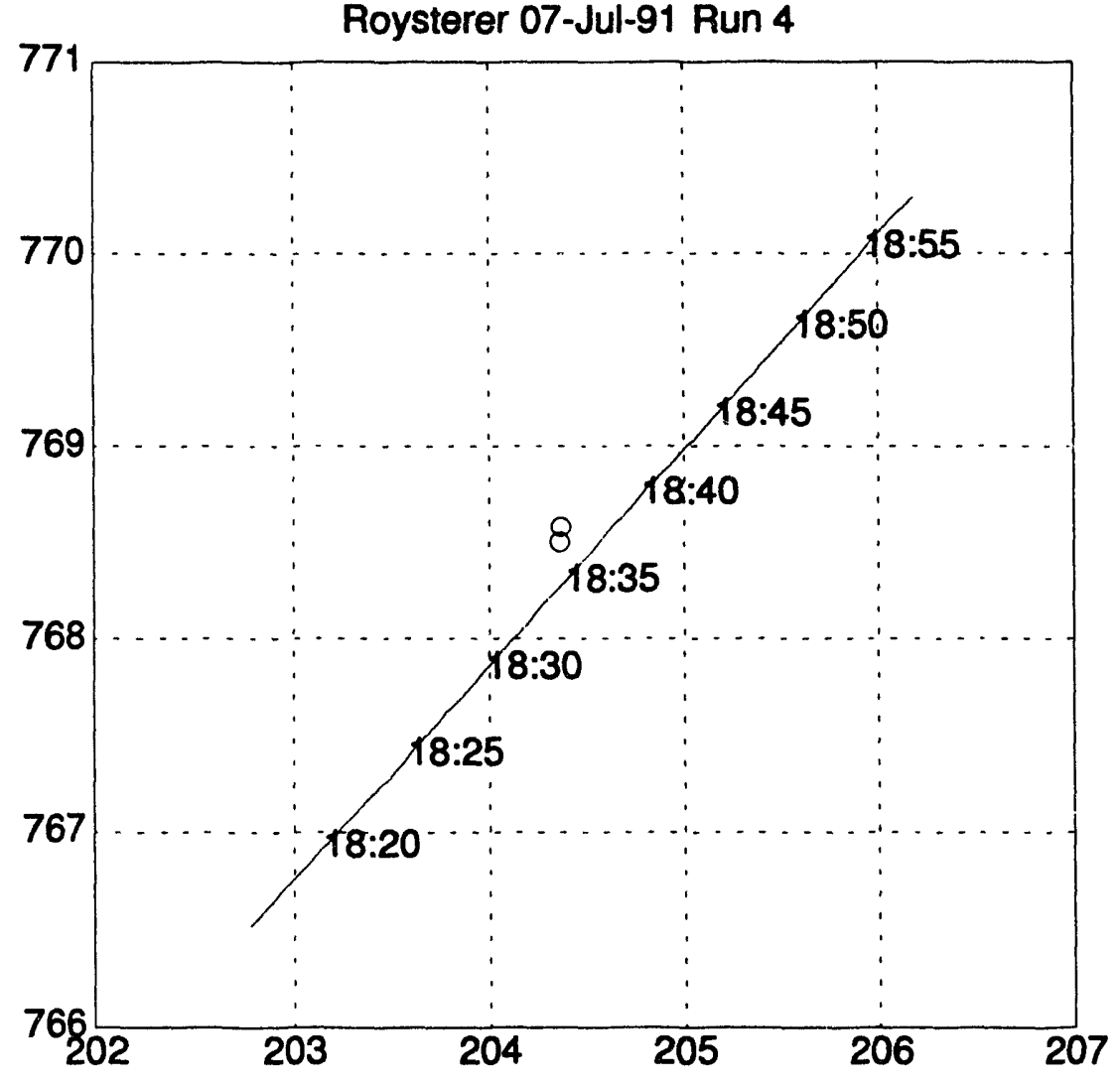


Roysterer 08-Jul-91 Run 1

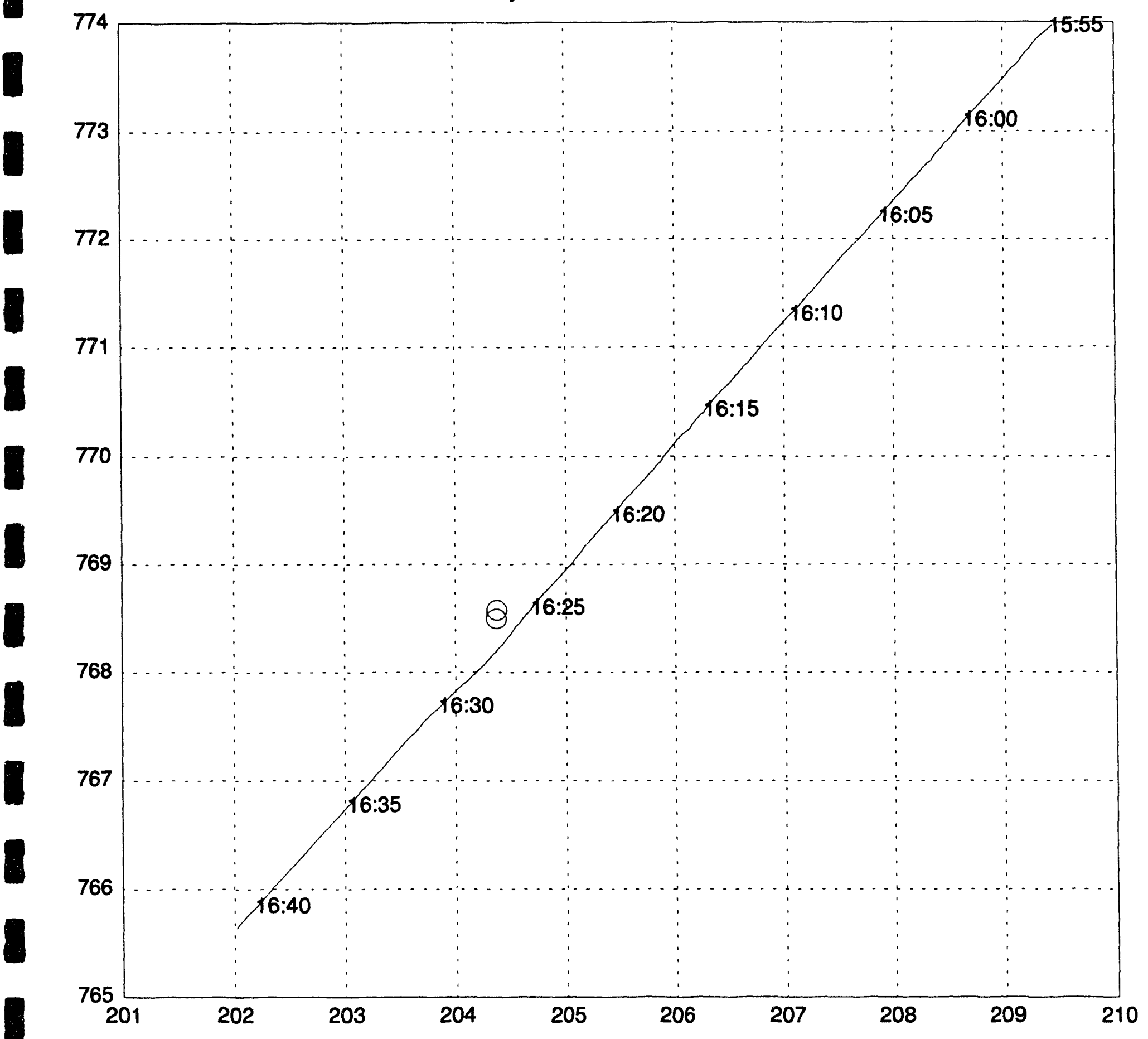




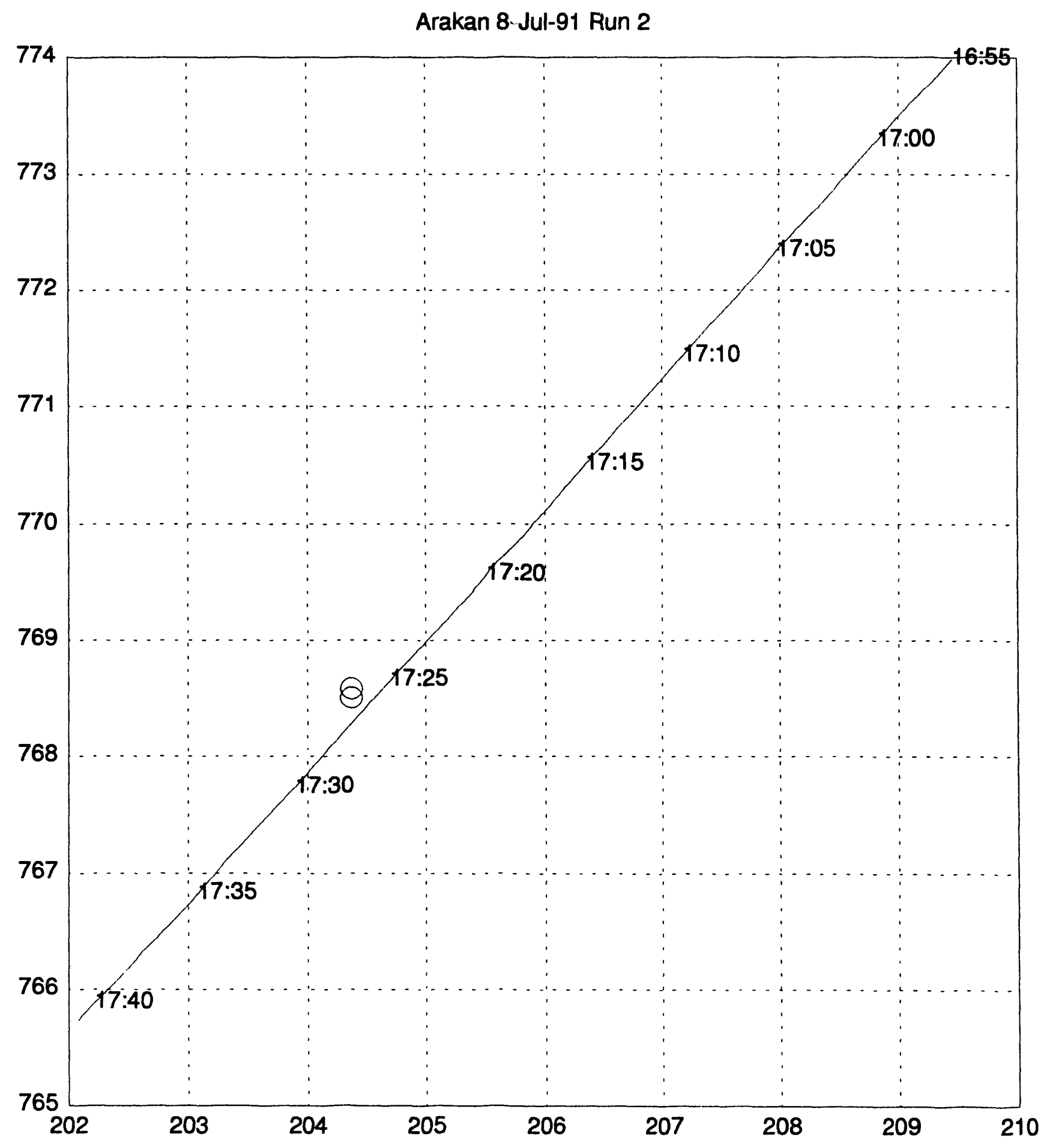




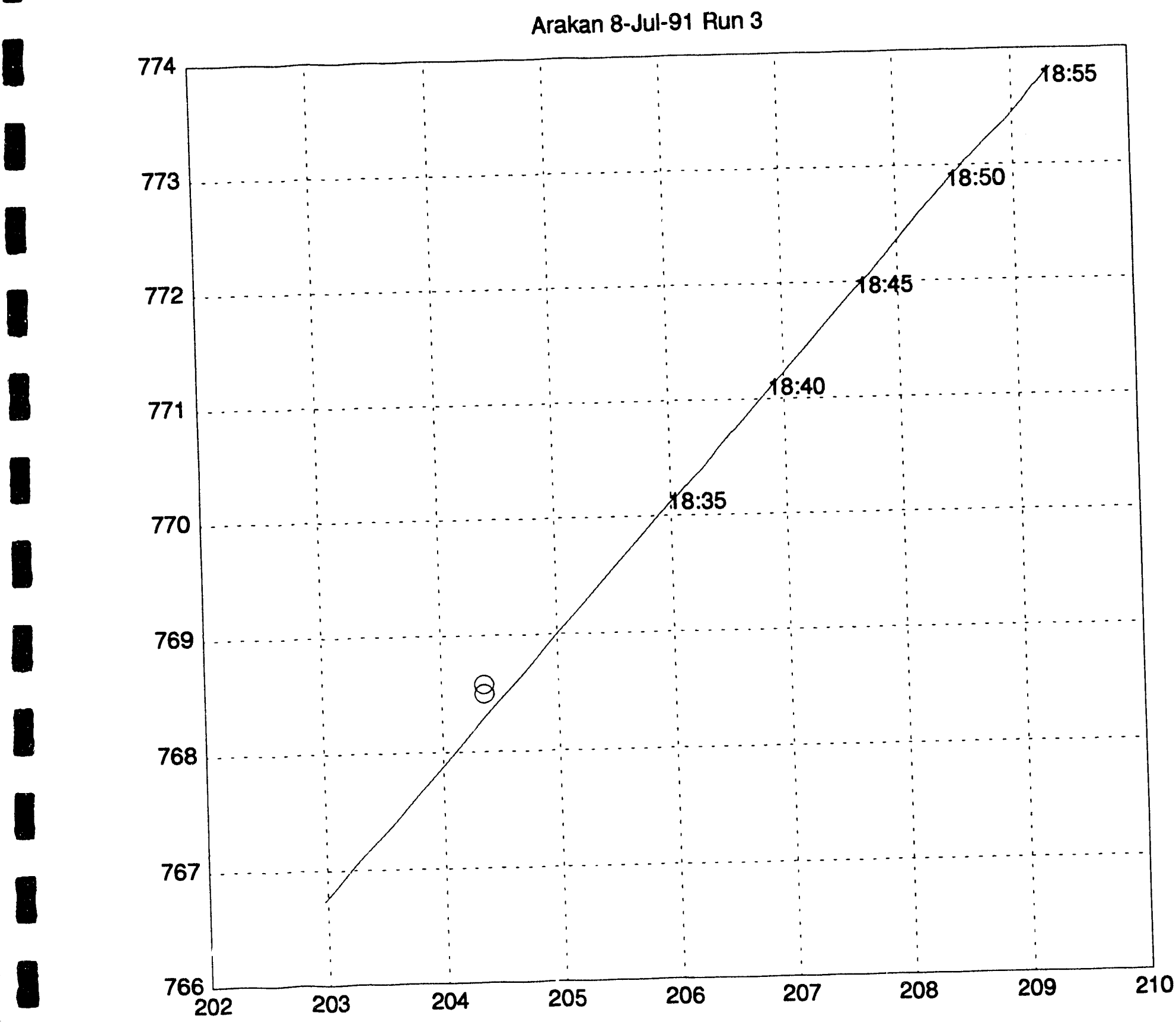


Roysterer 08-Jul-91 Run 4

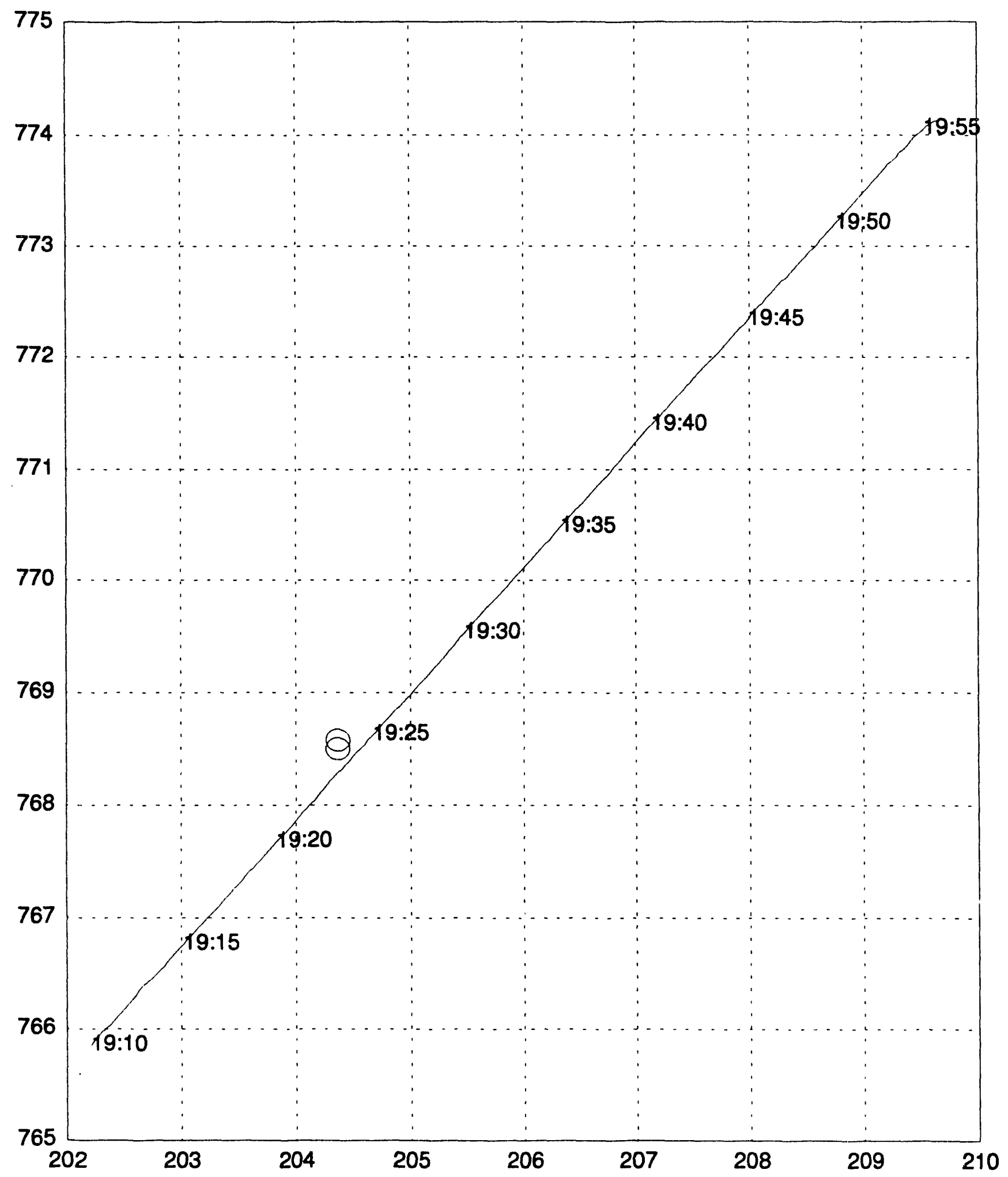


Roysterer 09-Jul-91 Run 1

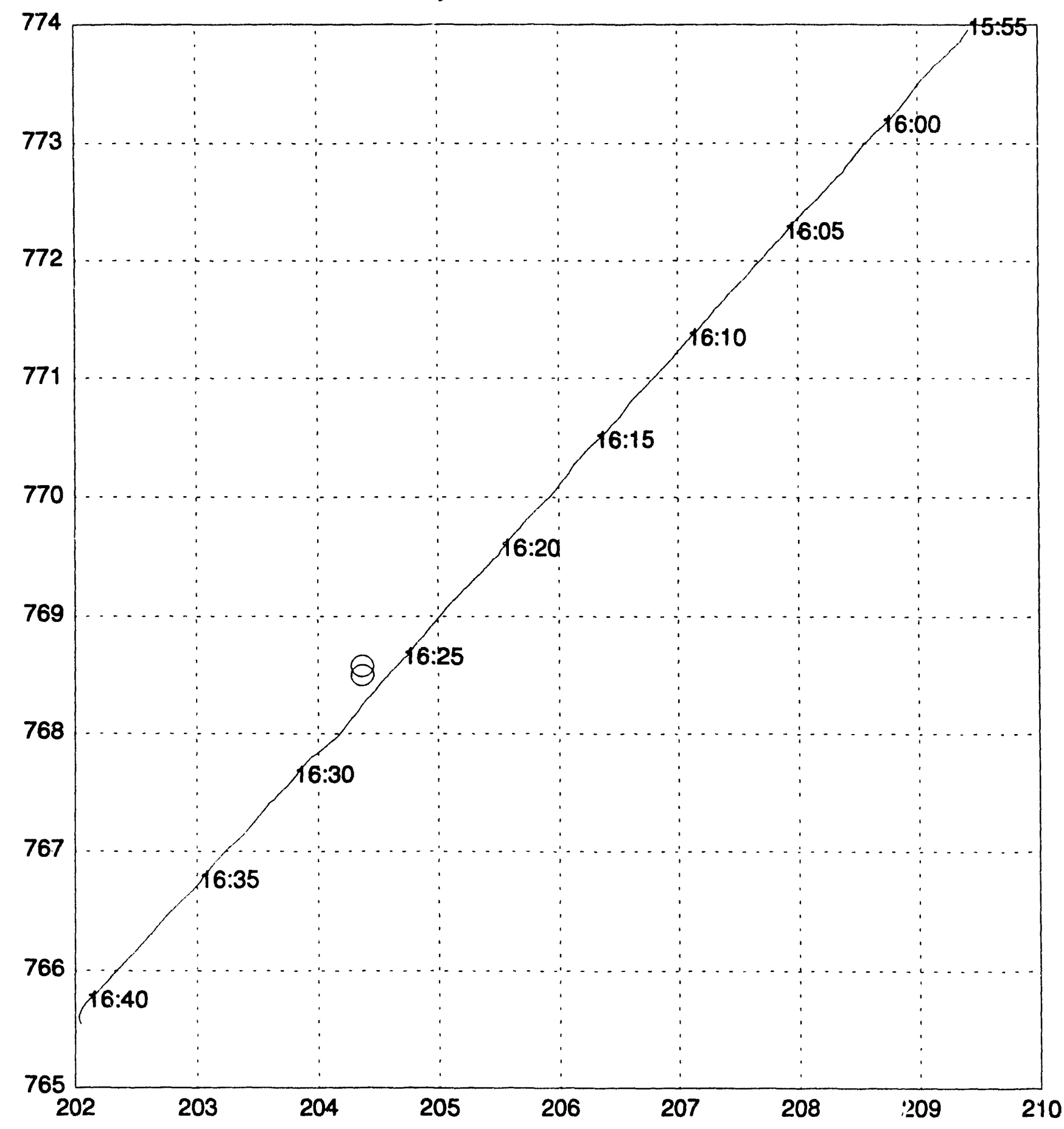




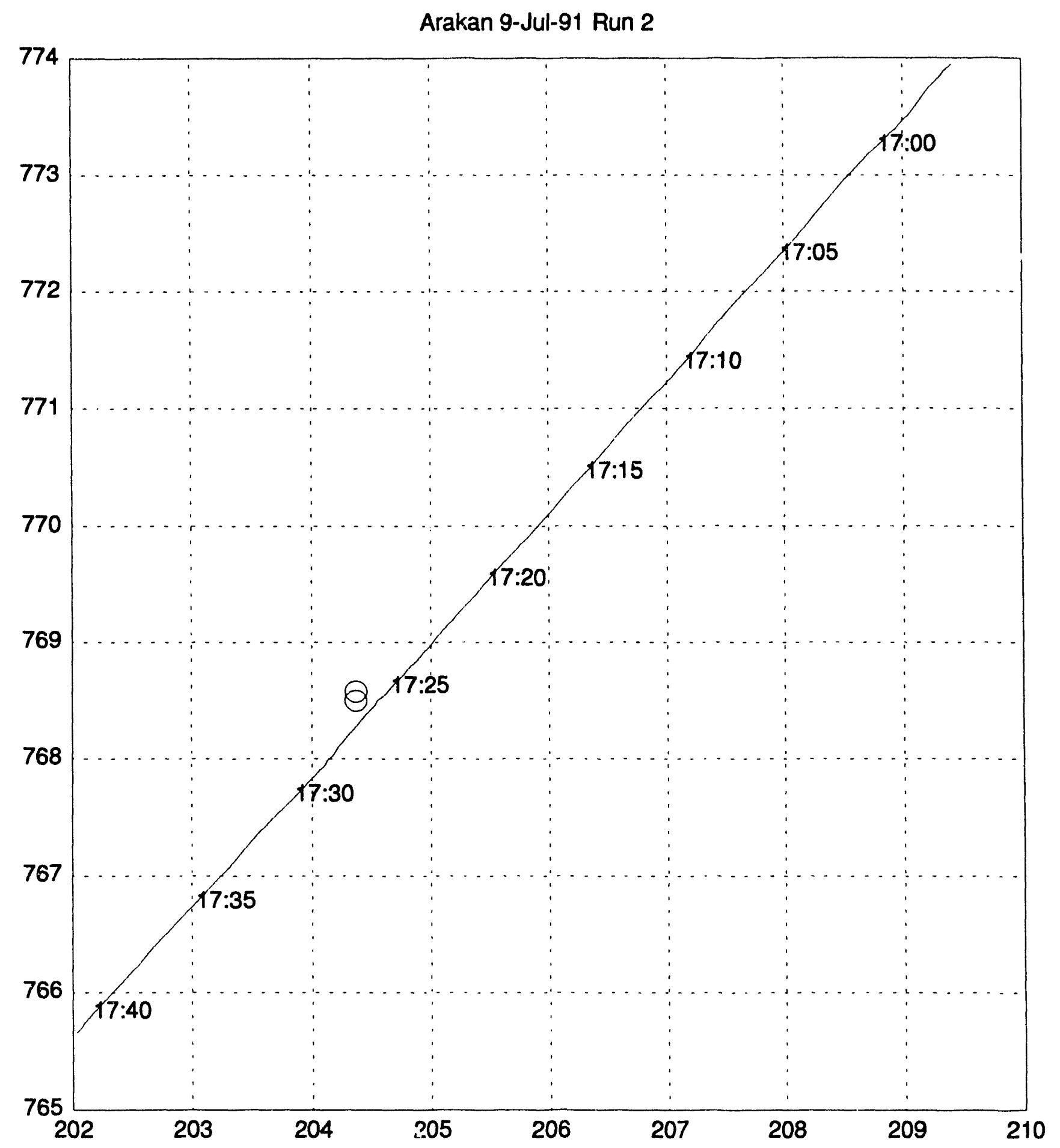


Arakan 9-Jul-91 Run 3

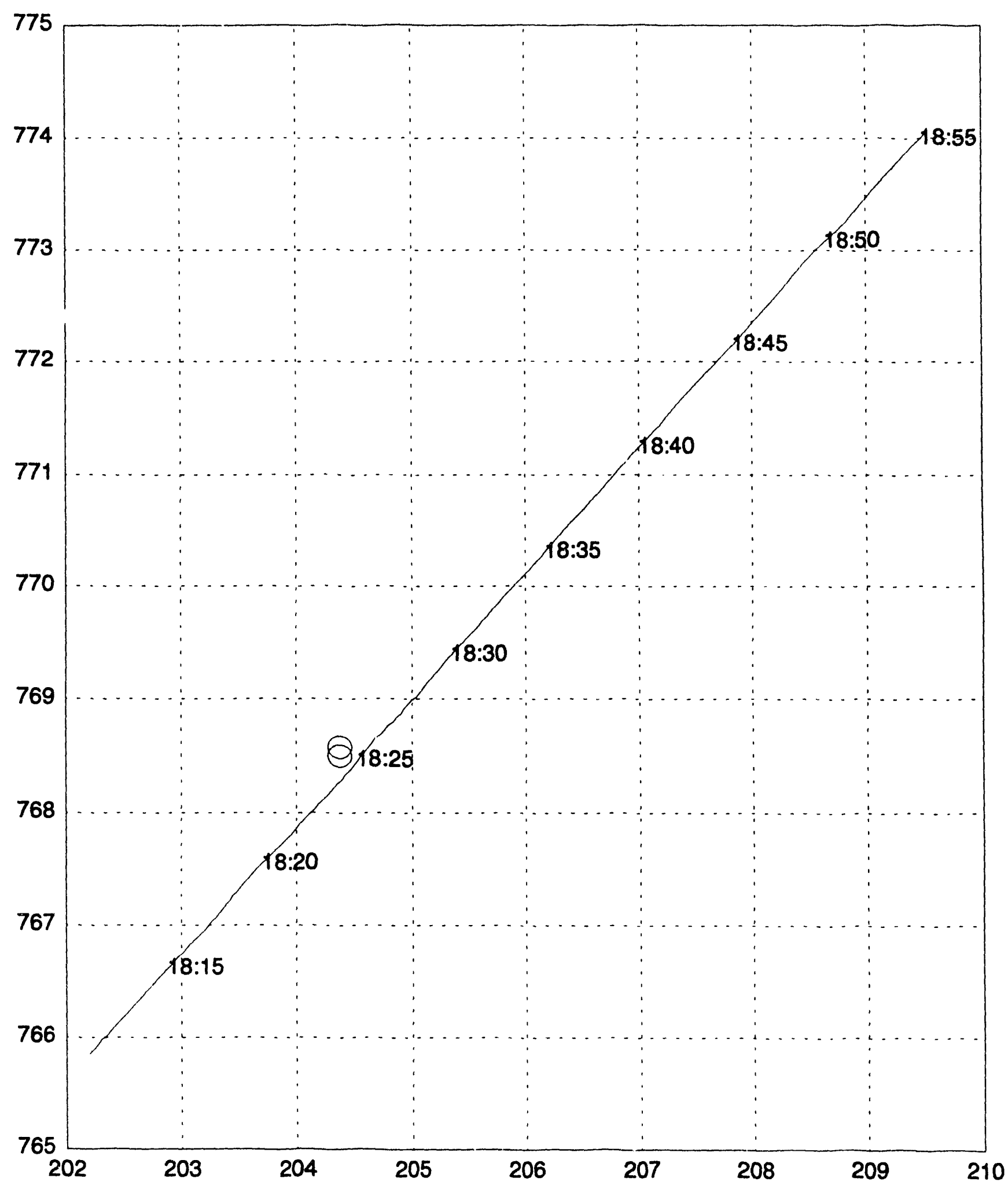


Roysterer 09-Jul-91 Run 4

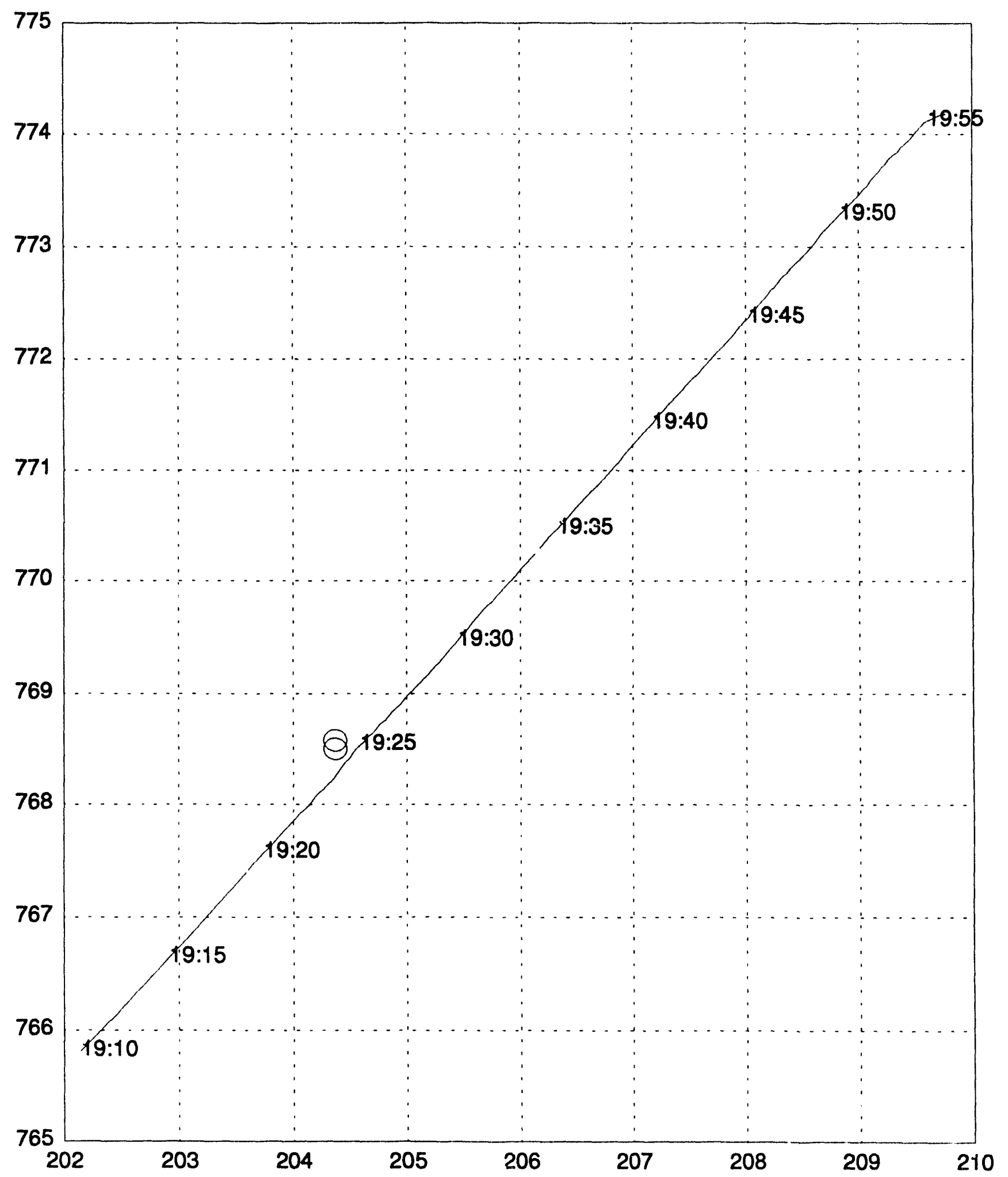




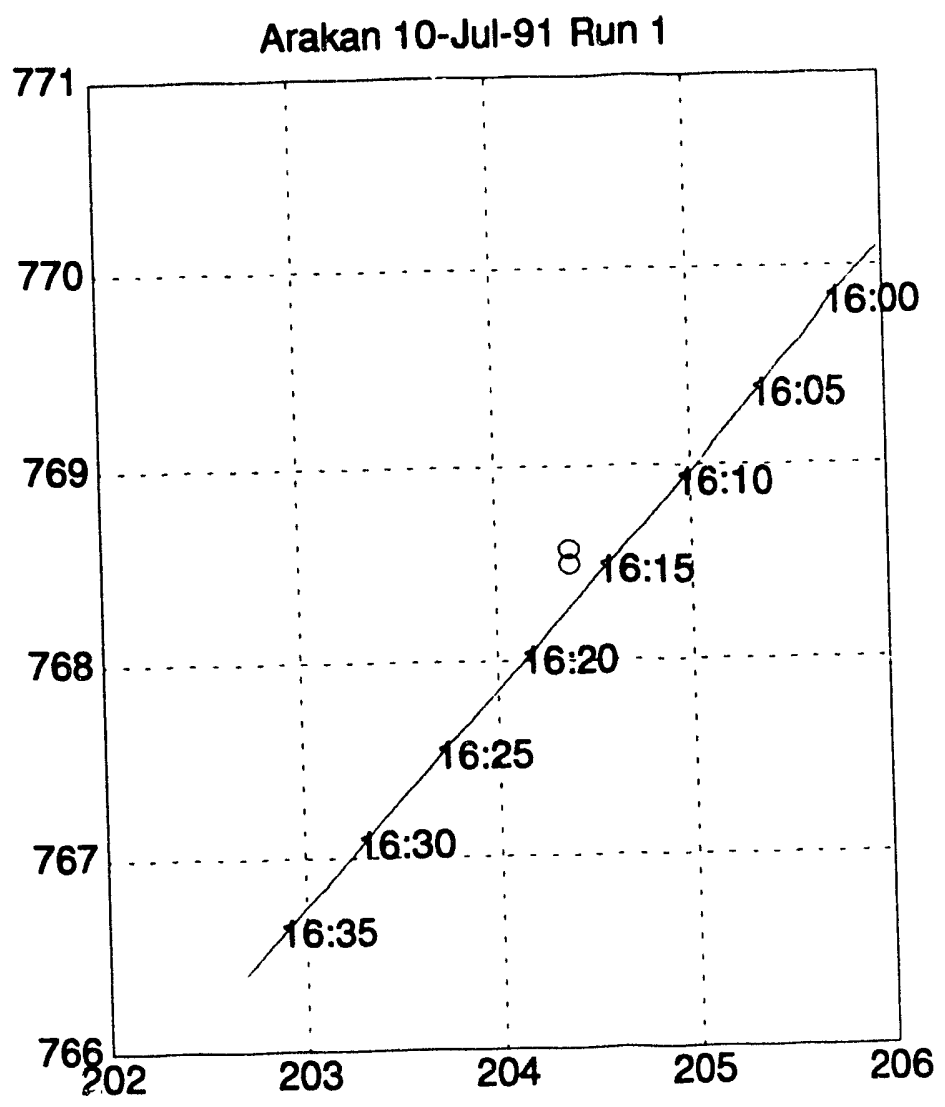




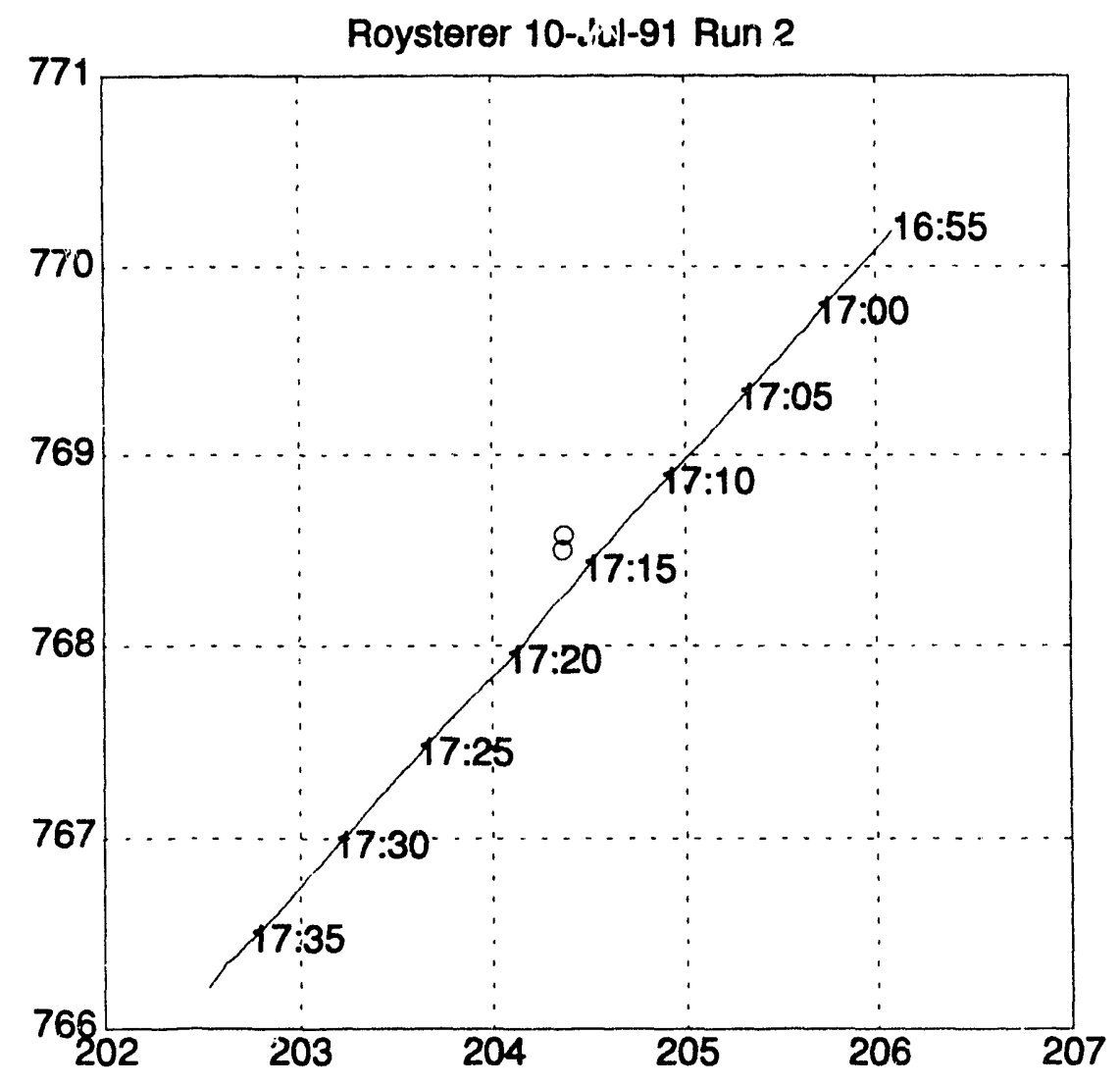




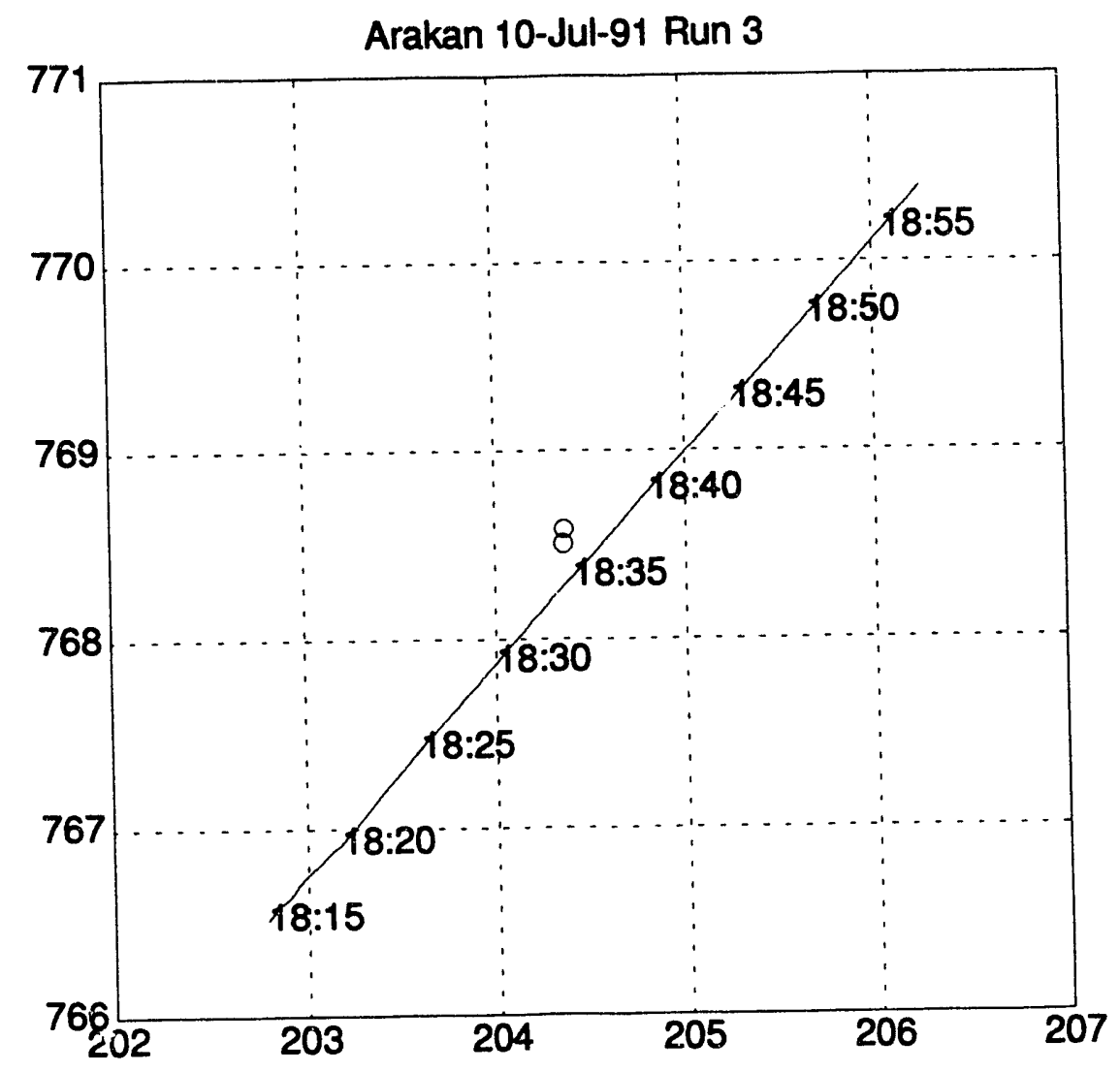




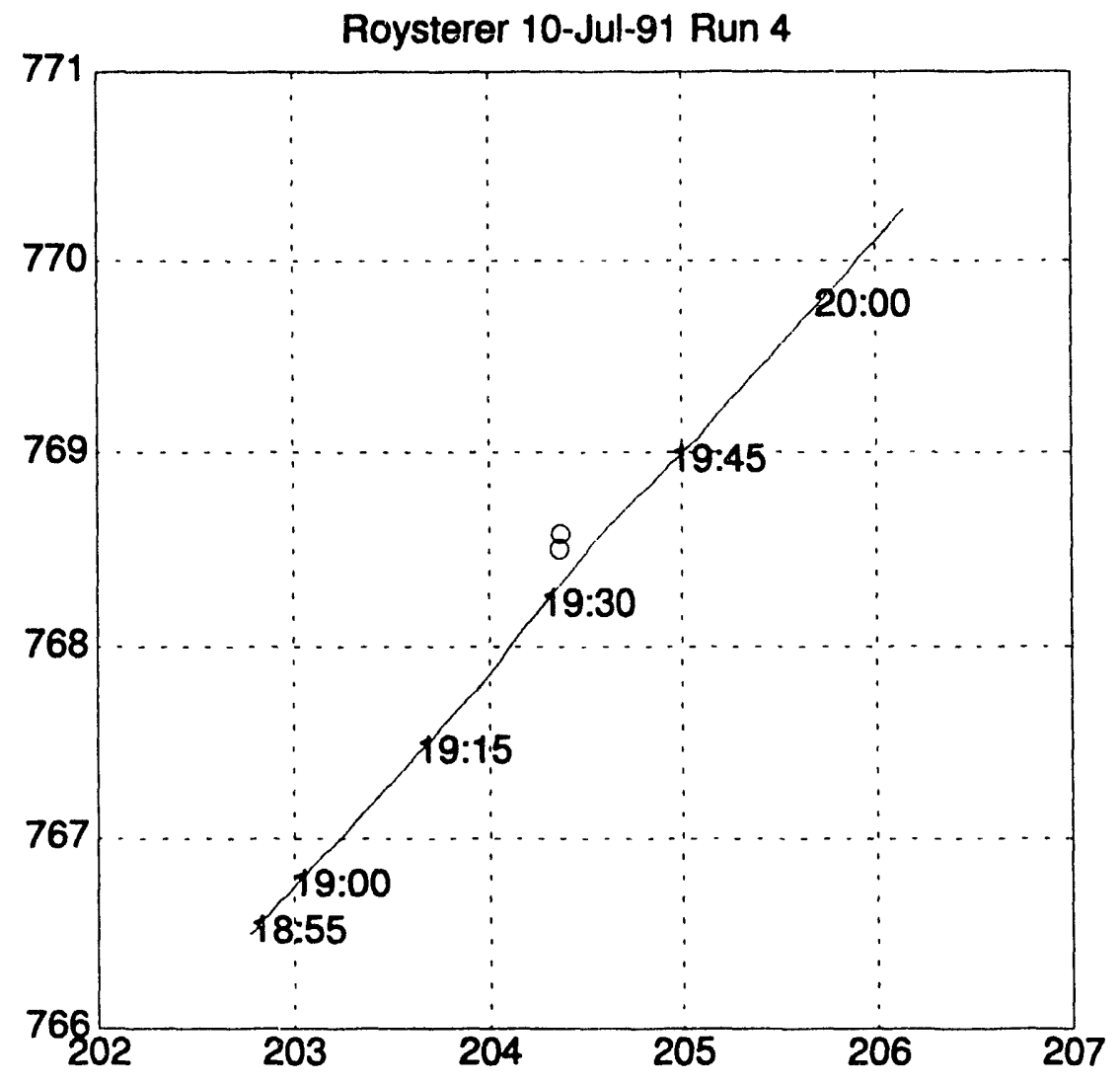


Arakan 11-Jul-91 Run 1

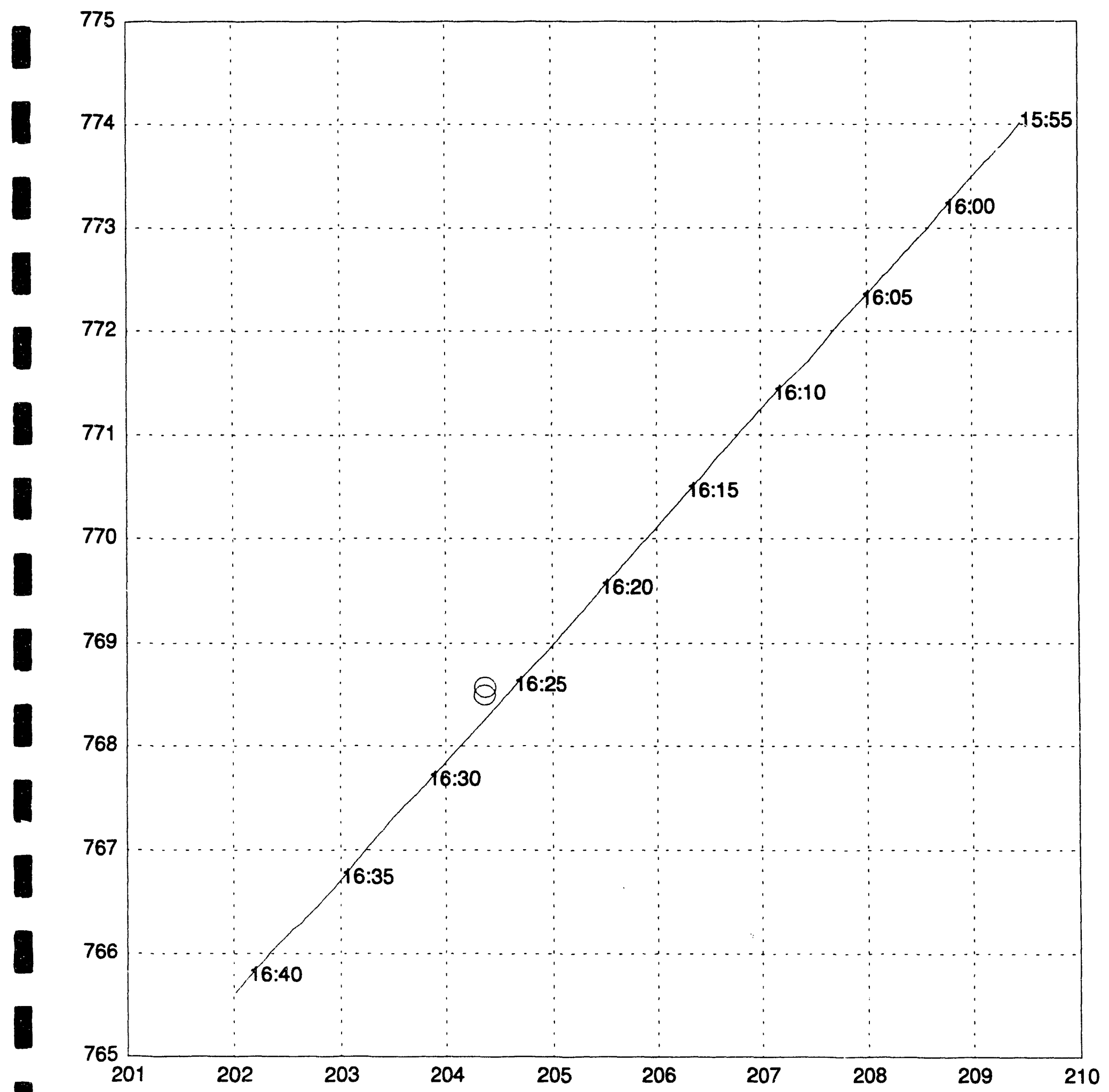


Roysterer 11-Jul-91 Run 2

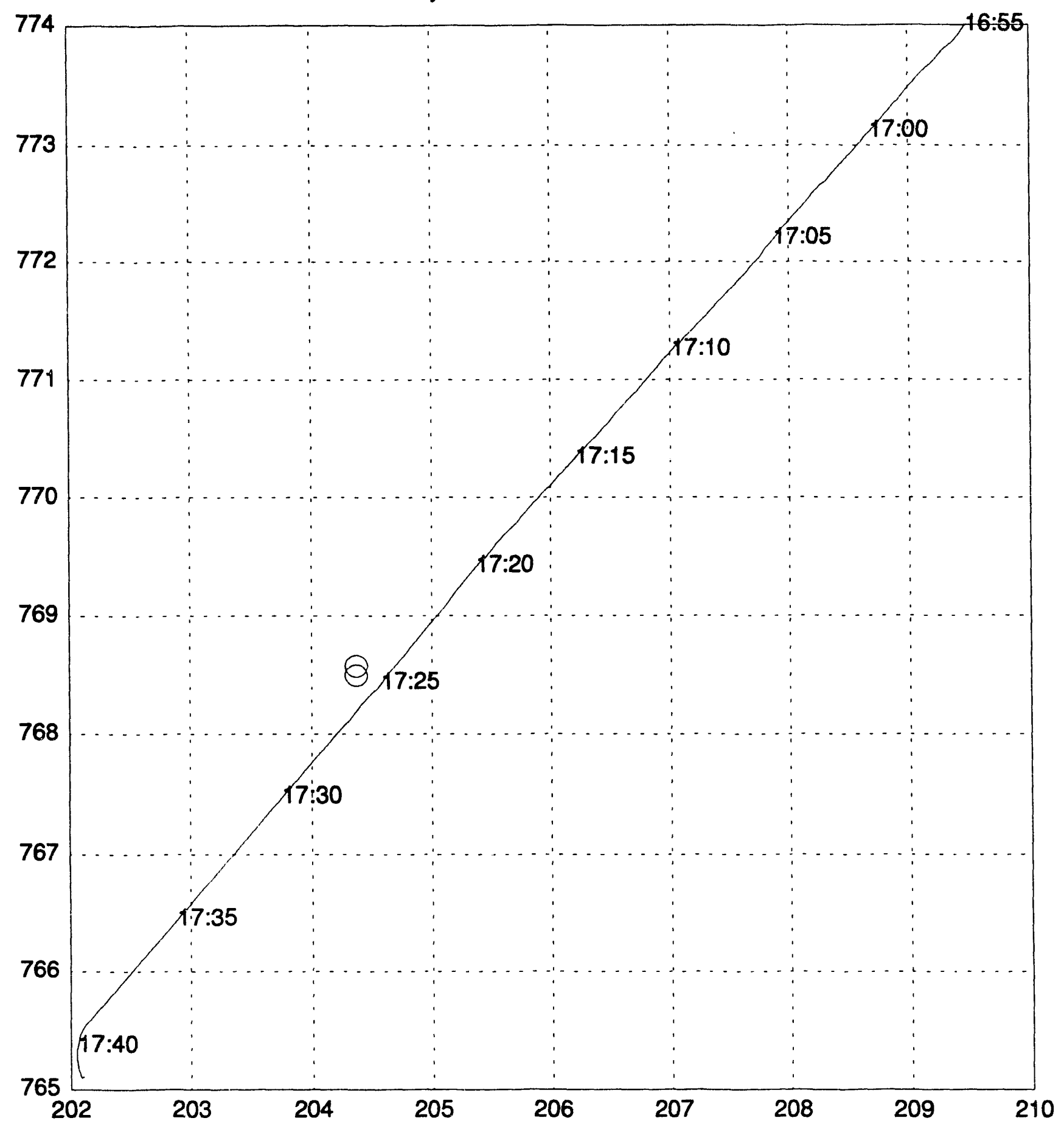


Arakan 11-Jul-91 Run 3

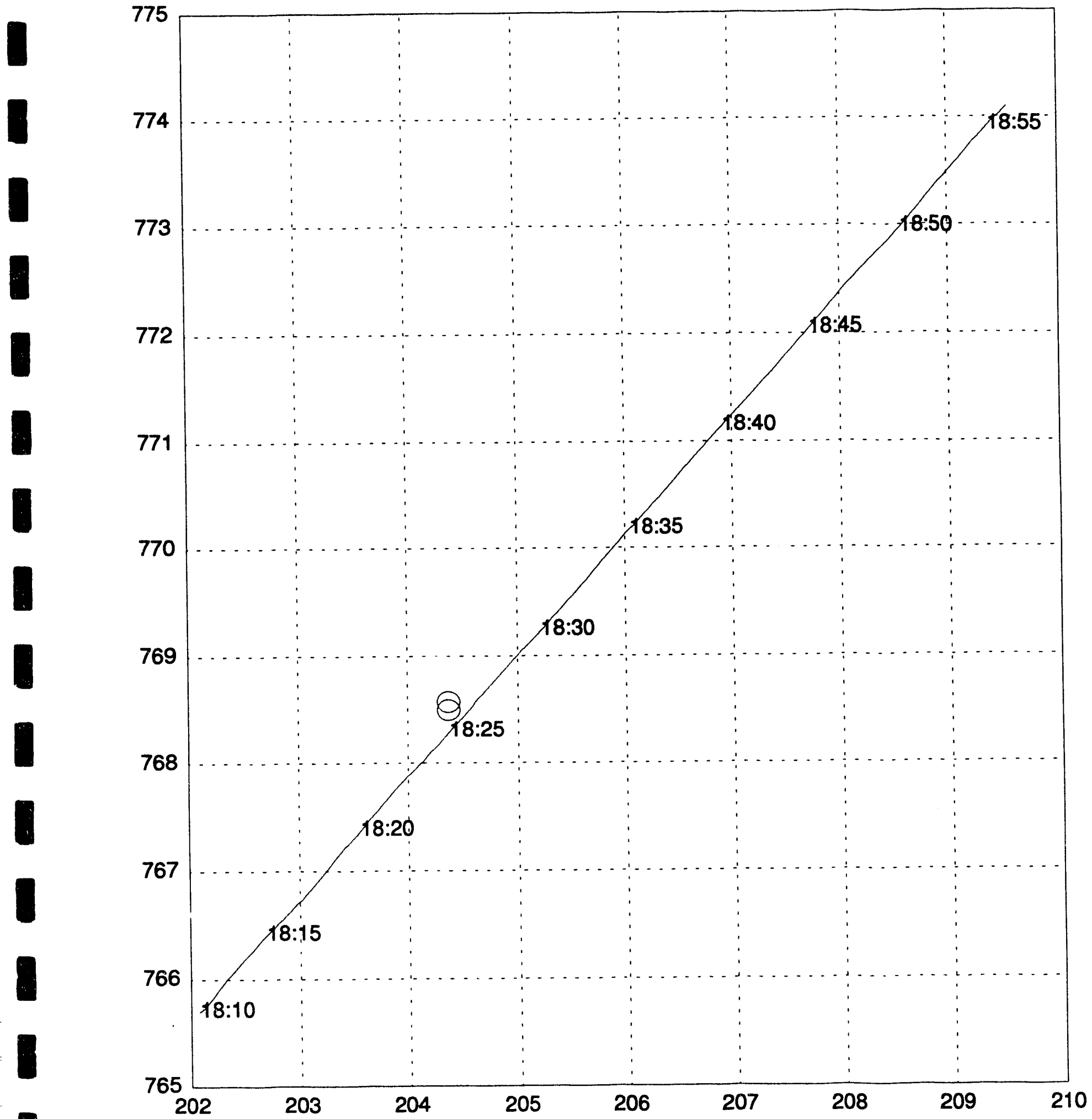


Roysterer 11-Jul-91 Run 4

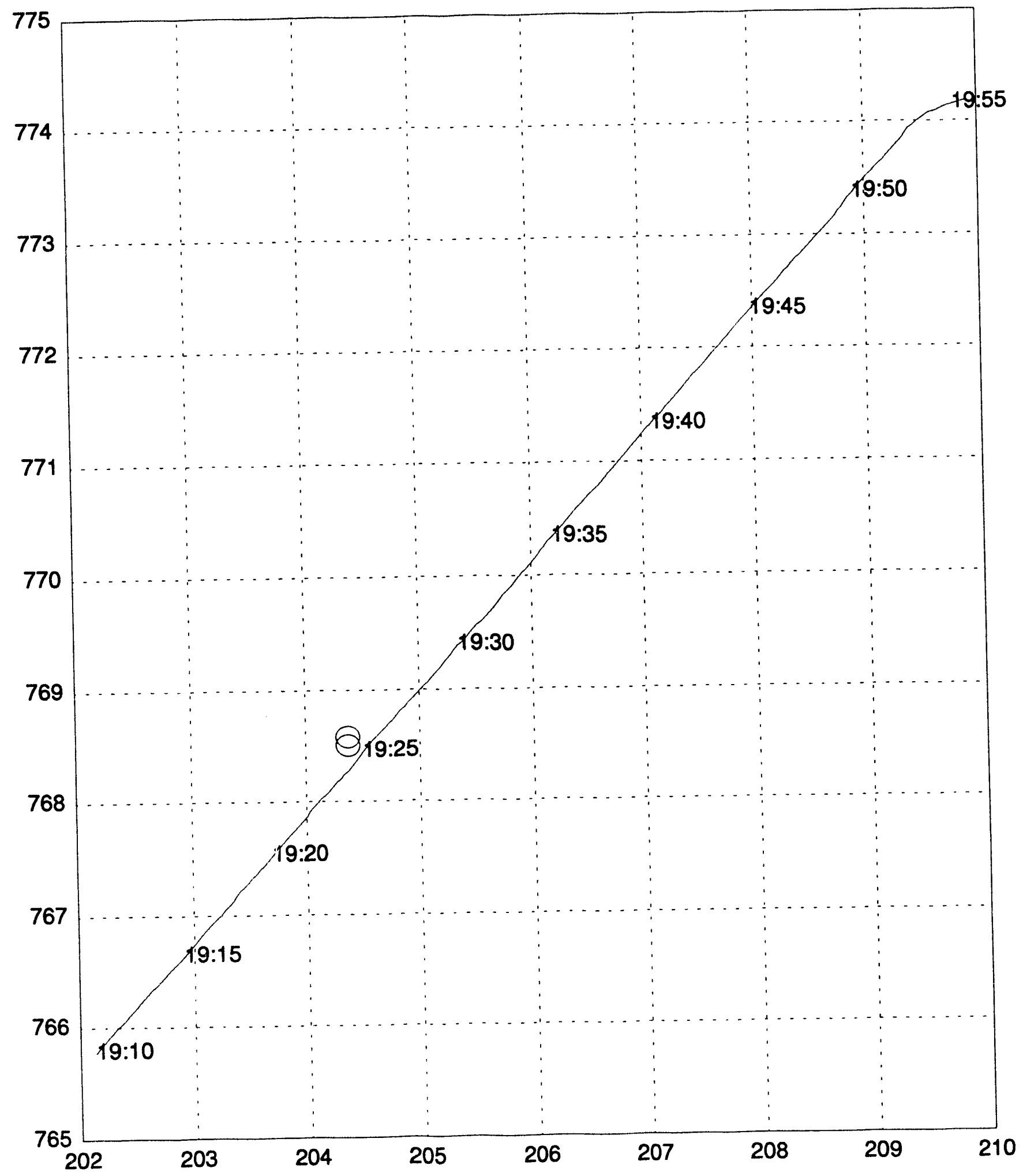




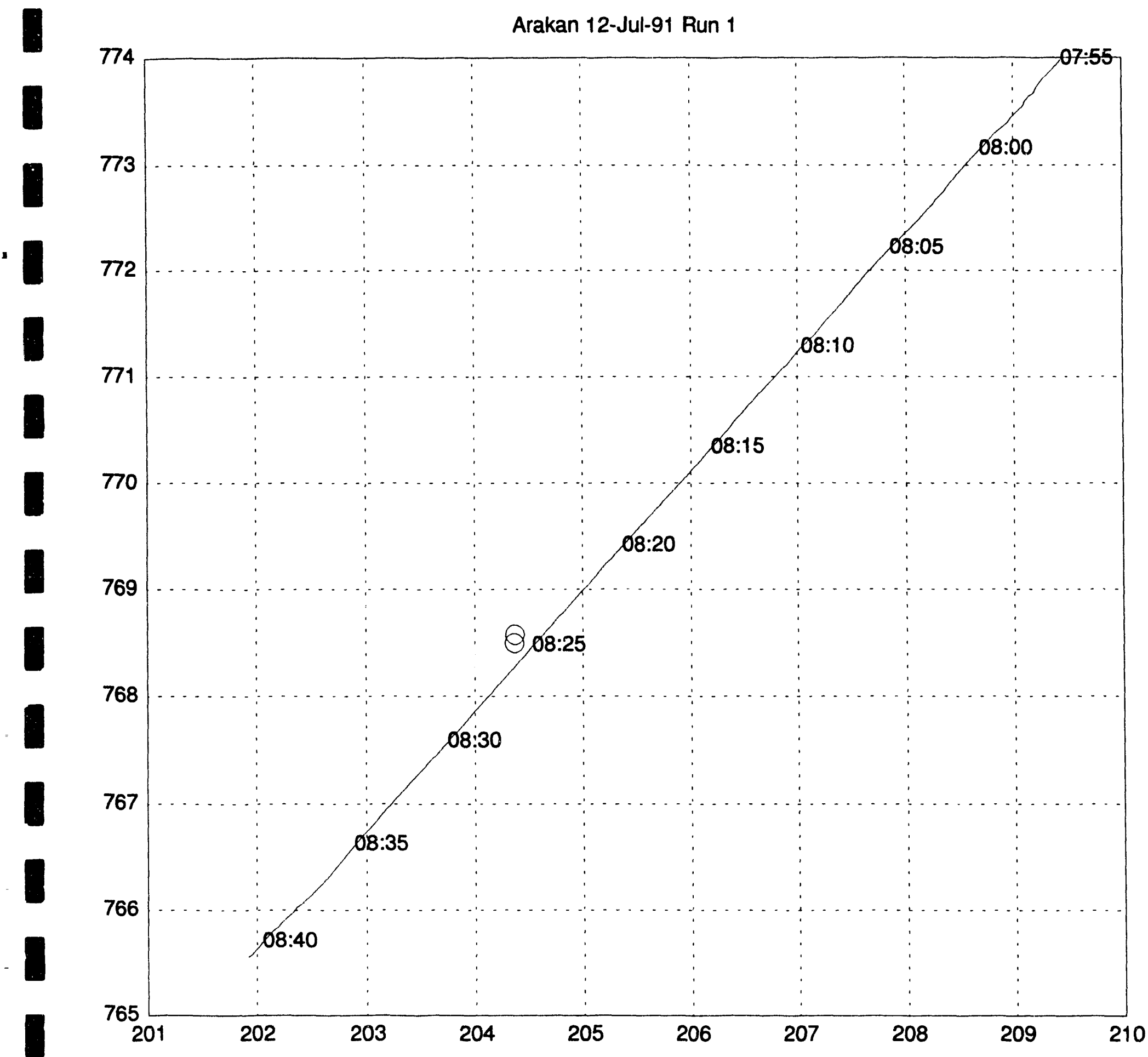


Roysterer 12-Jul-91 Run 2

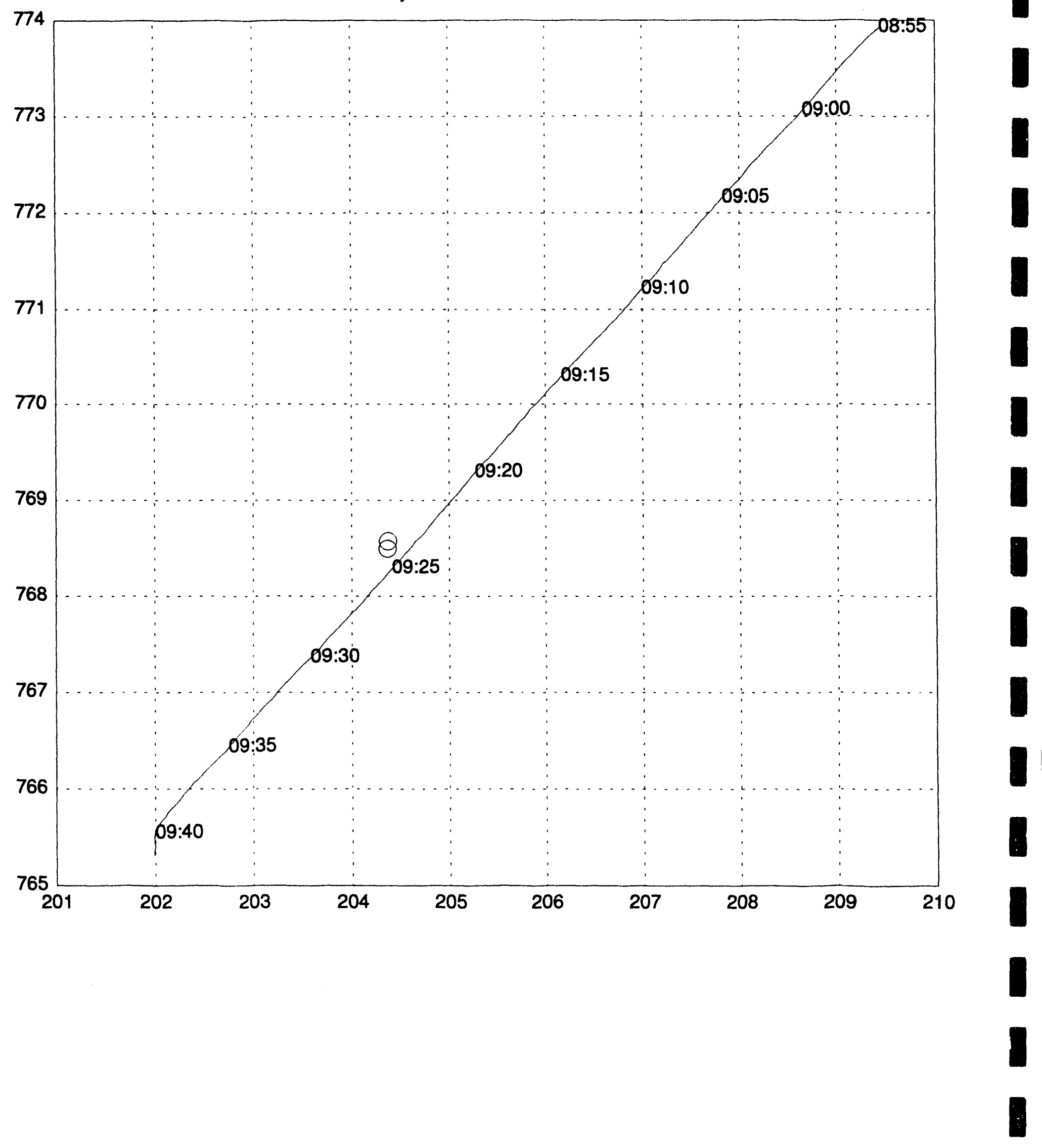


Arakan 12-Jul-91 Run 3

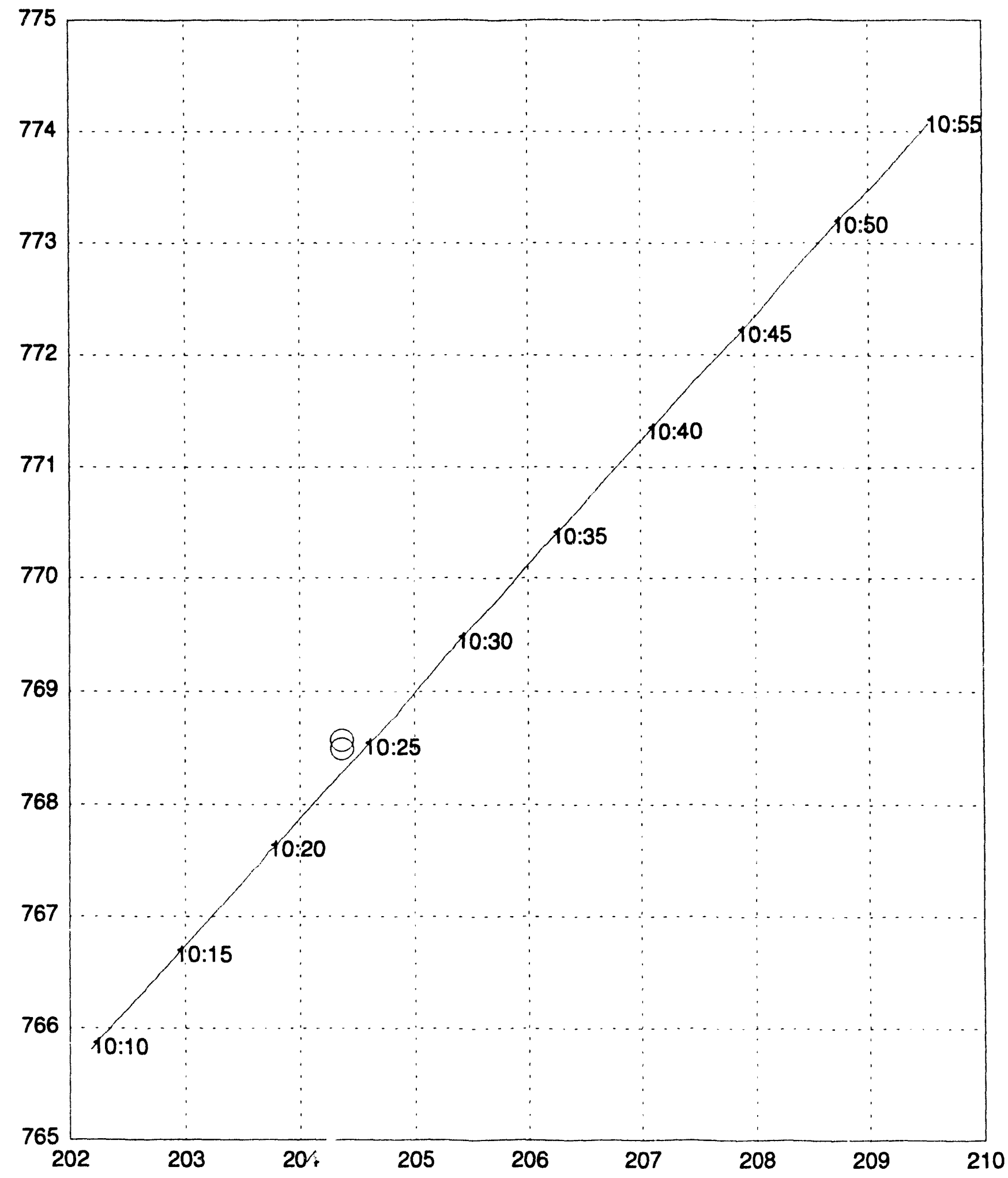


Roysterer 12-Jul-91 Run 4

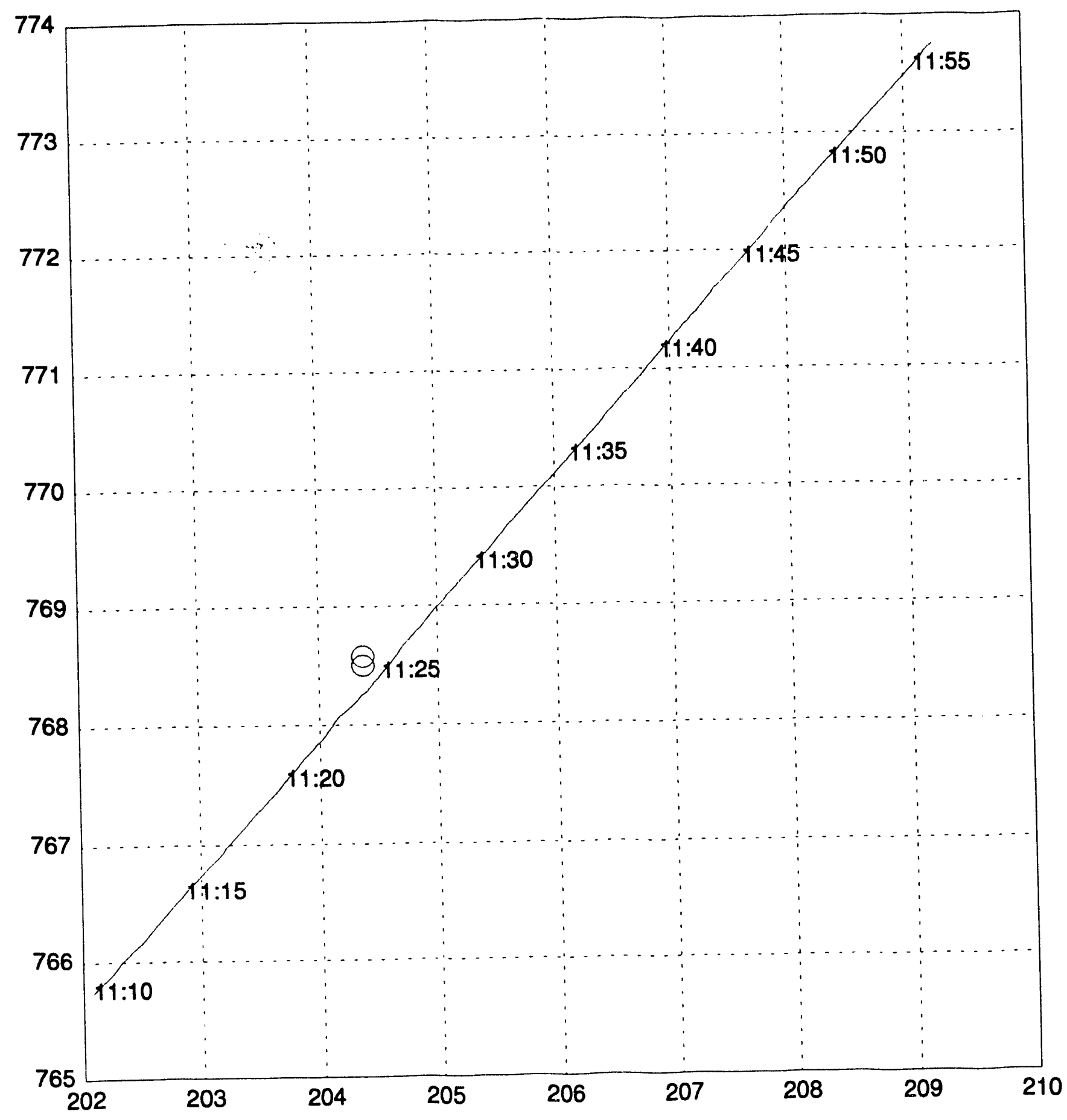


I

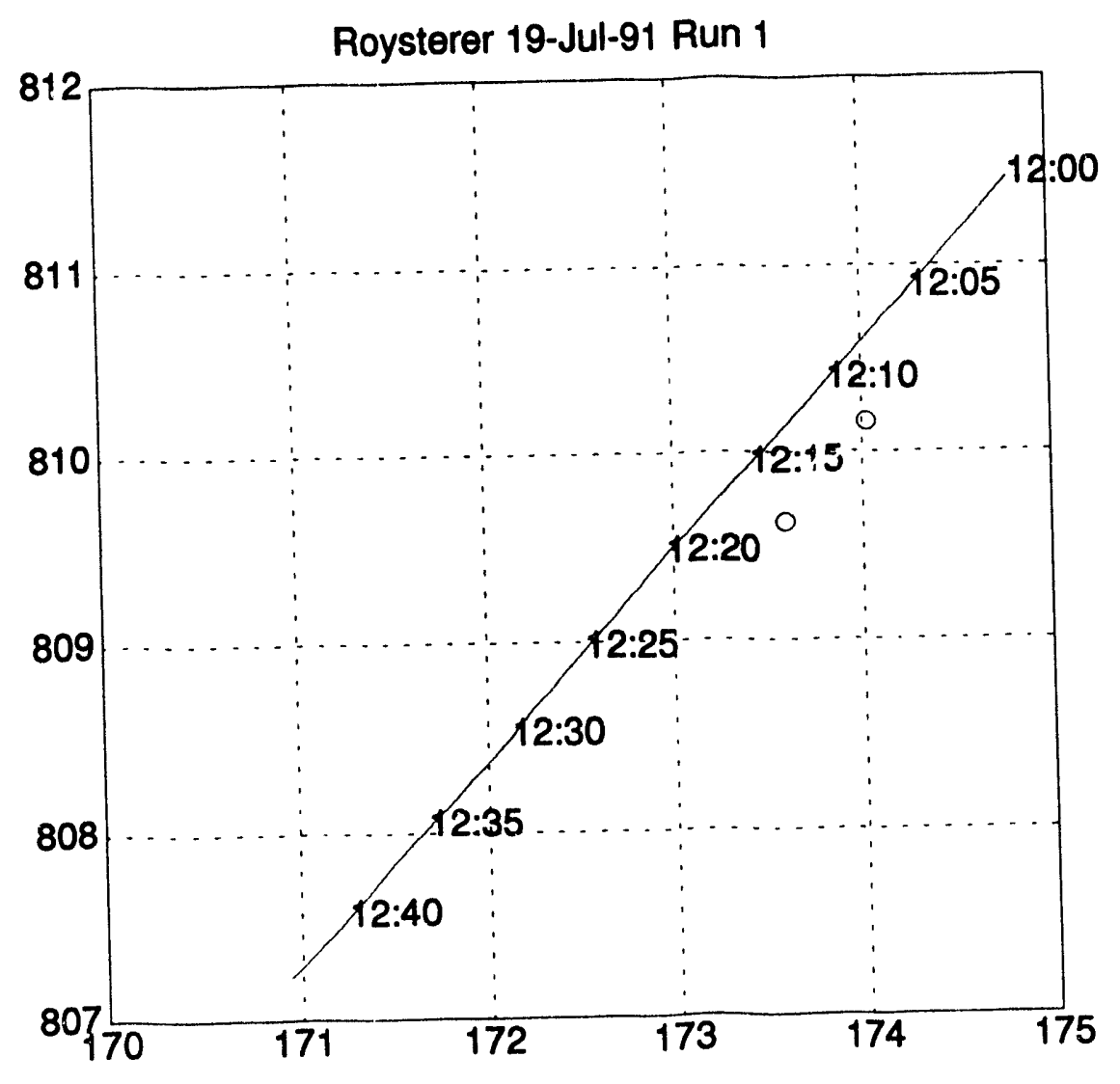




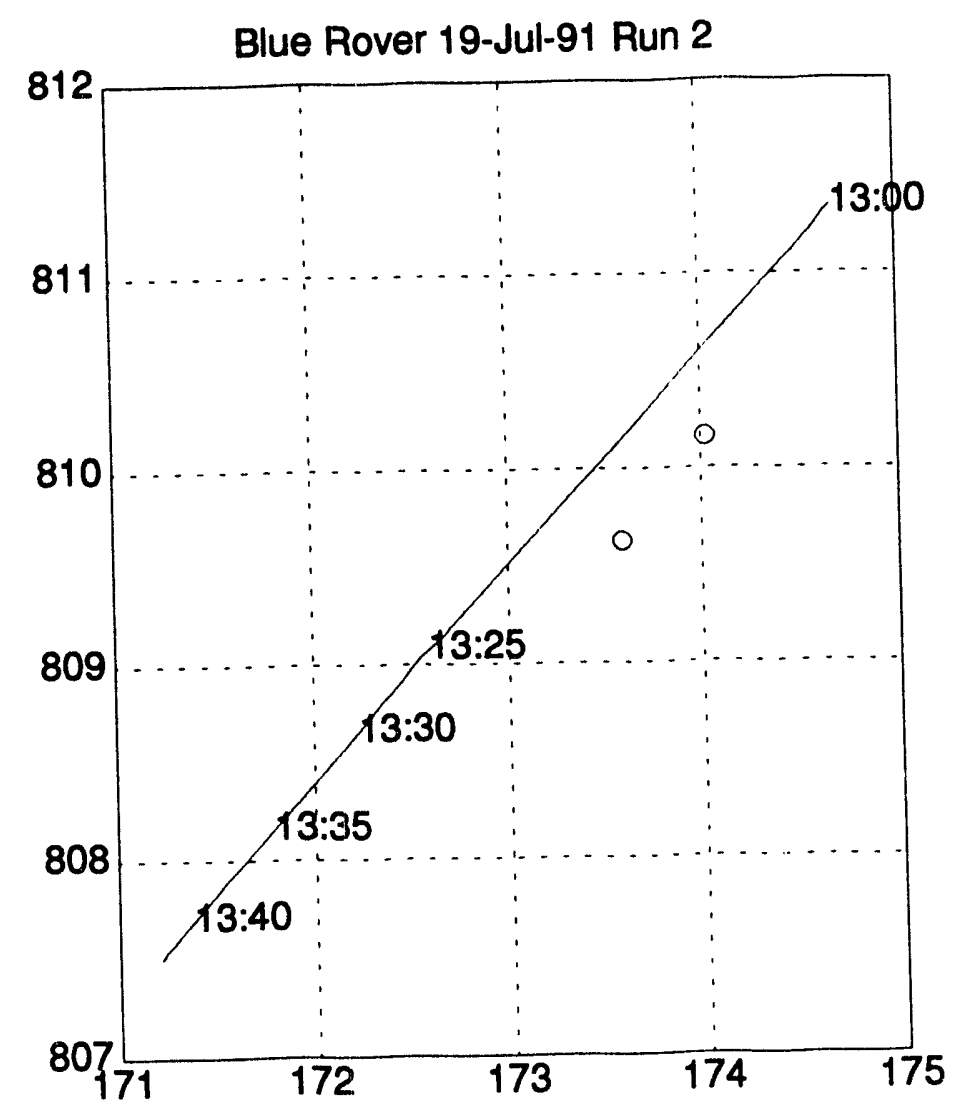




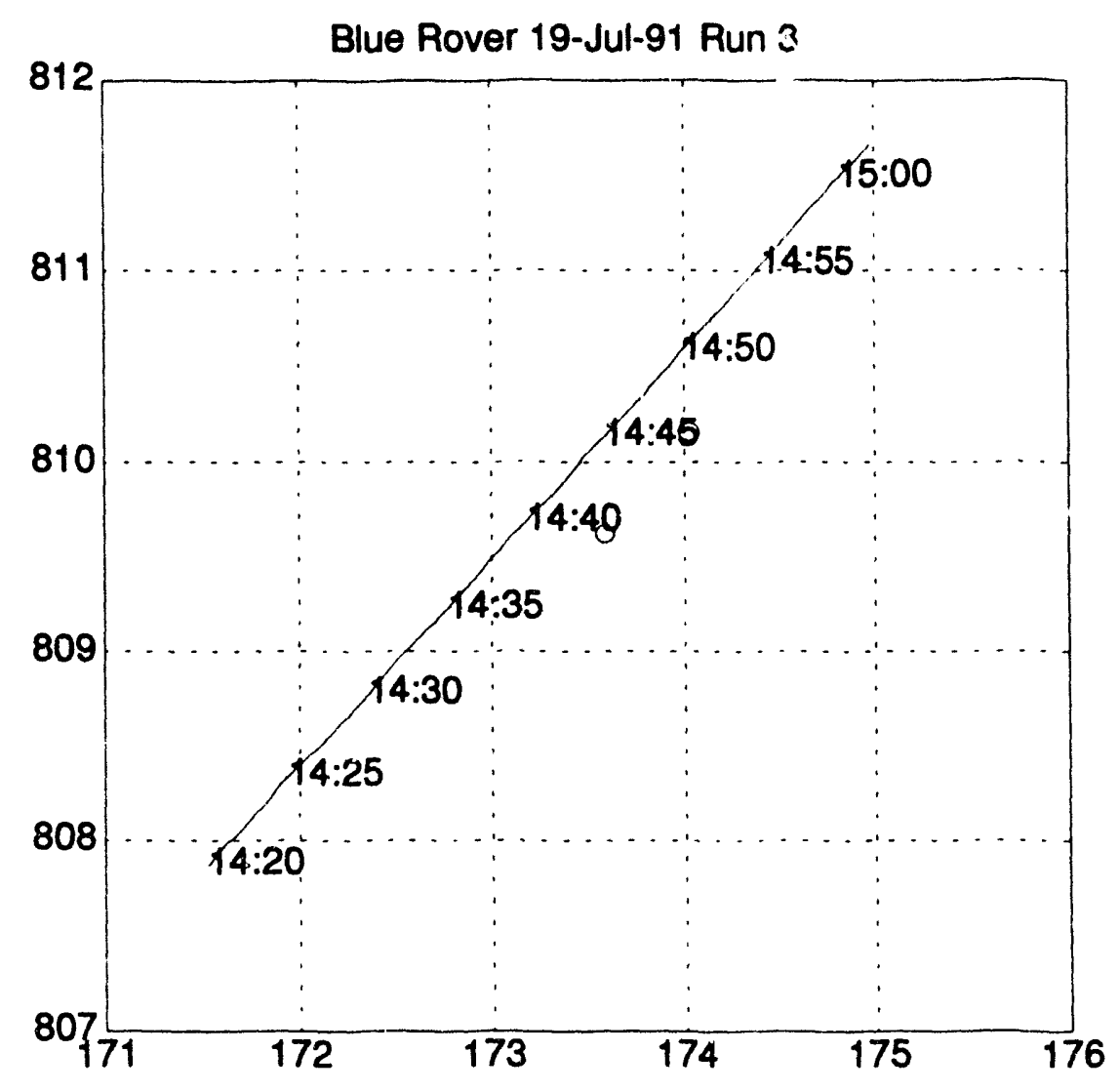




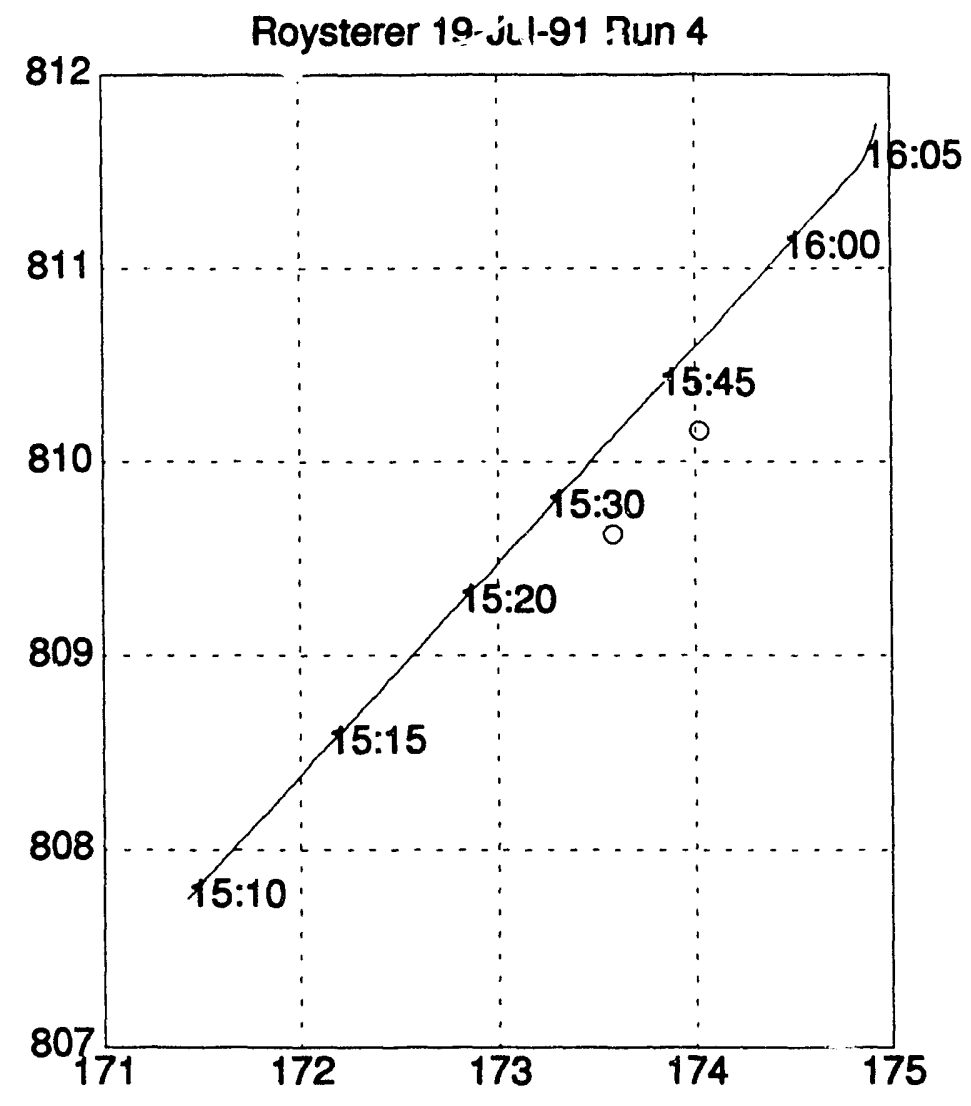




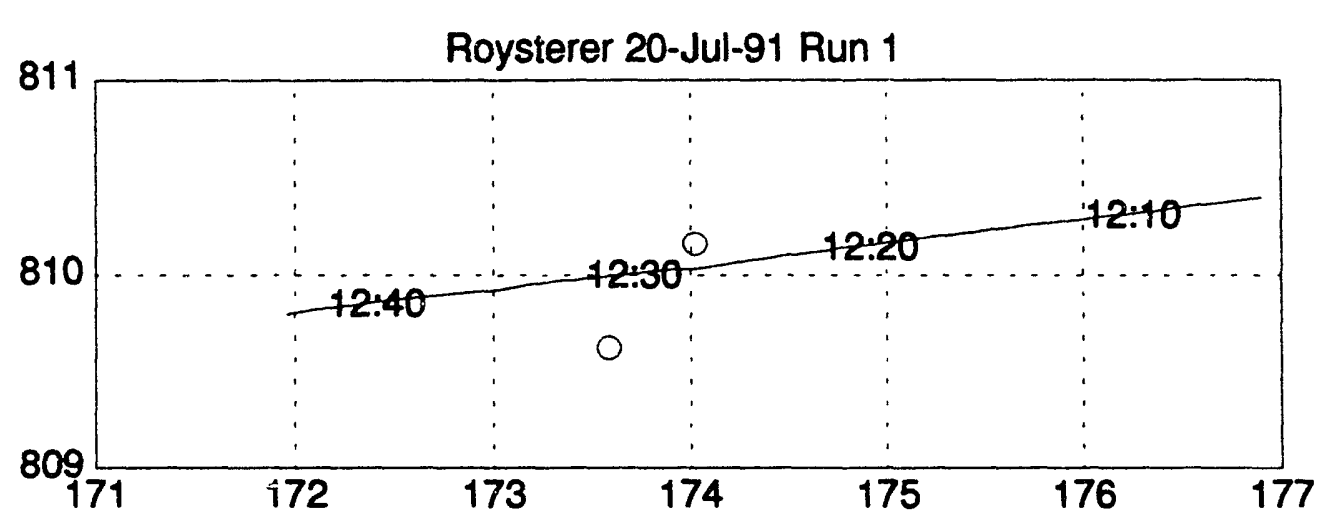




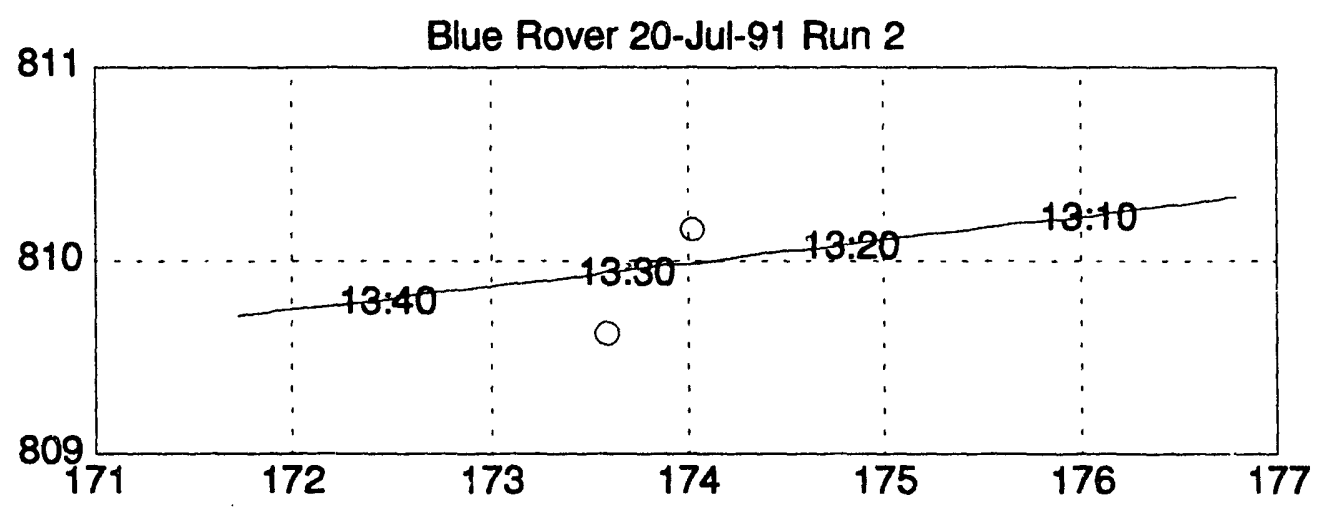




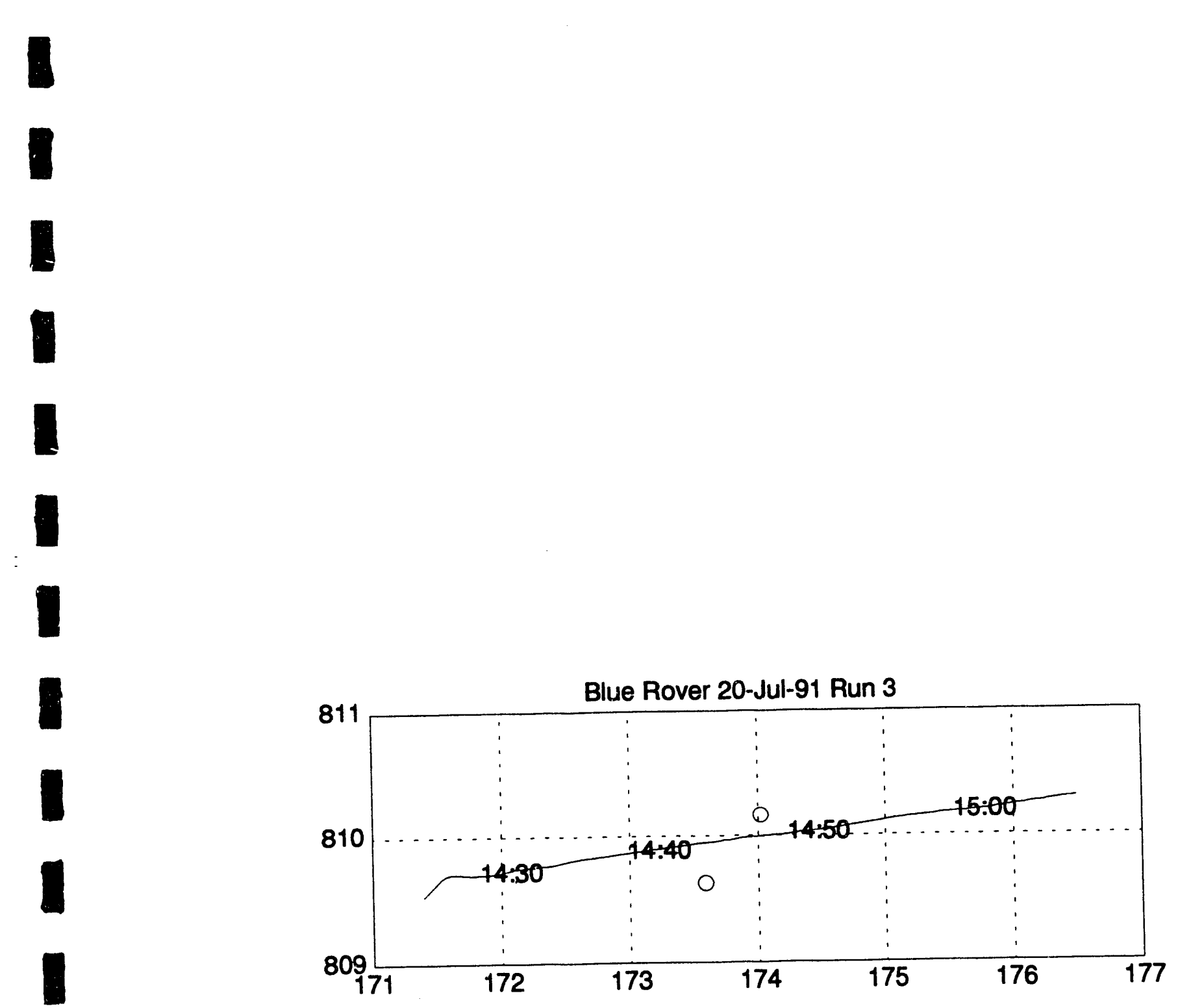


Roysterer 20-Jul-91 Run 4

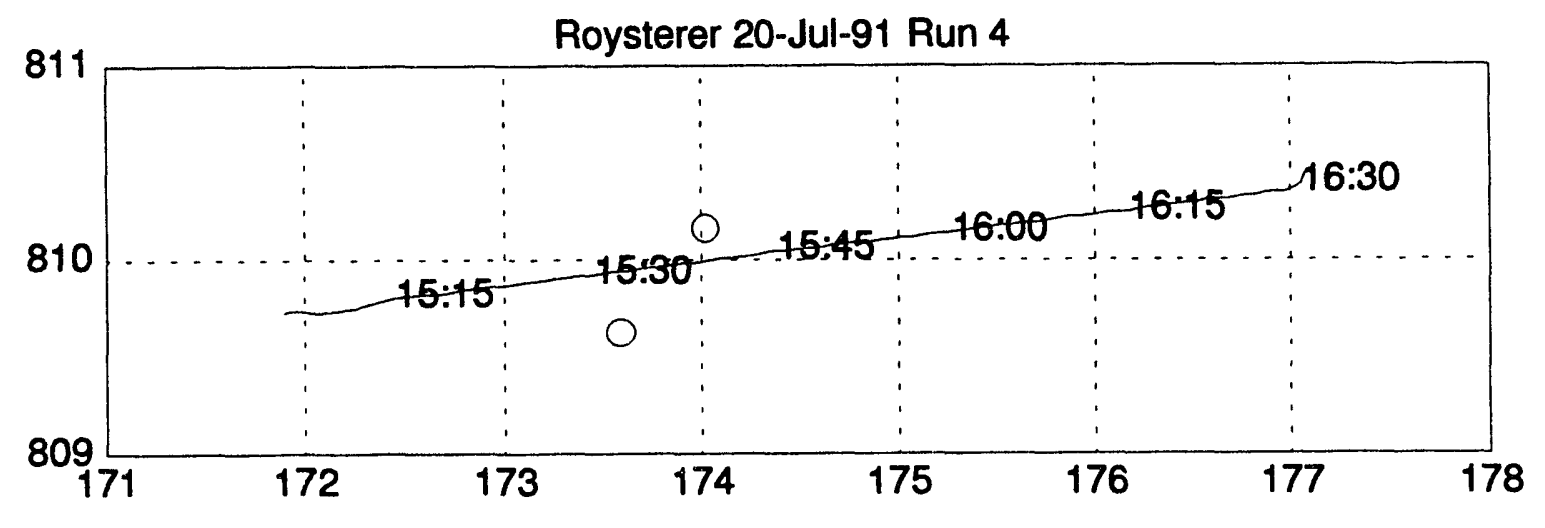


Blue Rover 21-Jul-91 Run 1

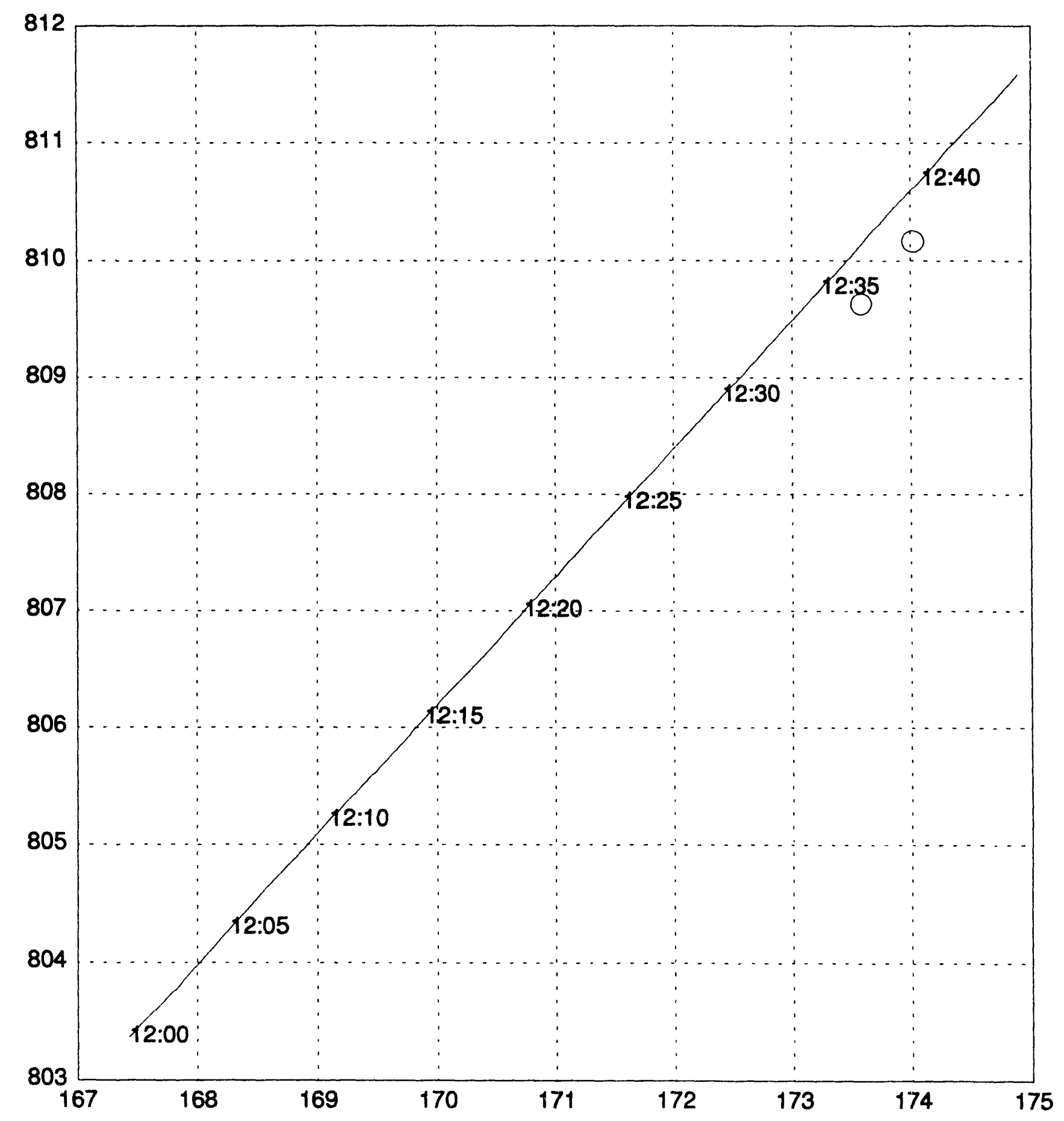


Roysterer 21-Jul-91 Run 2

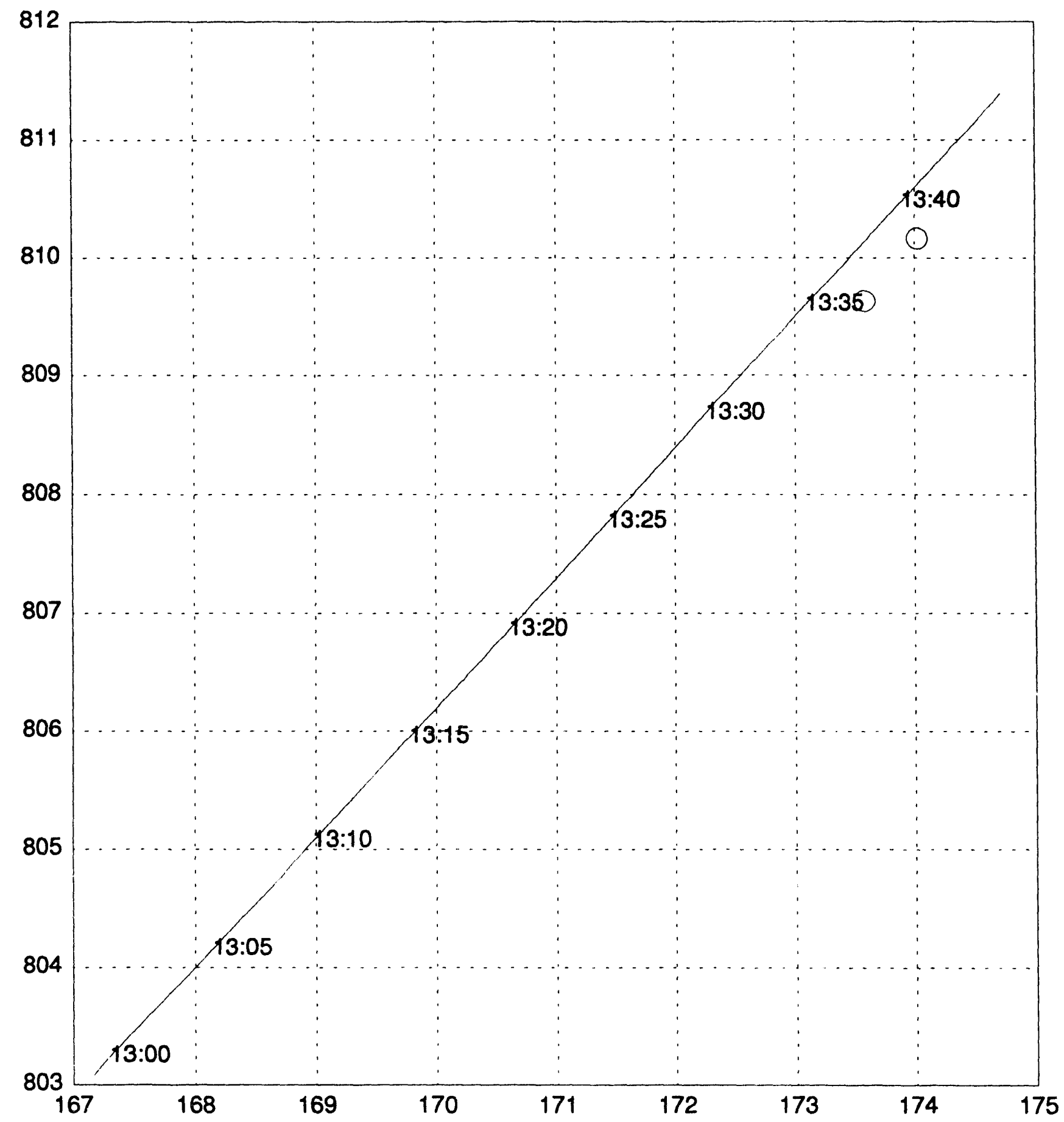


Roysterer 21-Jul-91 Run 3

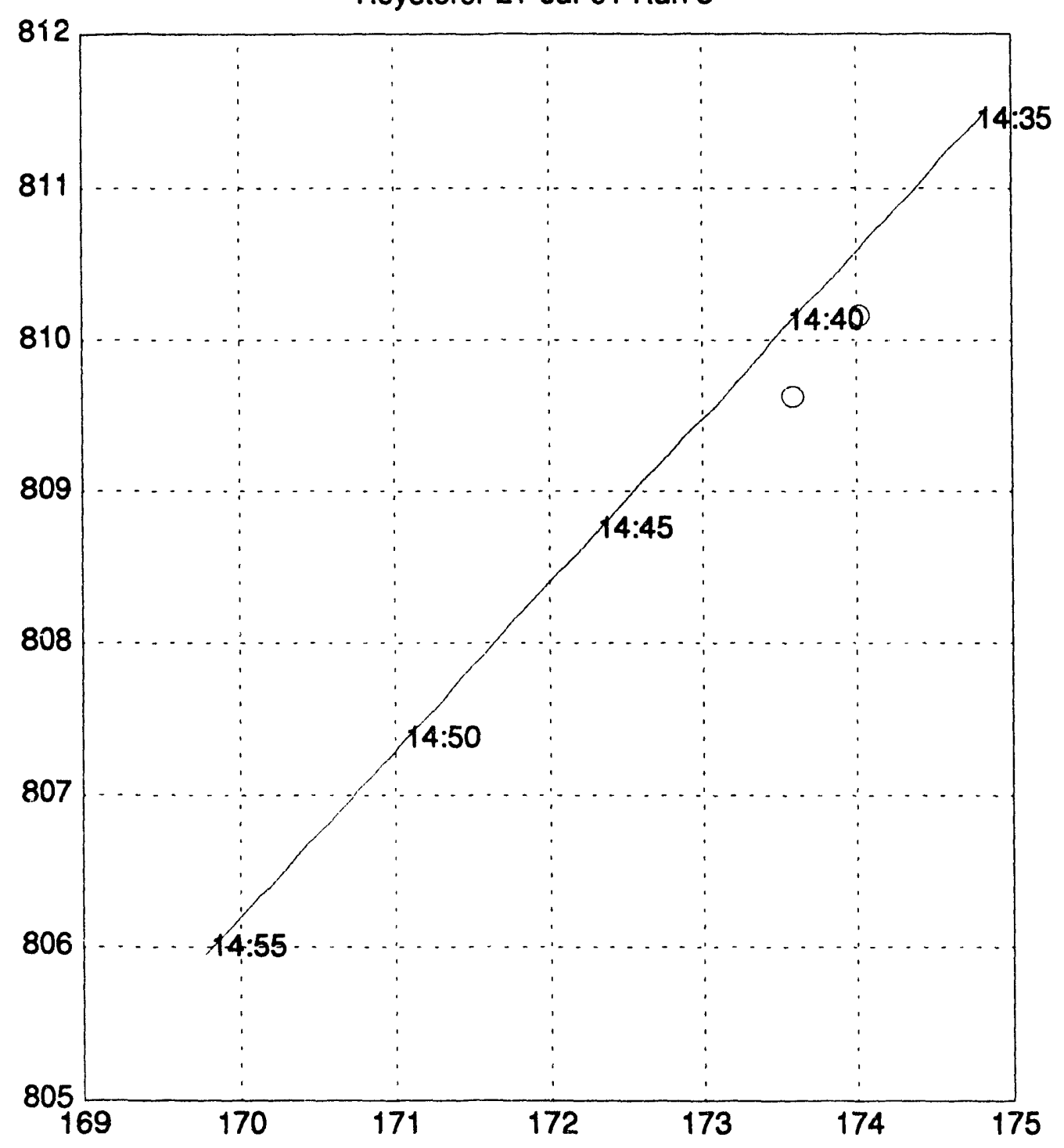


Blue Rover 21-Jul-91 Run 4

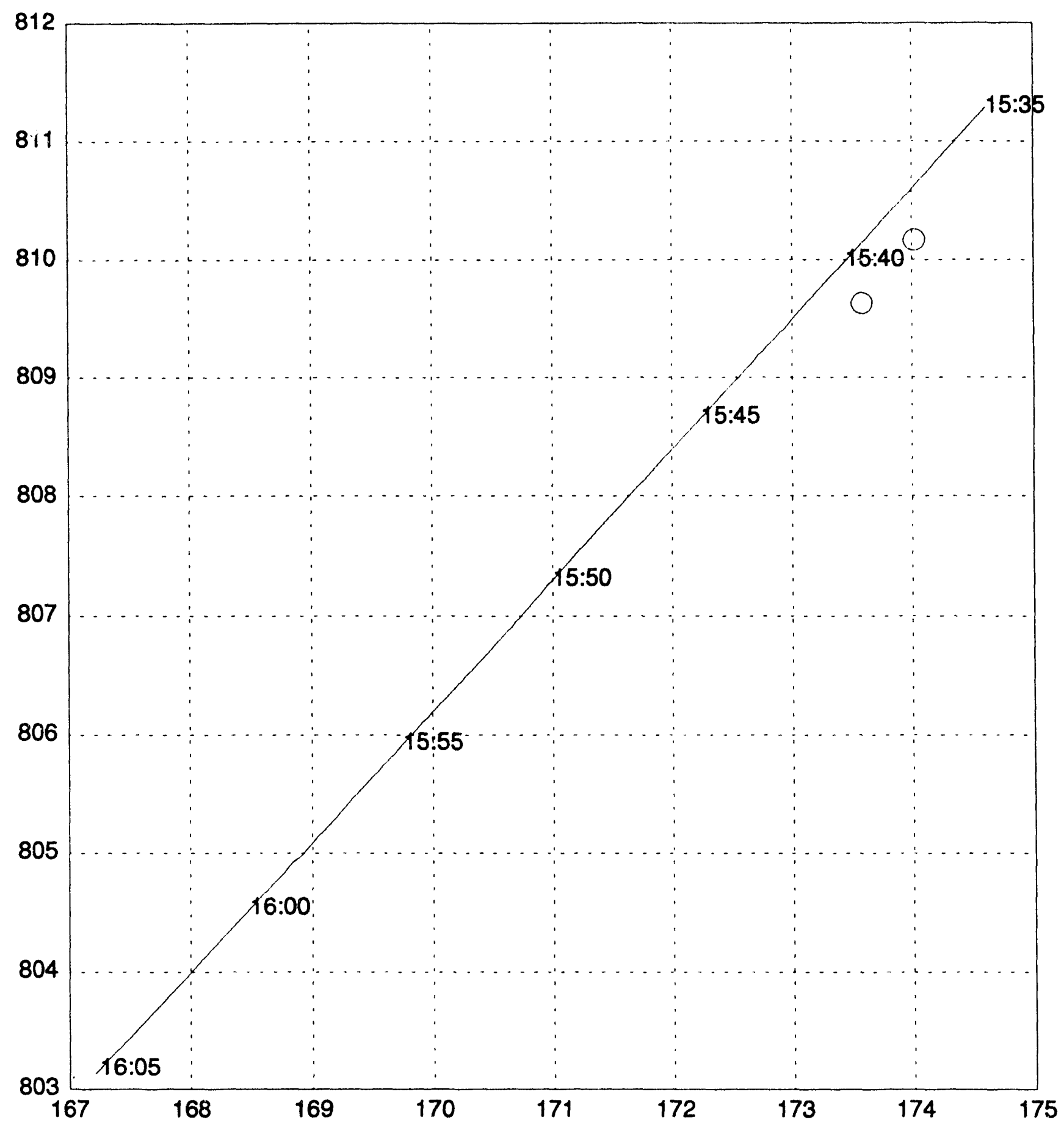




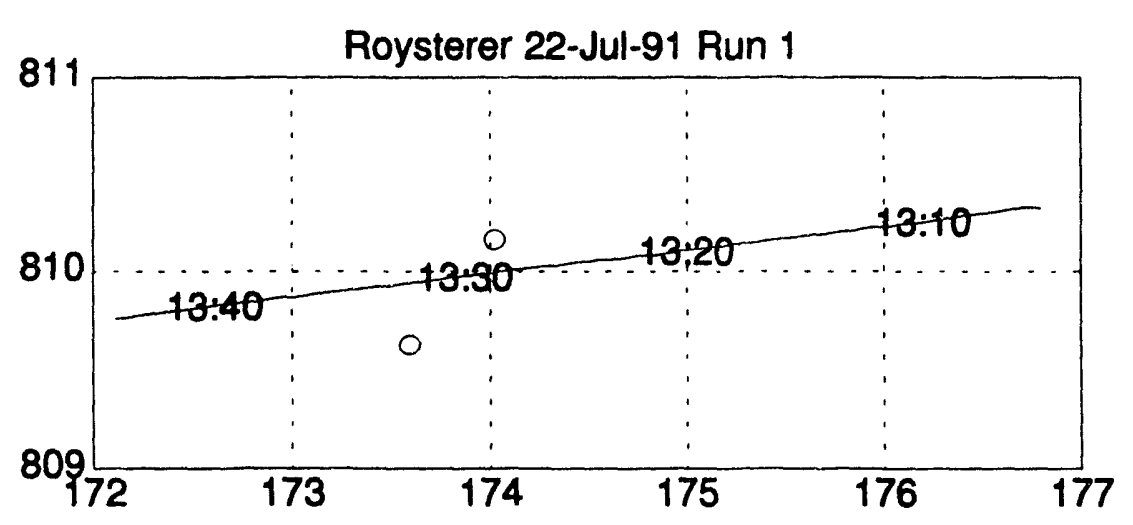




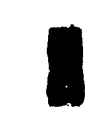

I

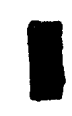

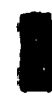

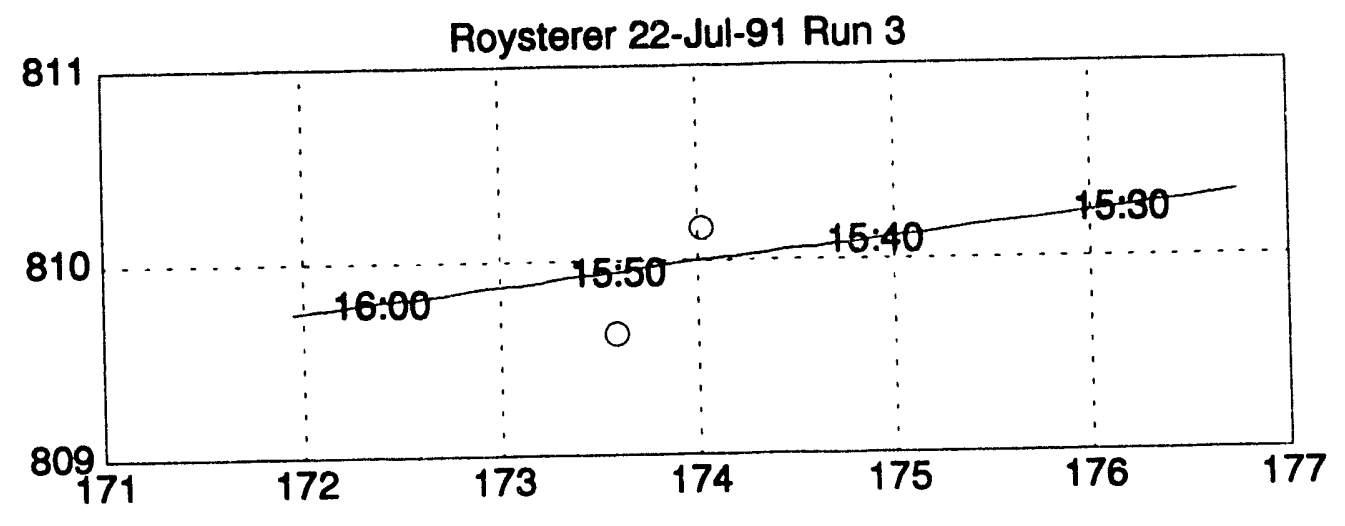




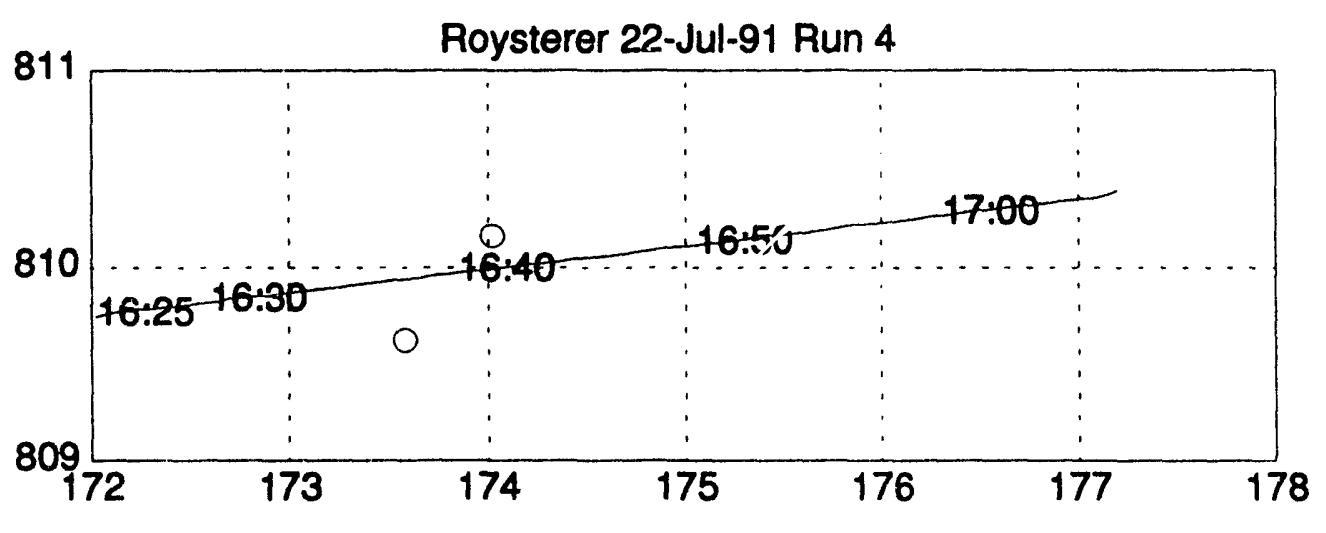




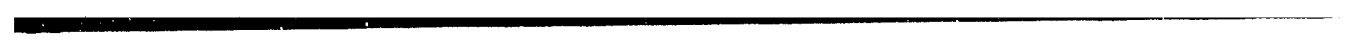

Ship Velocities 

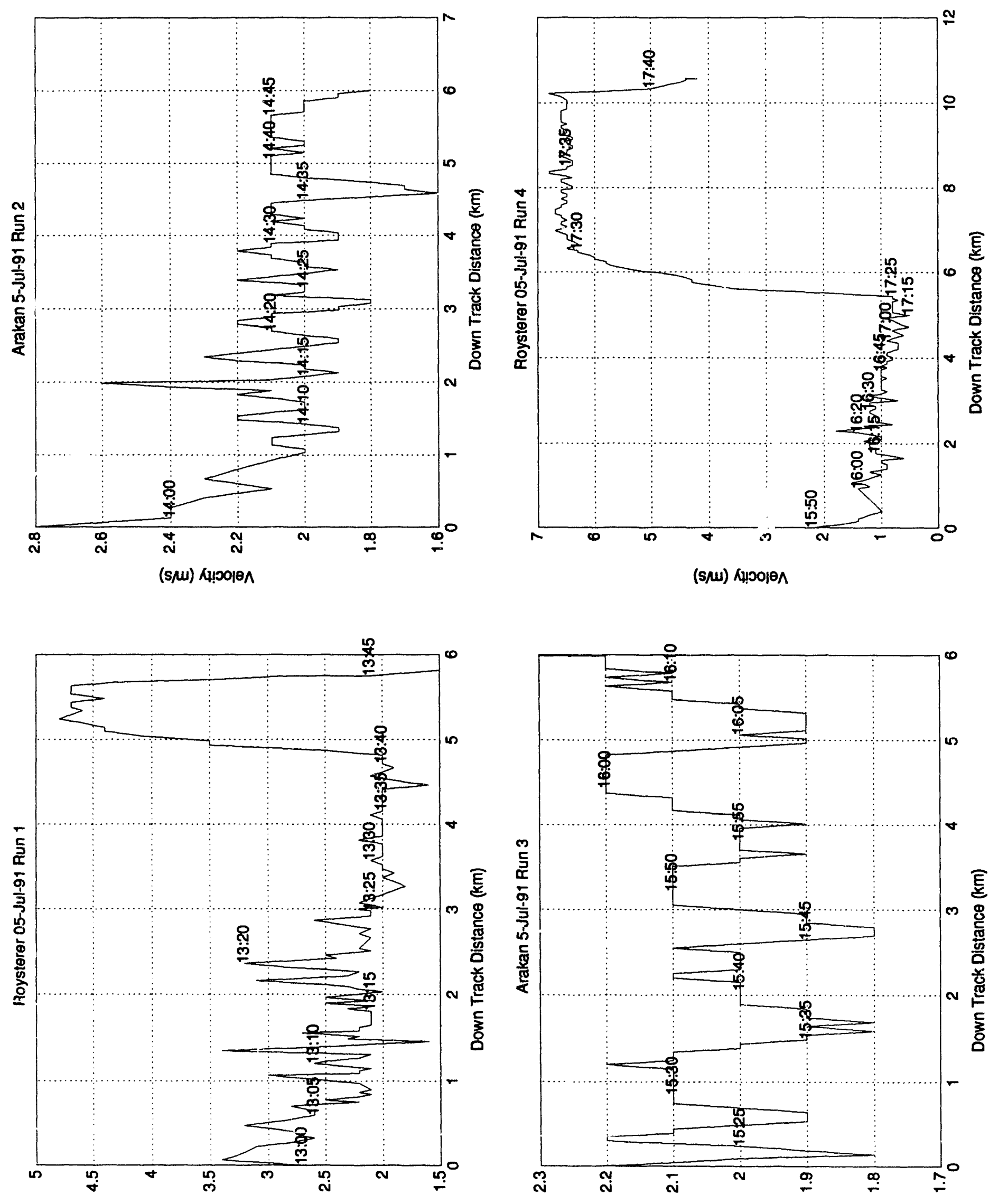

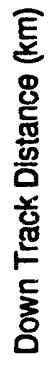

(s/u) ㅅ!잇

(s/u) ㅅ!잉ㅅ 

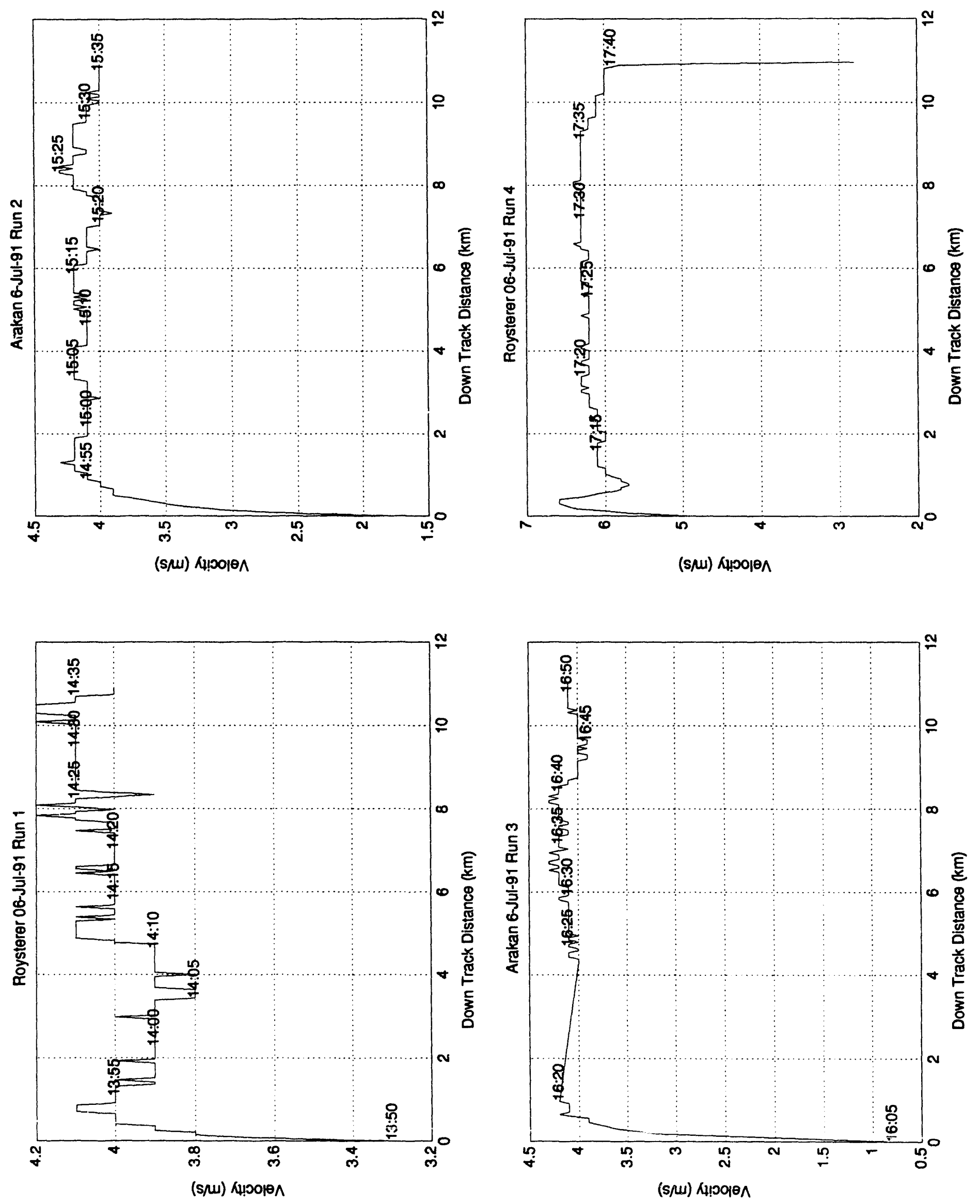

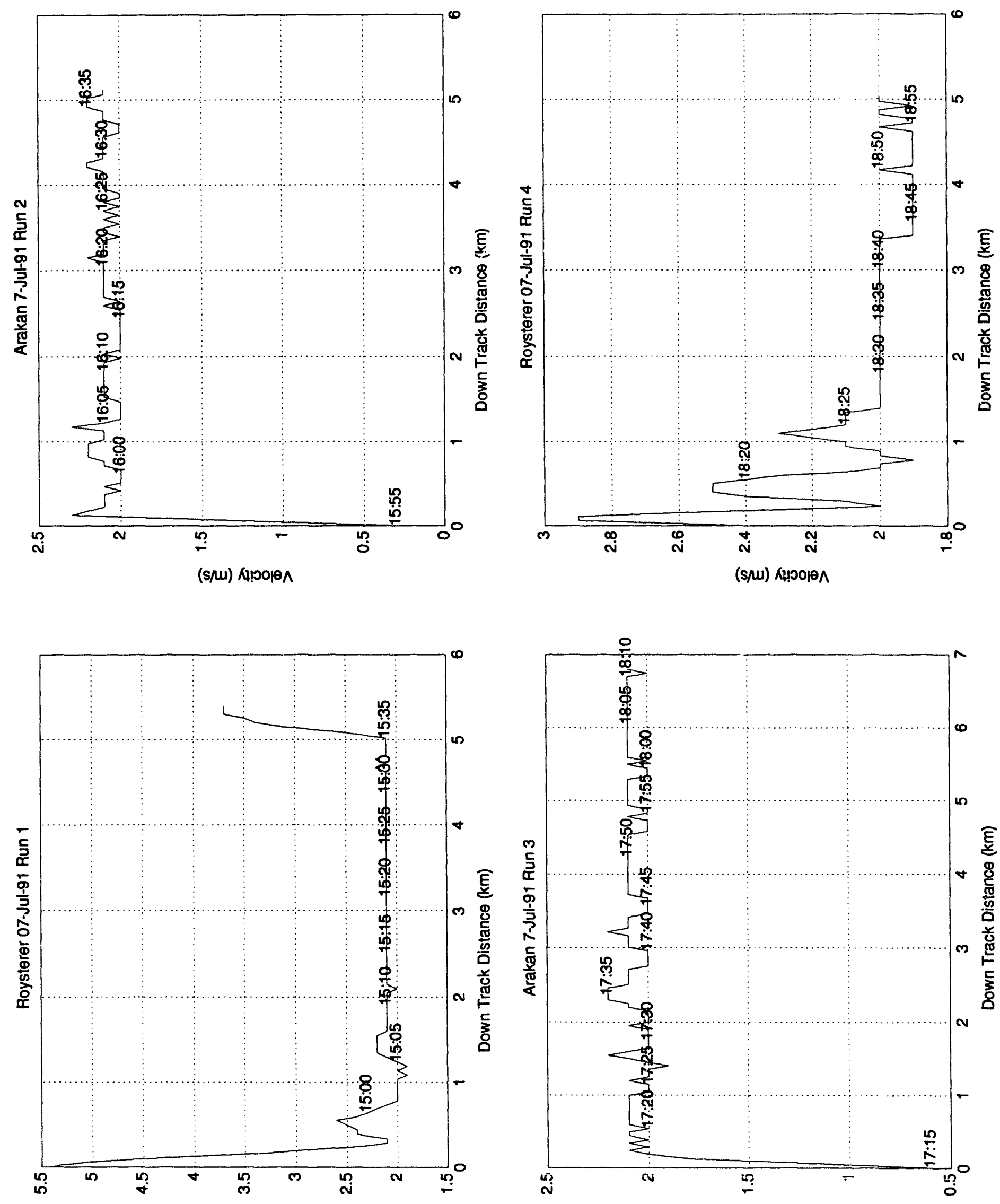

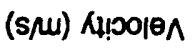

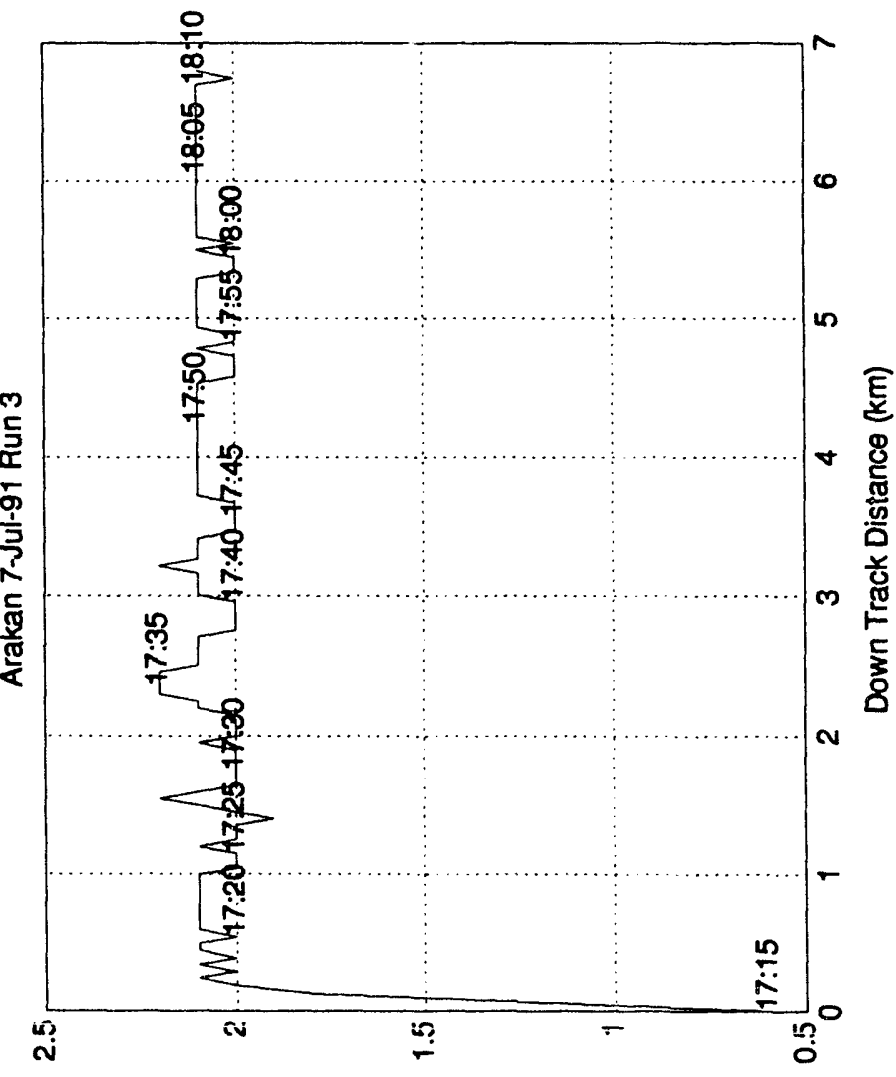

(s/u) ㅅ!잇ㅅ 

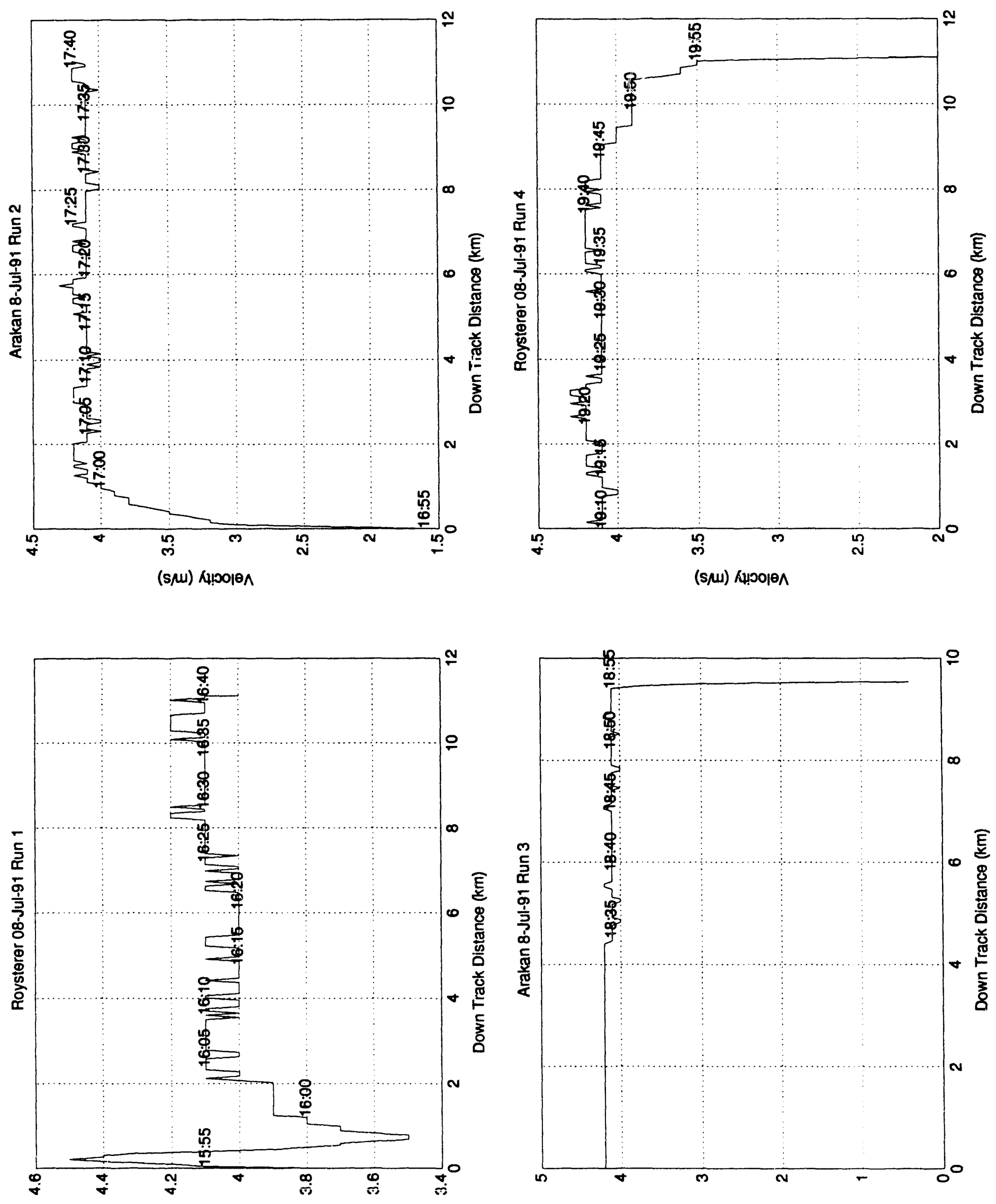

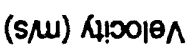

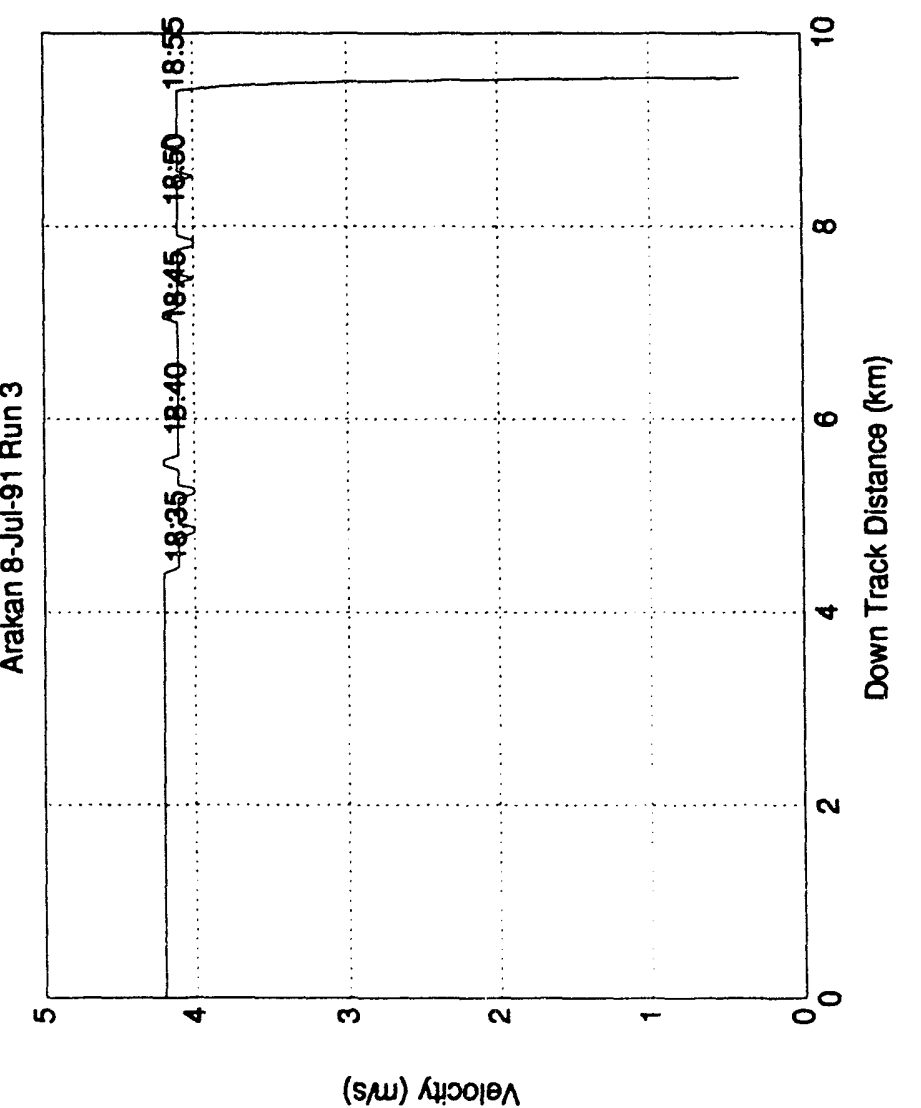



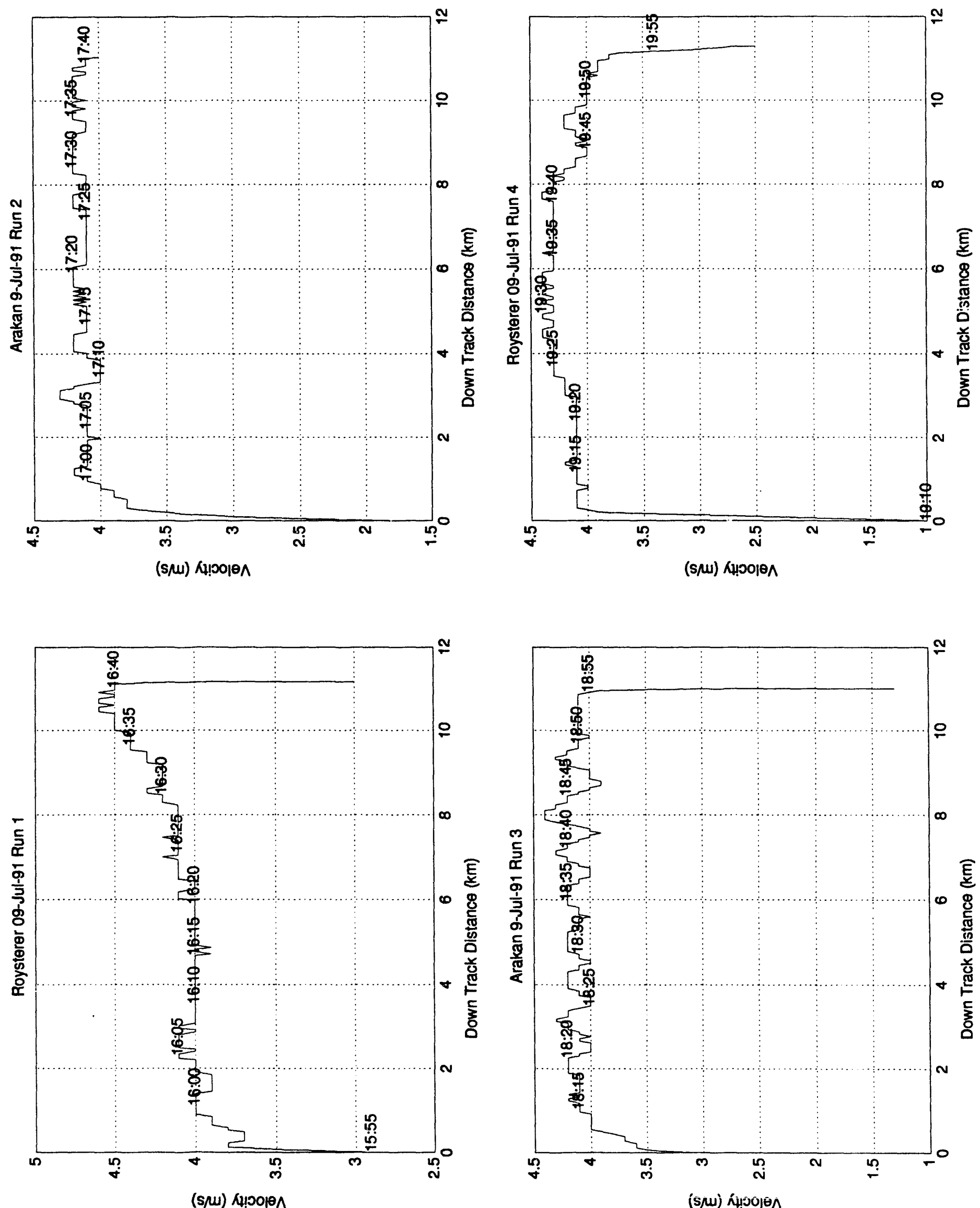

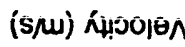

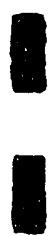

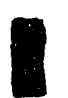

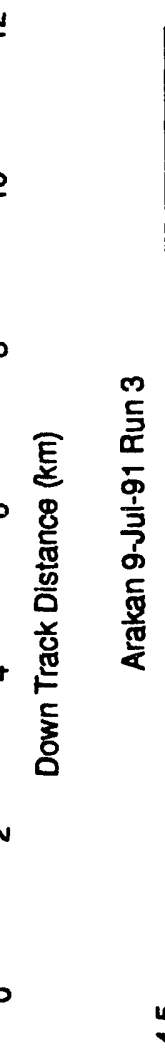



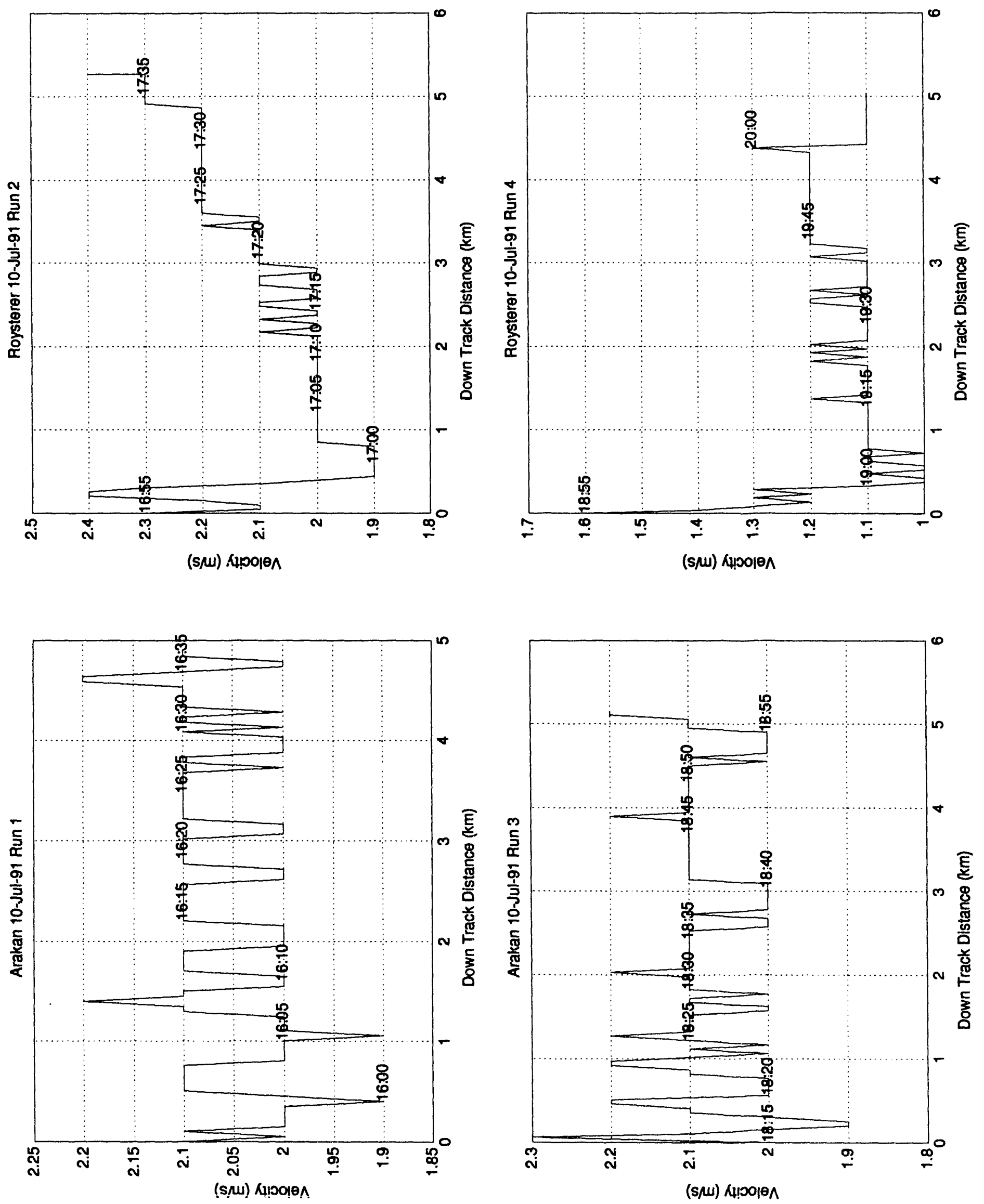


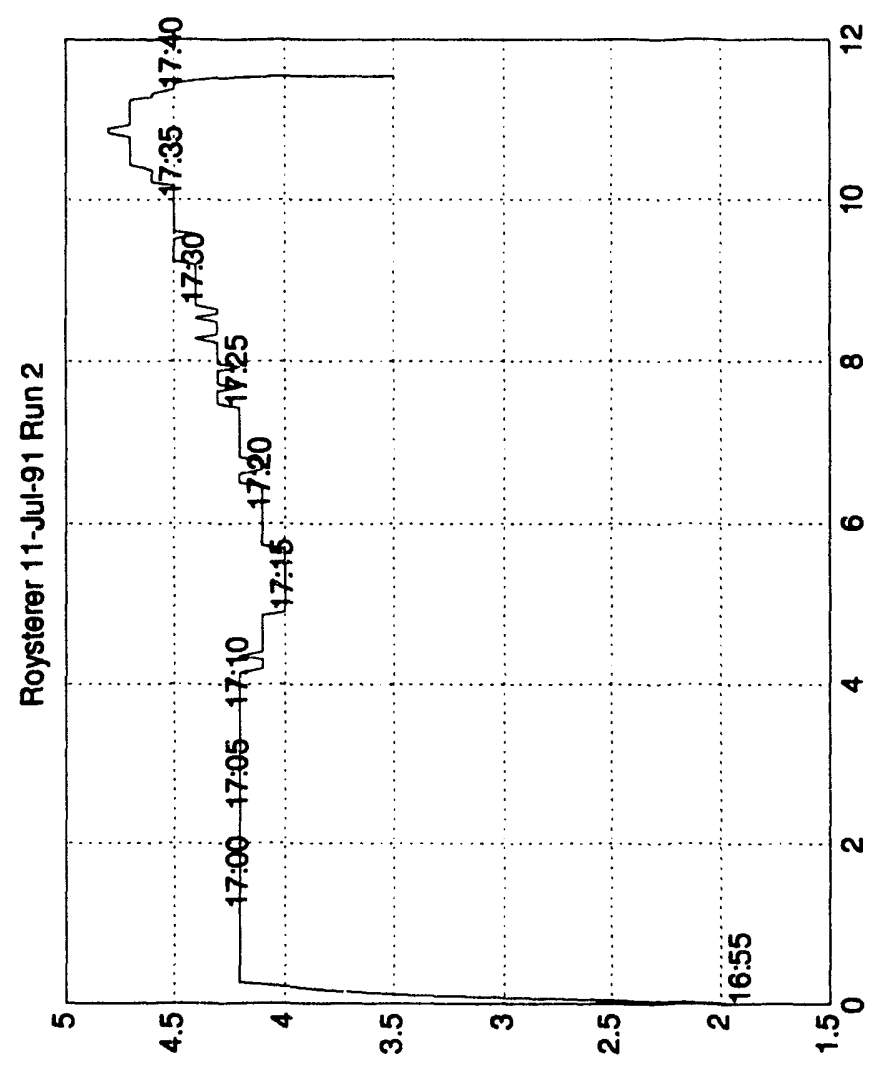

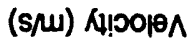

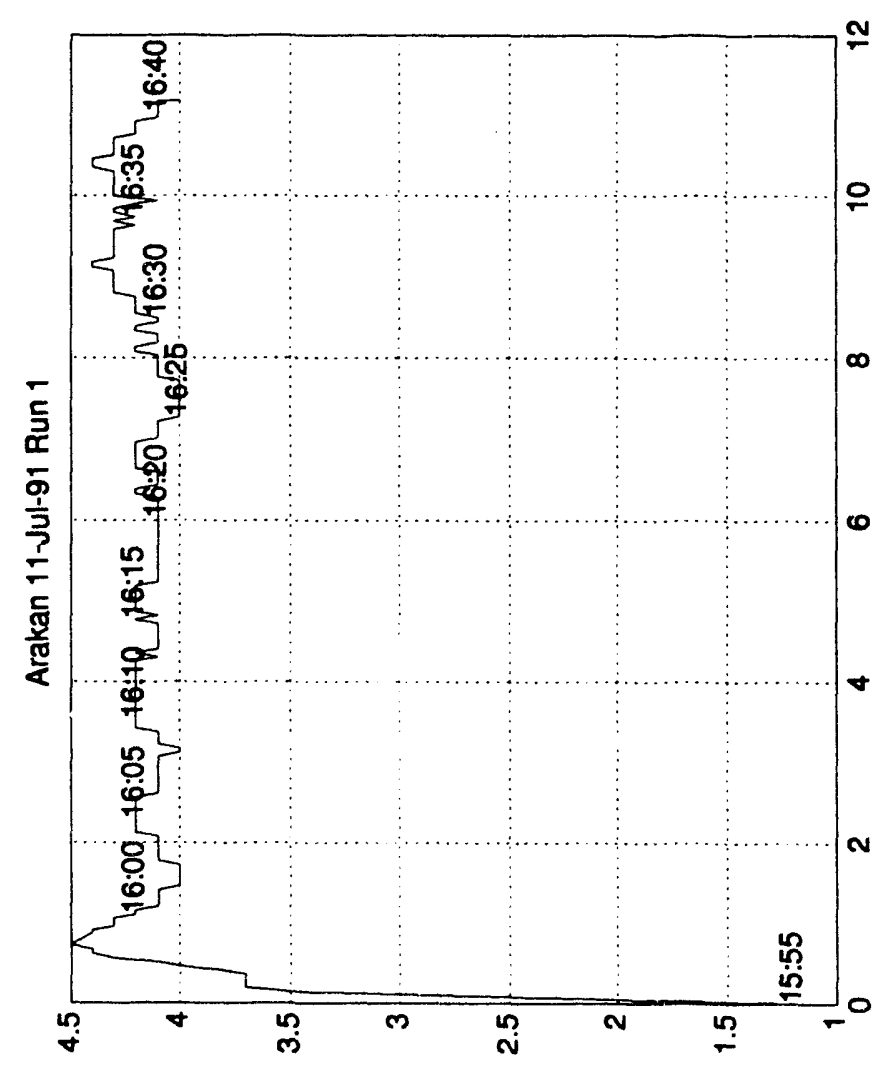

(s/2) 시잇

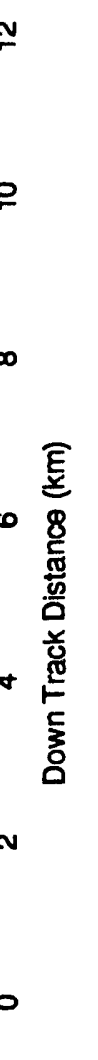

.
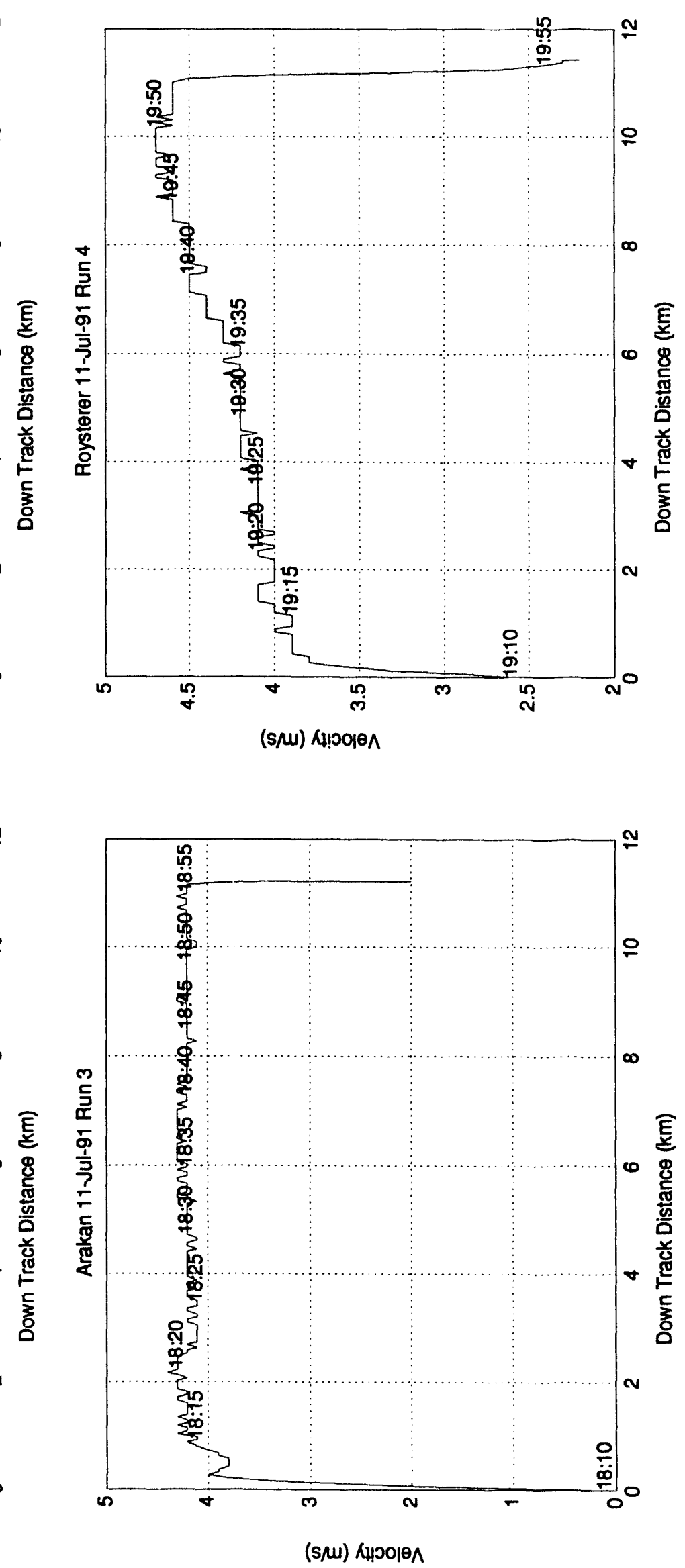


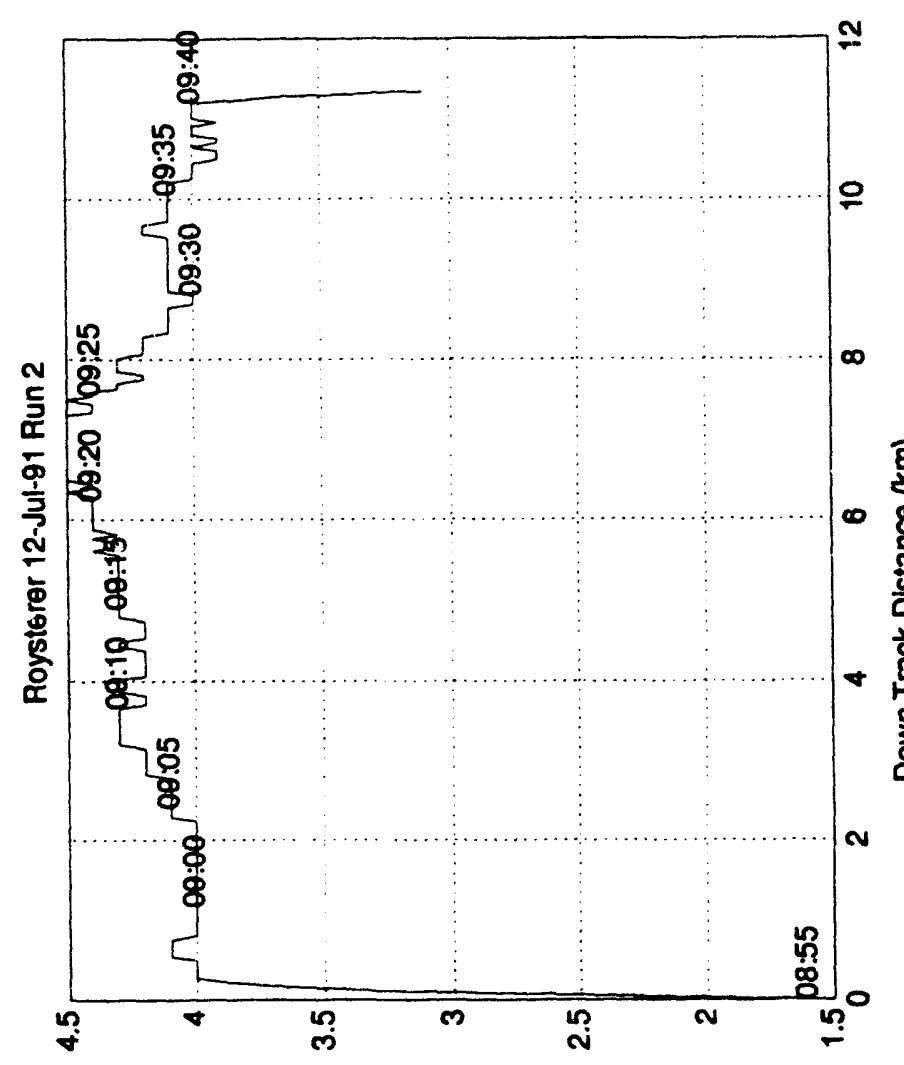

(s/u) $440010 \wedge$

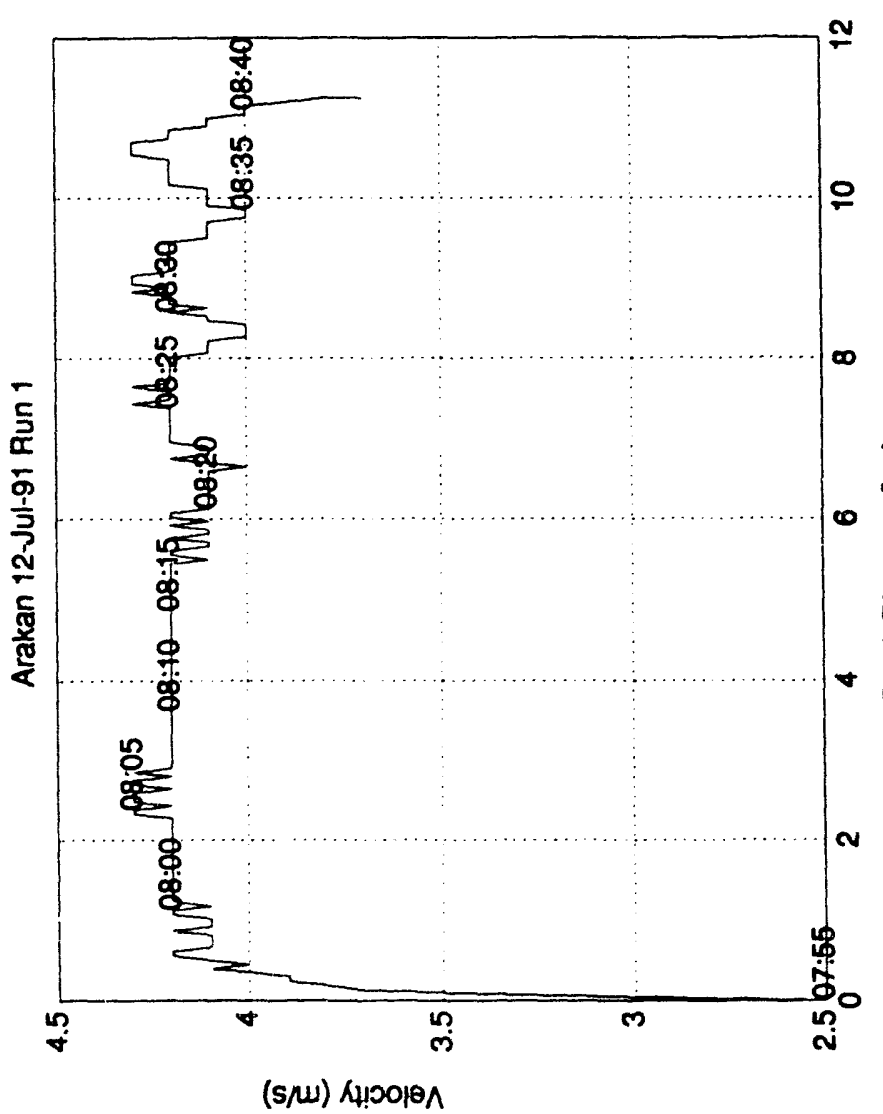

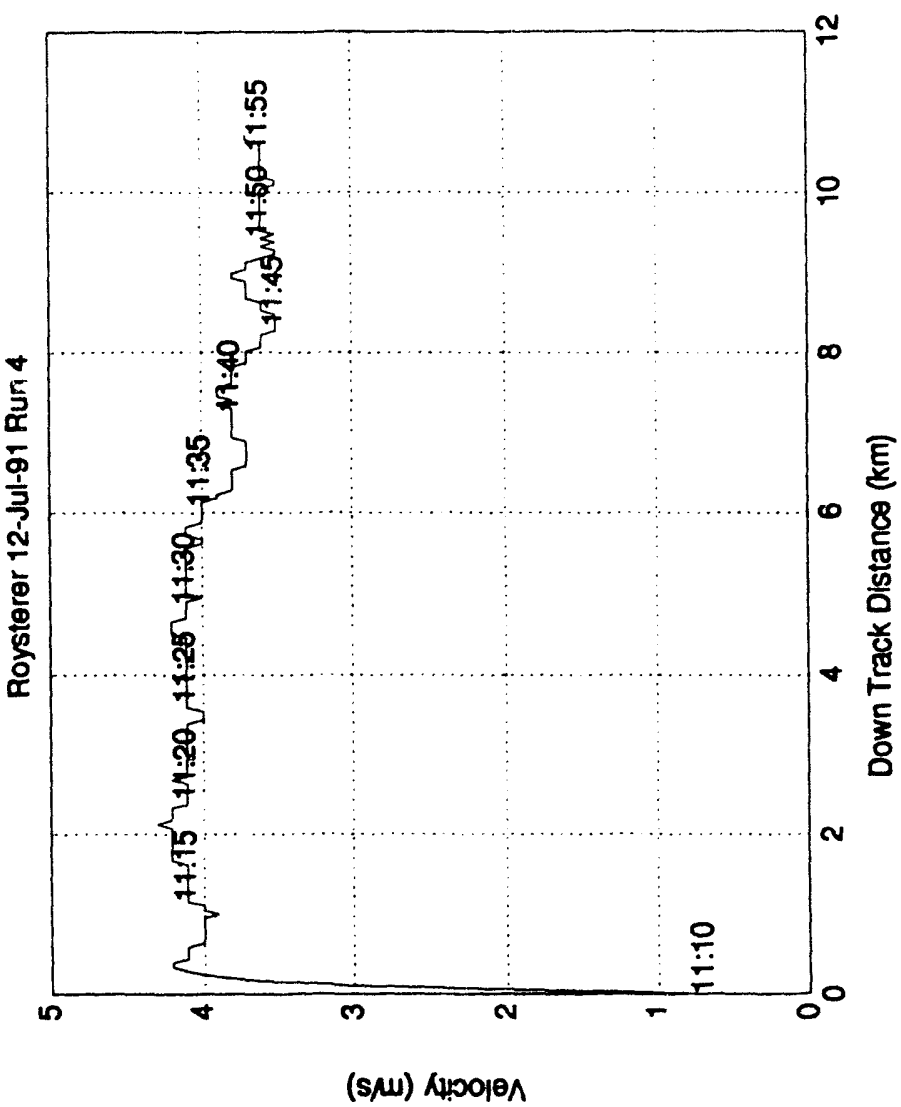

(s/u) $44001 \theta \wedge$

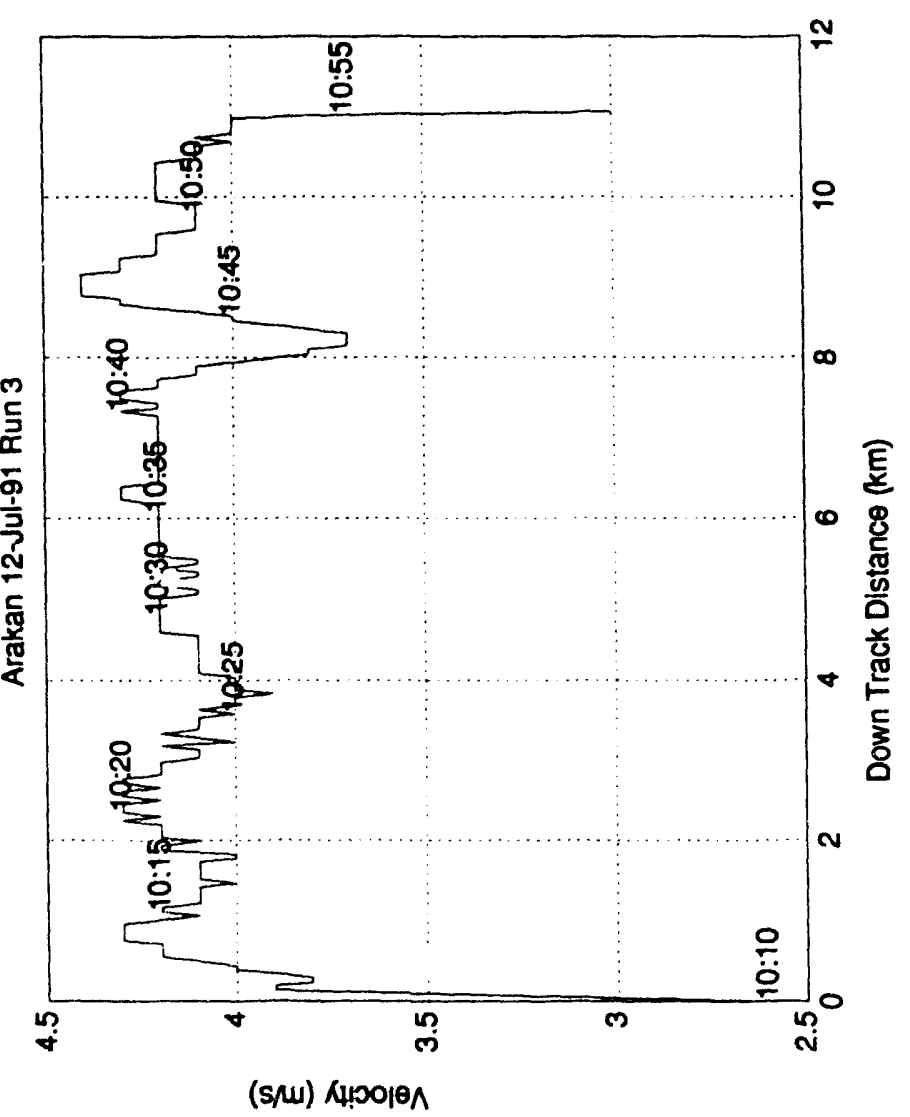



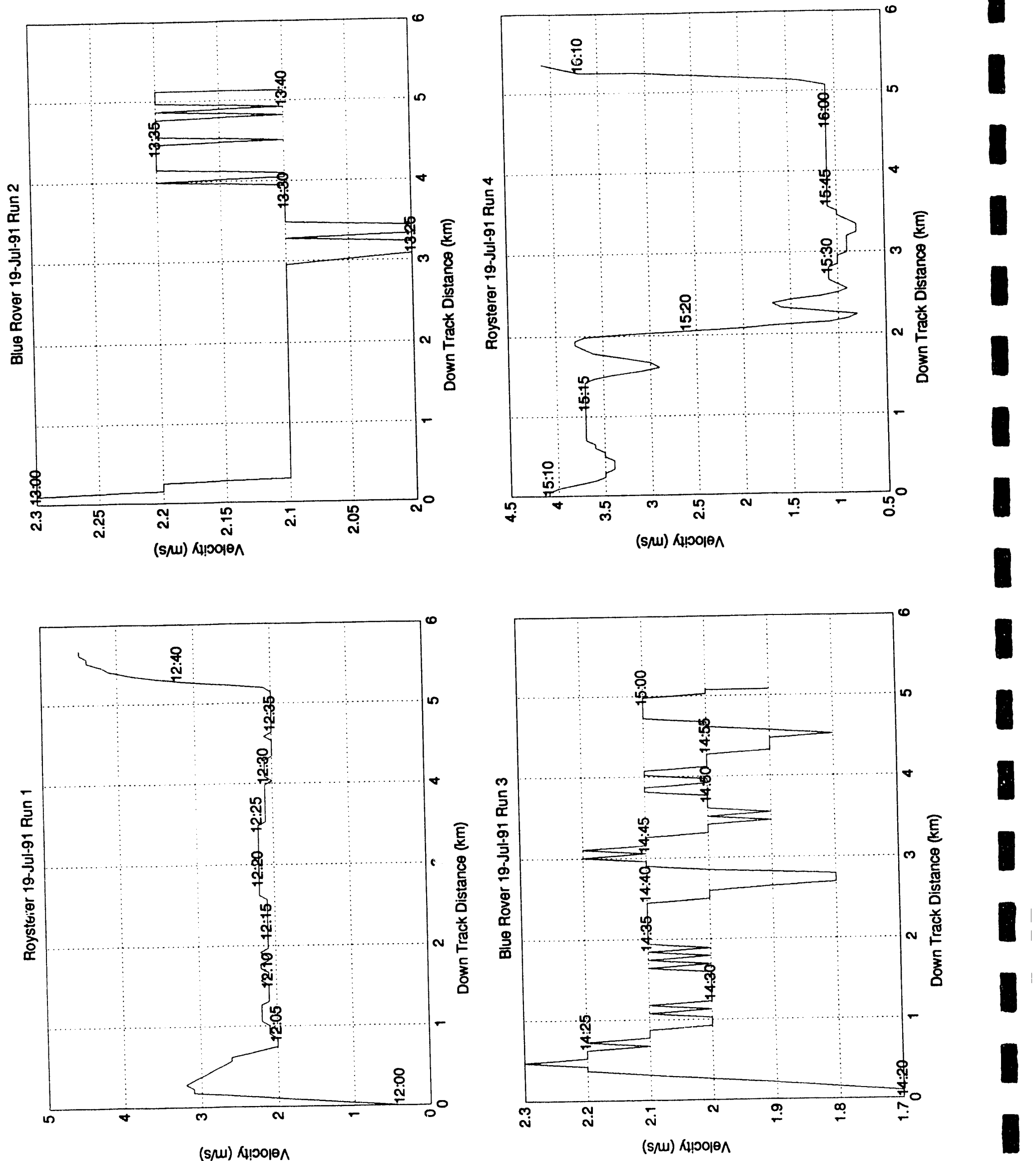

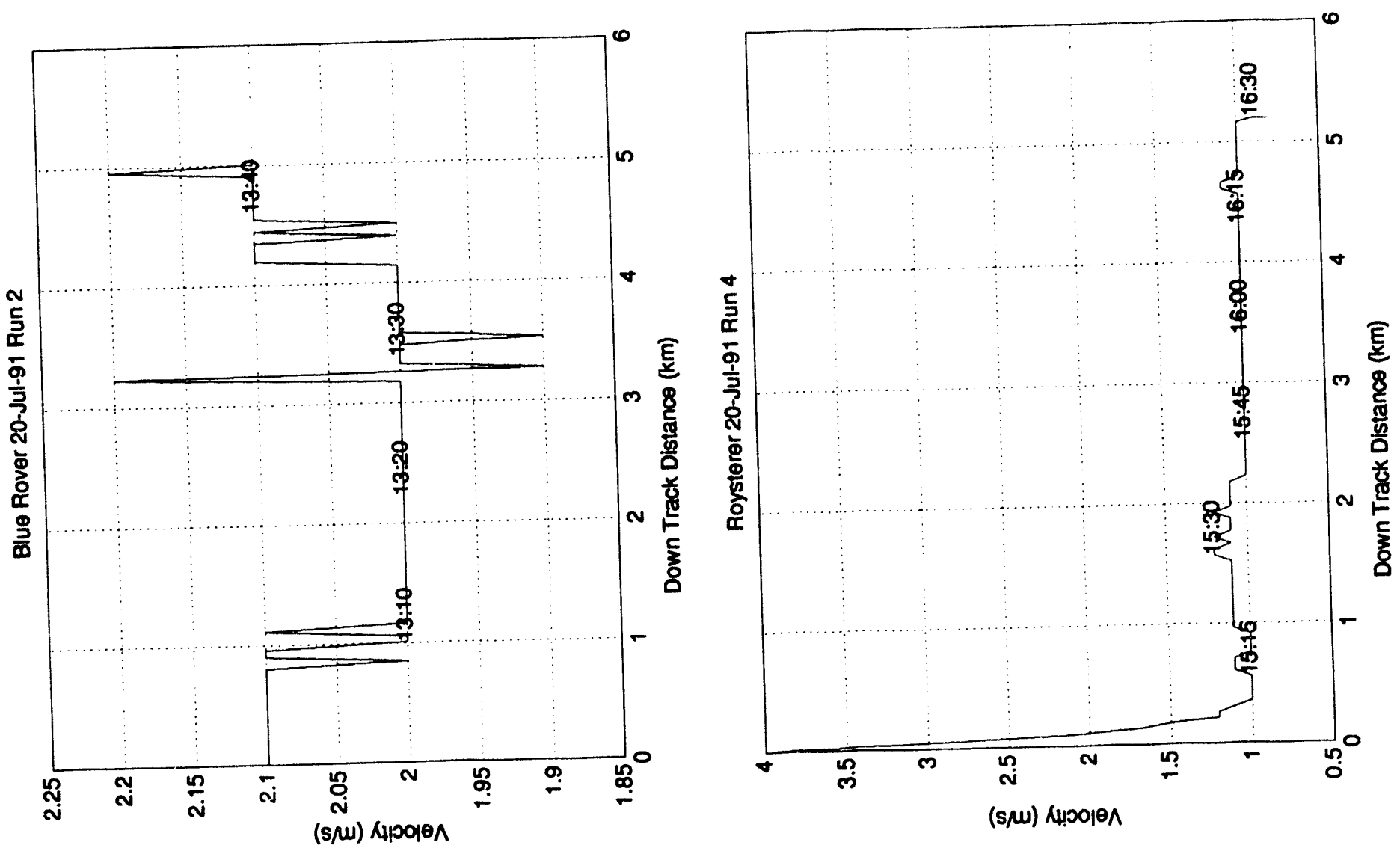

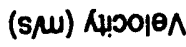
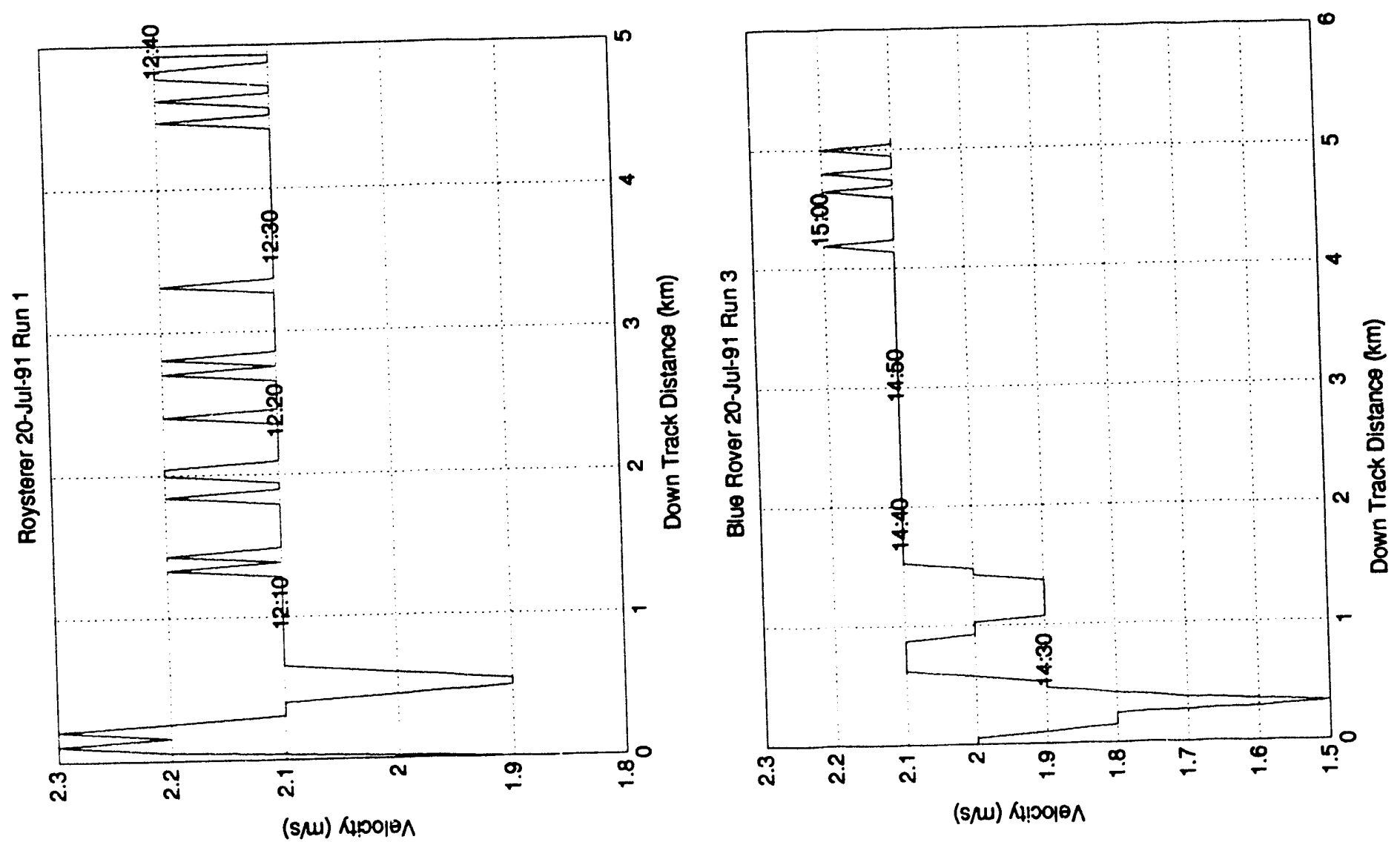


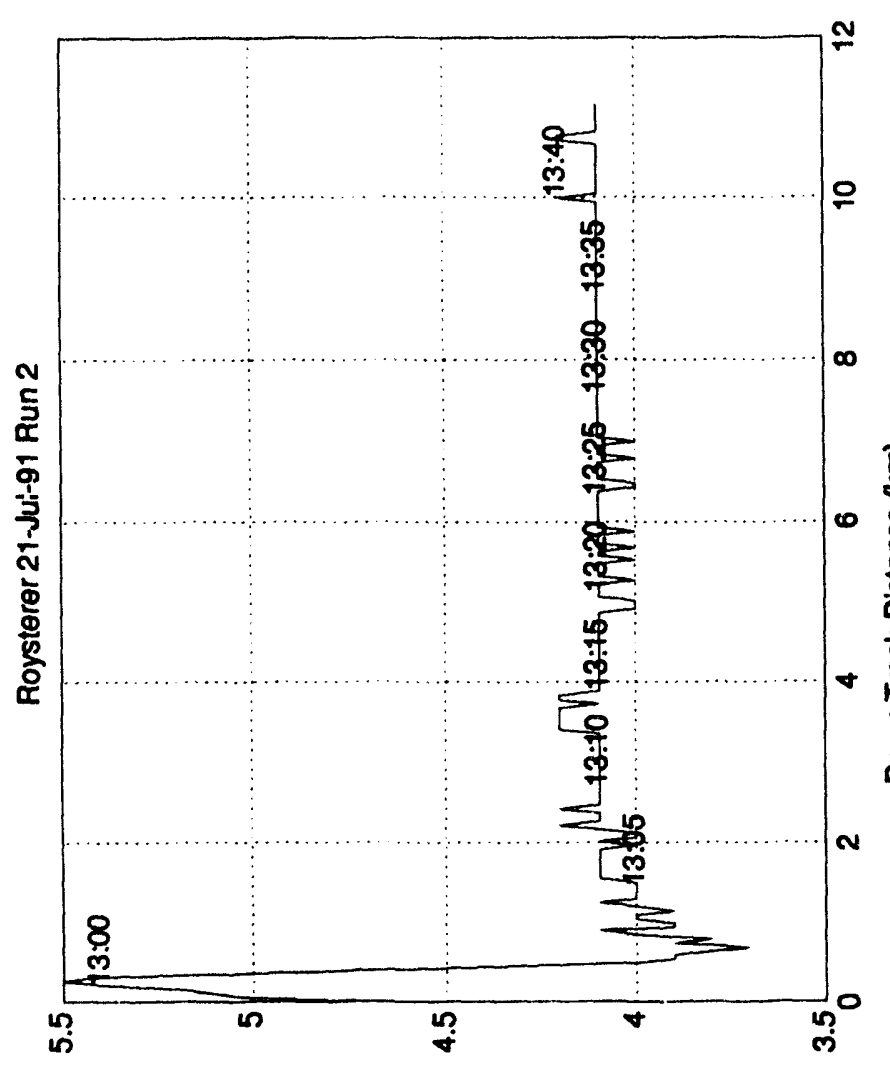

(s/u) 시잇

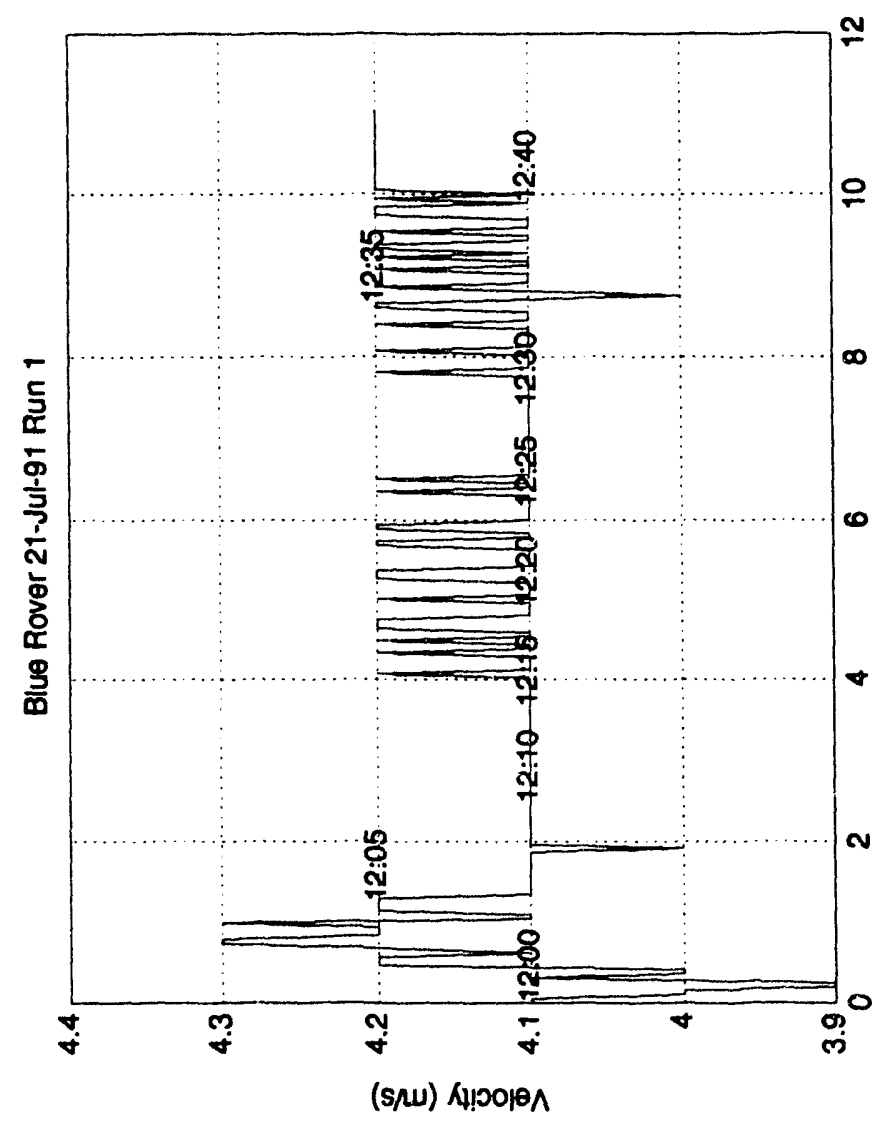

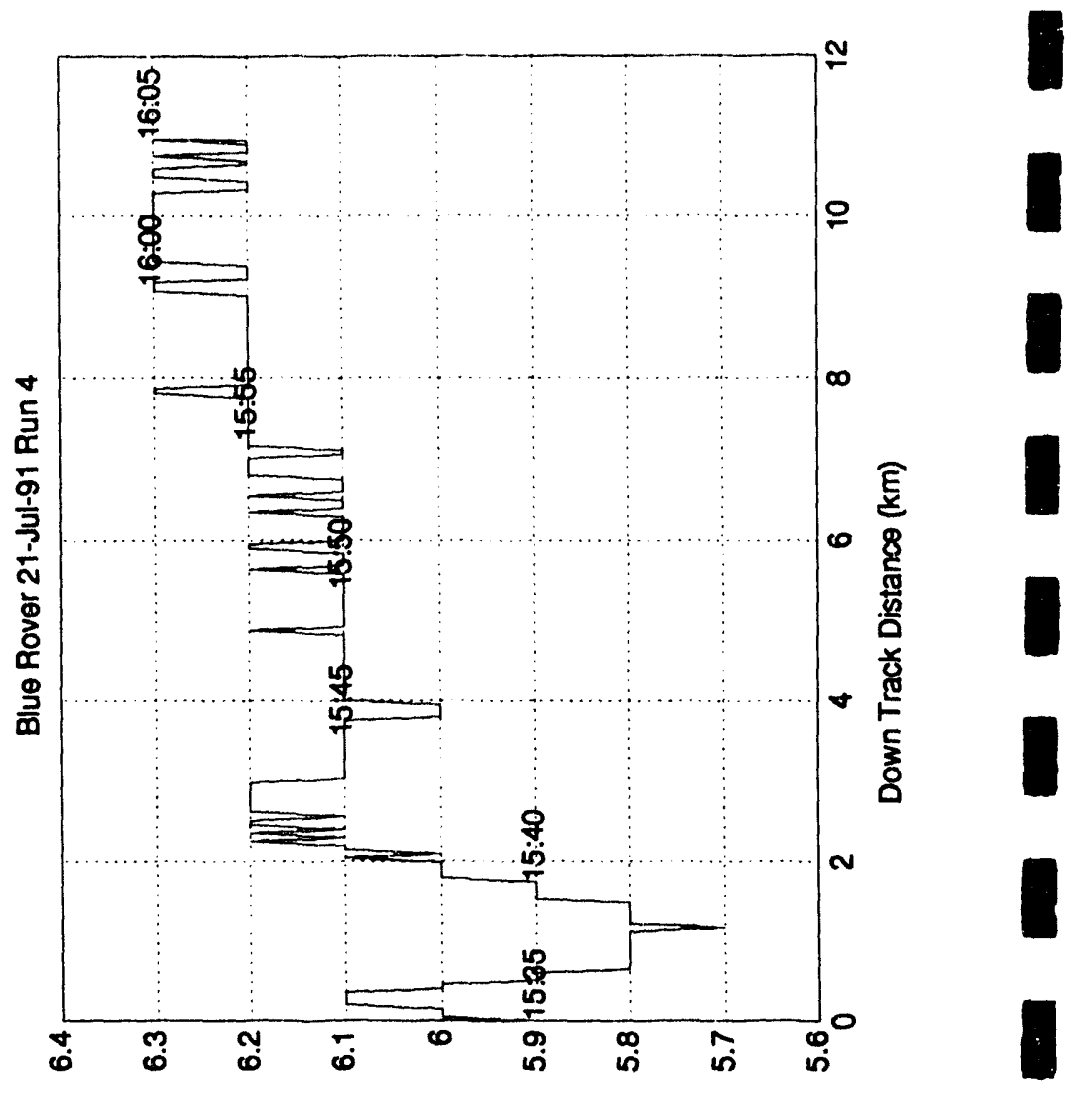

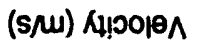

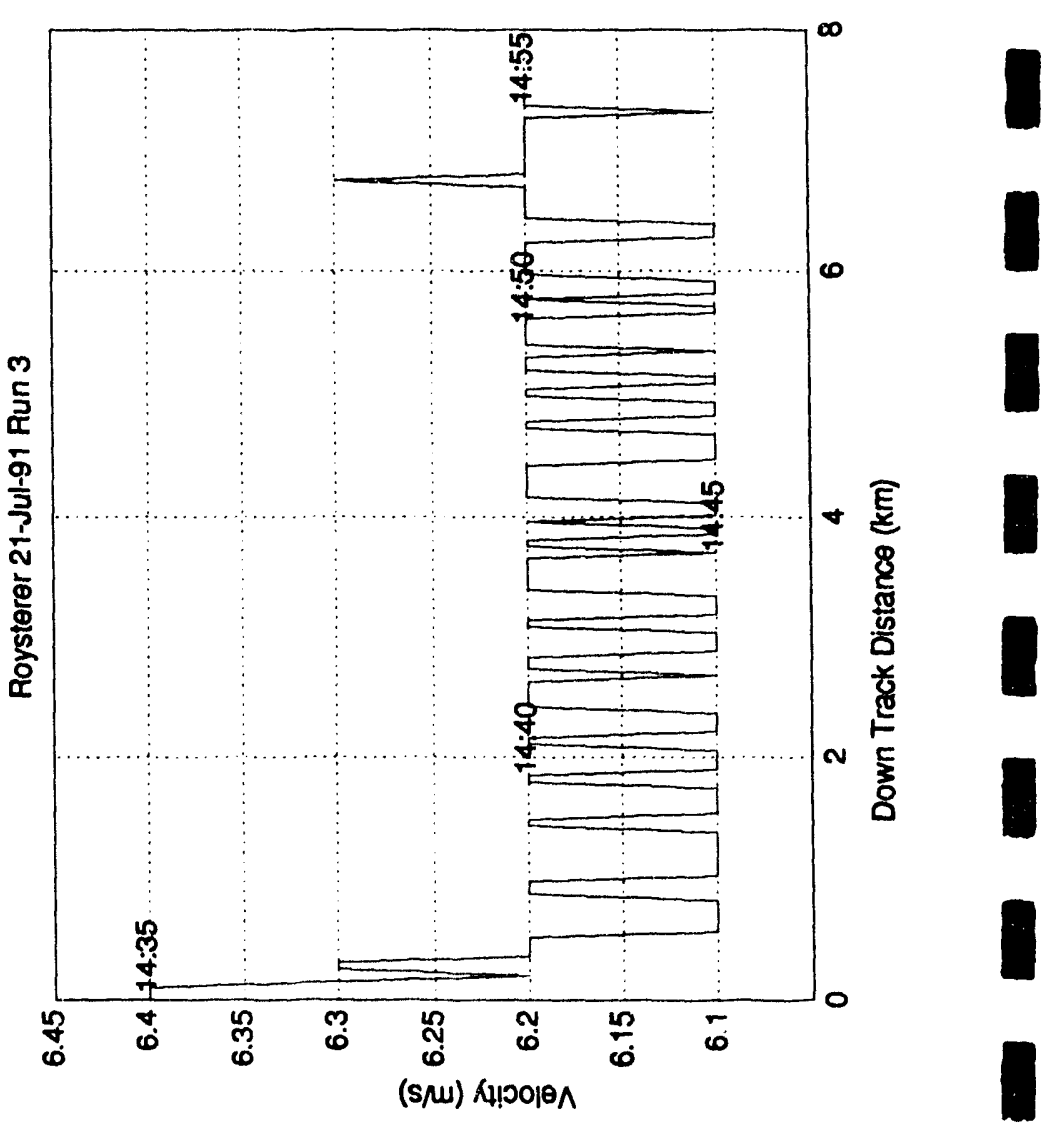



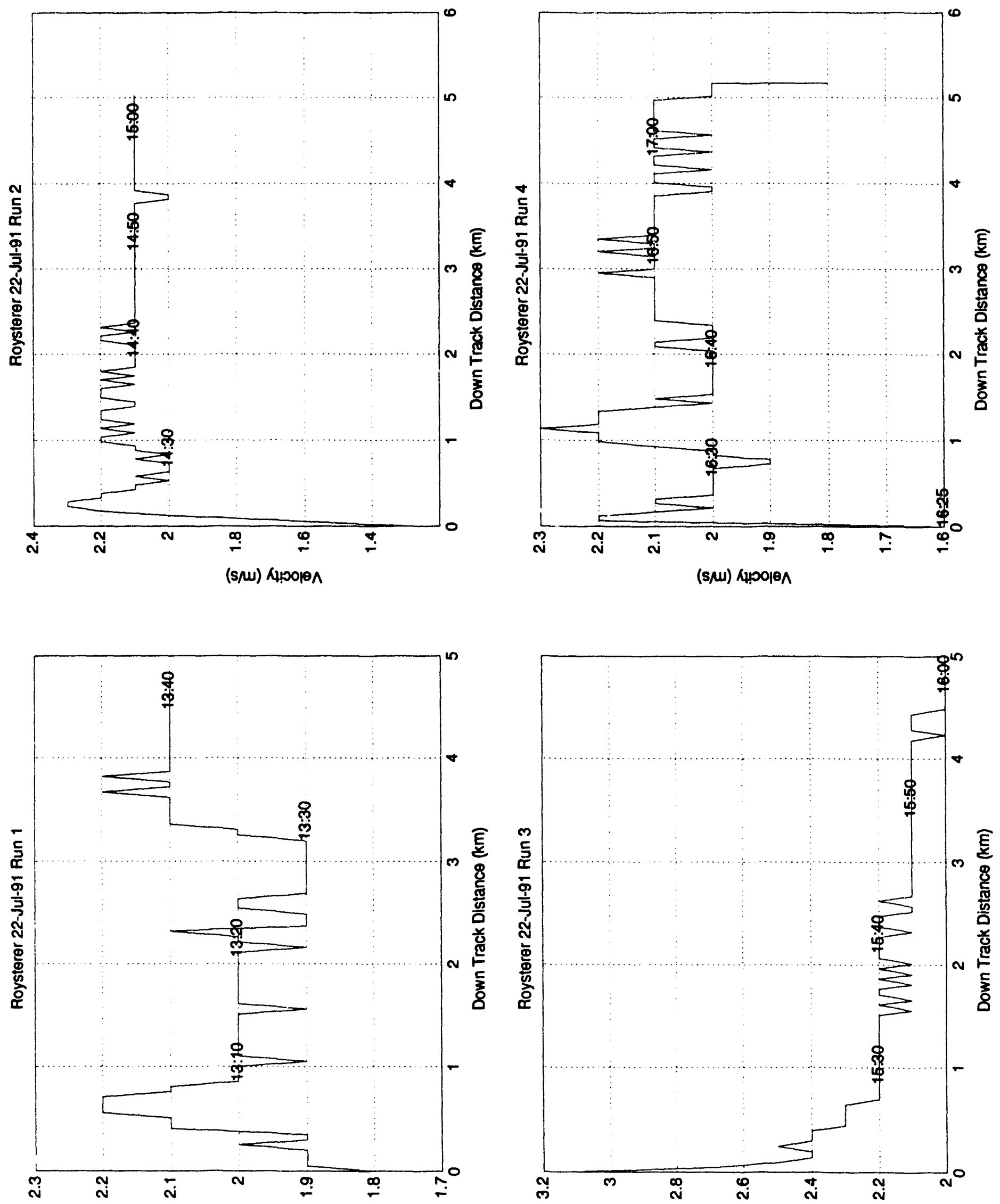

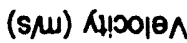

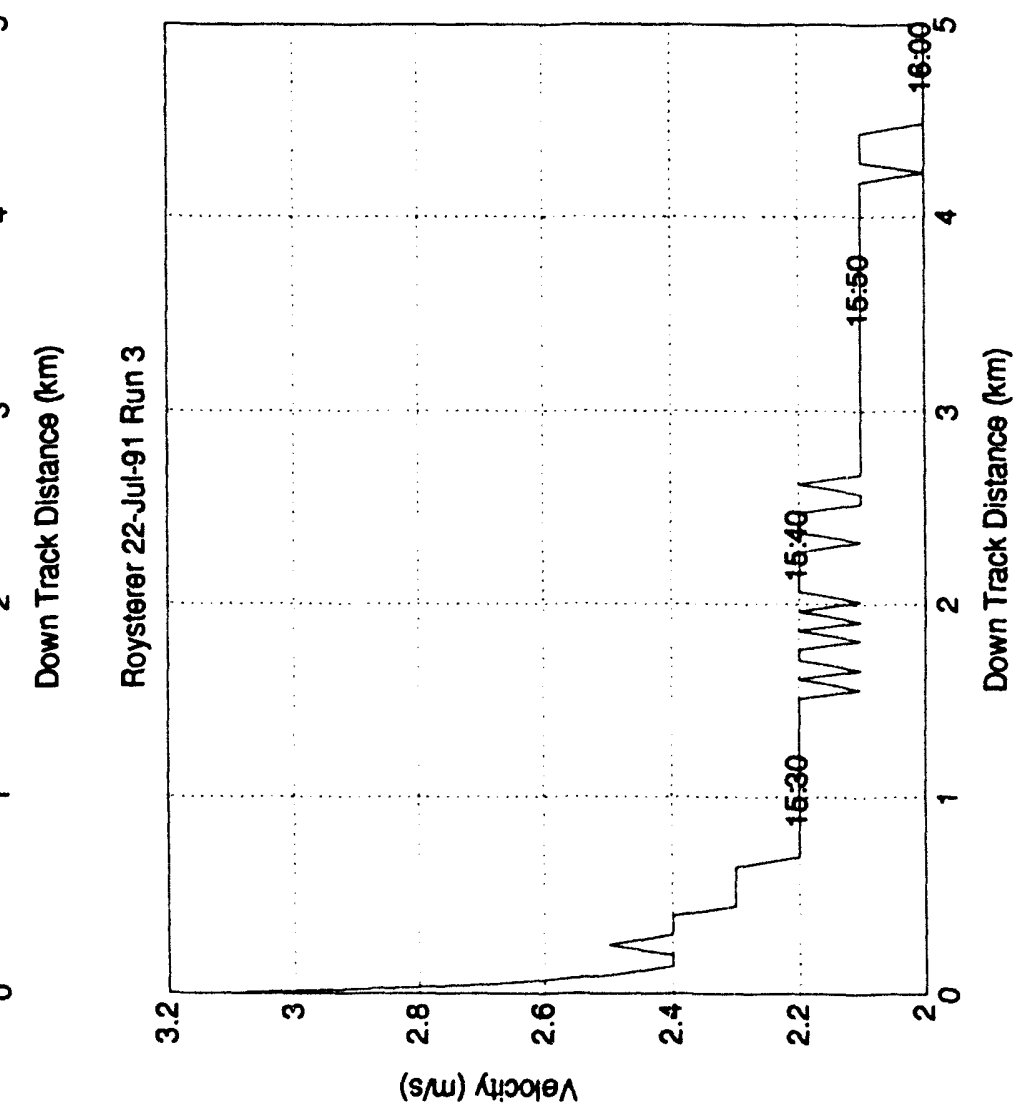



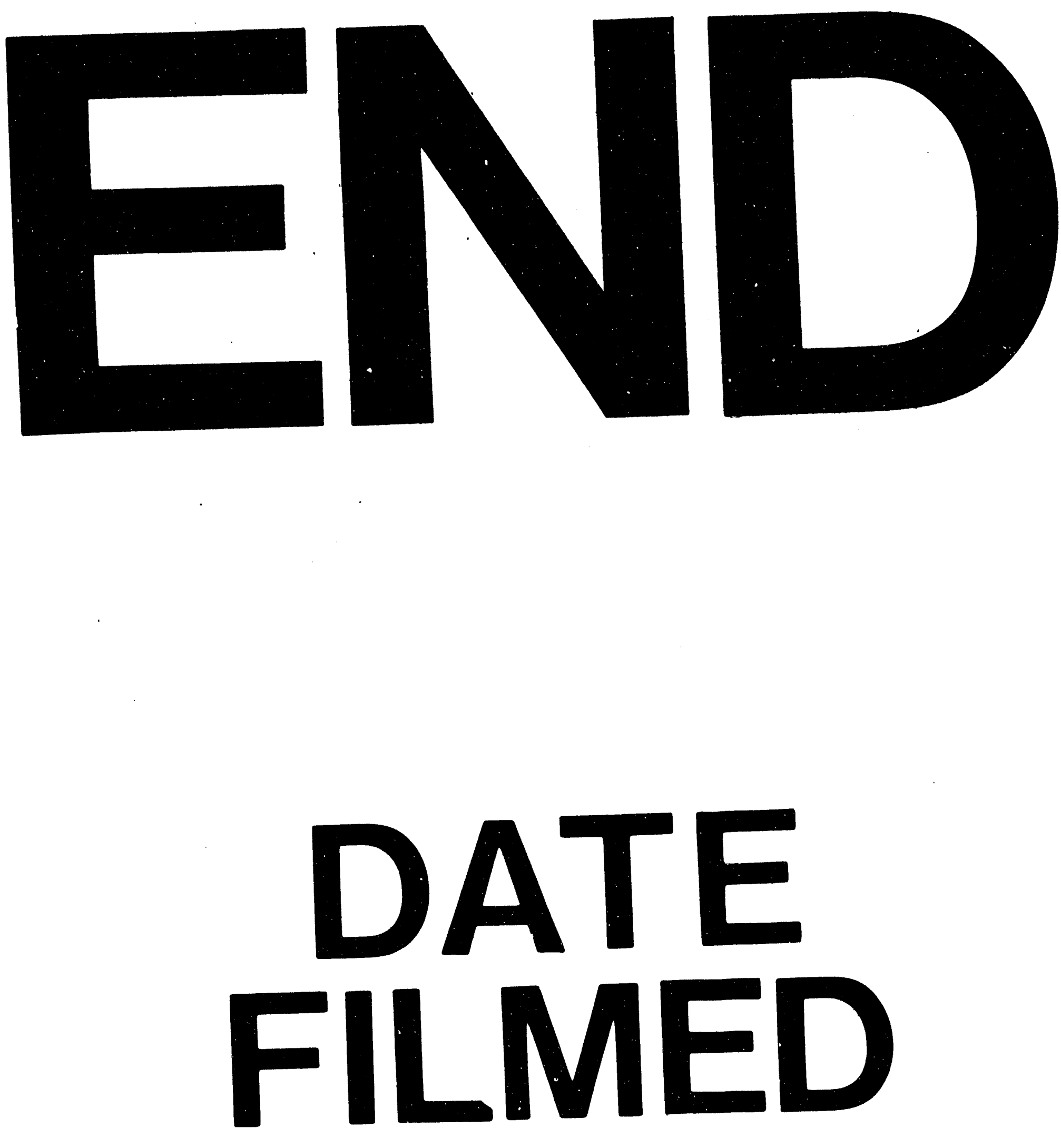

1

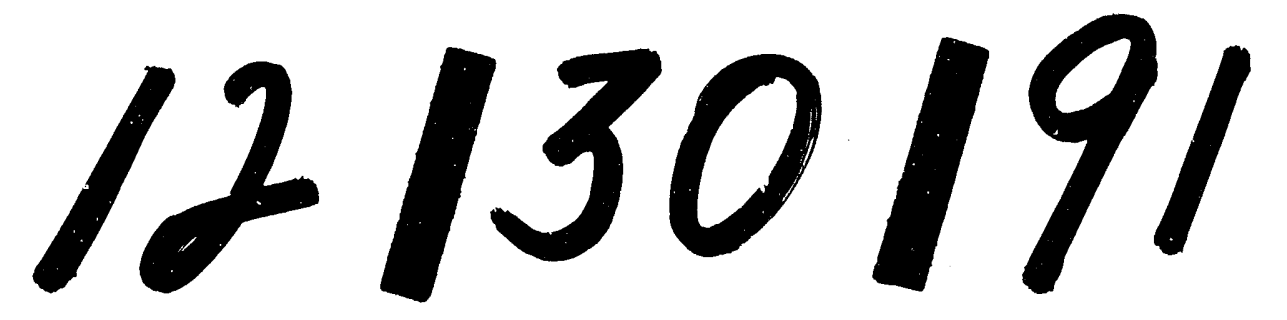




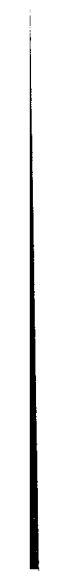

